\title{
Solvatação de Átomos de Positrônio
}

\author{
Mateus Bergami Rocha
}

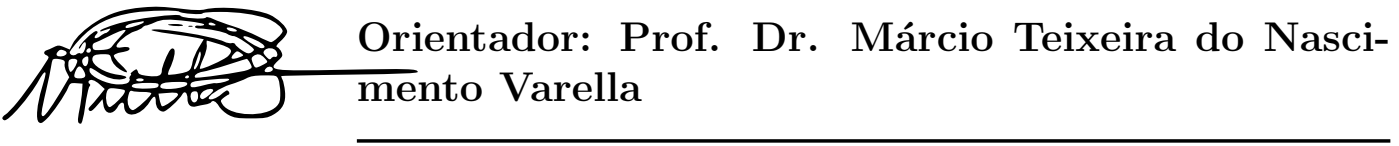

Dissertação apresentada ao Instituto de Física da Universidade de São Paulo para a obtenção do título de Mestre em Ciências.

\section{Banca Examinadora:}

Profa. Dra. Kaline Rabelo Coutinho - Presidente (IFUSP)

Prof. Dr. Mauro Carlos Costa Ribeiro (IQUSP)

Prof. Dr. José Rachid Mohallem (UFMG) 
FICHA CATALOGRÁFICA

Preparada pelo Serviço de Biblioteca e Informação do Instituto de Física da Universidade de São Paulo

Rocha, Mateus Bergami

Solvatação de átomos de positrônio. São Paulo, 2019.

Dissertação (Mestrado) - Universidade de São Paulo. Instituto de Física. Depto. de Física Geral

Orientador: Prof. Dr. Márcio Teixeira do Nascimento Varella

Área de Concentração: Modelagem Molecular

Unitermos: 1. Solvatação; 2. Física molecular; 3. Física computacional.

USP/IF/SBI-085/2019 
University of São Paulo

Physics Institute

\title{
Solvation of Positronium Atoms
}

\author{
Mateus Bergami Rocha
}

Supervisor: Prof. Dr. Márcio Teixeira do Nascimento Varella

Dissertation submitted to the Physics Institute of the University of São Paulo in partial fulfillment of the requirements for the degree of Master of Science.

\section{Examining Committee:}

Profa. Dra. Kaline Rabelo Coutinho - President (IFUSP)

Prof. Dr. Mauro Carlos Costa Ribeiro (IQUSP)

Prof. Dr. José Rachid Mohallem (UFMG) 


\section{Agradecimentos}

Eu gostaria primeiramente de dedicar essa dissertação ao meu pai, Gilcenio Radicchi Rocha, que não está mais entre nós mas estará para sempre no meu coração.

Agradeço à minha amada mãe, pelo incentivo, exemplo e carinho durante toda minha vida.

Agradeço ao meu orientador, Prof. Dr. Márcio Teixeira do Nascimento Varella, pela oportunidade, confiança e ensinamentos durante essa jornada.

Agradeço aos membros do grupo de Física Molecular e Modelagem pelas discussões e auxílios ao longo desse trabalho. Em especial, eu gostaria de agradecer à Profa. Dra. Kaline Rabelo Coutinho, pela paciência e colaboração.

Agradeço aos meus amigos capixabas Rodolfo, Gabriel, Vinícius e Laiza pela amizade e apoio desde a graduação.

Agradeço ao Instituto de Física da Universidade de São Paulo por todo suporte durante a realização deste trabalho.

O presente trabalho foi realizado com apoio da Coordenação de Aperfeiçoamento de Pessoal de Nível Superior - Brasil (CAPES) - Código de Financiamento 001. 


\section{RESUMO}

Nas últimas décadas o interesse na física e na química dos sistemas positrônicos têm sido cada vez maior. O avanço nas técnicas de produção e manipulação de pósitrons permitiu importantes resultados experimentais no estudo de átomos de positrônio (Ps) em baixas energias, e simulações dos traços positrônicos em água sugerem a ocorrência de estados de equilíbrio termodinâmico do Ps solvatado em água. Neste trabalho desenvolvemos um campo de força para a interação Ps-água, que permite a realização de simulações de Monte Carlo do Ps solvatado em equilíbrio termodinâmico. O campo de força foi construído a partir de cálculos precisos para o coeficiente de dispersão da interação Ps-O, e também de modelos para a determinação desses coeficientes. Através deste campo de força realizamos simulações de Monte Carlo determinando propriedades termodinâmicas e estruturais do líquido. As configurações estatisticamente descorrelacionadas, representativas do enesemble NpT, foram geradas a partir das simulações de Monte Carlo. Posteriormente, realizamos cálculos quânticos para as configurações do líquido utilizando o método Any Particle Molecular Orbital. Os cálculos concentraram-se nas energias dos orbitais eletrônicos e positrônicos, simplesmente ocupados, as quais permitem estimativas das energias de ionização vertical do átomo de positrônio hidratado.

Palavras chave: positrônio, solvatação, campo de força, energia de ionização vertical. 


\begin{abstract}
In the last decades the interest in the physics and chemistry of positronic systems has increased. The advance in the techniques of production and manipulation of positrons has allowed important experimental results in the research on positronium (Ps) atoms at low energies, and simulations of positron slowing down in water suggests the occurrence of thermalized solvated Ps atoms along the positron tracks. We developed a force field for Ps-water interactions, which allows for Monte Carlo simulations of the solvated Ps at thermodynamical equilibrium. The force field was built from precise calculations for the dispersion coefficient of the Ps-O interaction, and also models for determining these coefficients. Through this force field we perform Monte Carlo simulations determining thermodynamic and structural properties of the liquid. Statistically uncorrelated Ps-solvent configurations, representative of the NpT ensemble, were generated from the MC simulations. Subsequently, we performed quantum mechanical calculations for the Ps-solvent configurations employing the APMO method. The calculations focused on the energies of the electronic and positronic singly occupied orbitals, which allow for estimates of the vertical detachment energies of the hydrated Ps atom.
\end{abstract}

Keywords: positronium, solvation, force field, vertical detachment energy. 


\section{LISTA DE ABREVIAÇÕES}

\begin{tabular}{|c|c|}
\hline AA & Aproximação Adiabática \\
\hline $\mathrm{ABO}$ & Aproximação de Born-Oppenheimer \\
\hline APMO & Any Particle Molecular Orbital \\
\hline ASEC & Average Solvent Electrostatic Configuration \\
\hline DM & Dinâmica Molecular \\
\hline ES & Equação de Schrödinger Independente do Tempo \\
\hline $\mathrm{HF}$ & Hartree-Fock \\
\hline MM & Molecular Mechanics \\
\hline $\mathrm{MC}$ & Monte Carlo \\
\hline MP2 & Teoria de Pertubação de Møller-Plsset de $2^{\text {a }}$ Ordem \\
\hline $\mathrm{NpT}$ & Ensemble Isobárico \\
\hline NVT & Ensemble Canônico \\
\hline P2 & Teoria de Propagadores de $2^{\mathrm{a}}$ Ordem \\
\hline Ps & Átomo de Positrônio \\
\hline PET & Positron Emission Tomograph \\
\hline QM & Quantum Mechanics \\
\hline $\mathrm{QM} / \mathrm{MM}$ & Quantum Mechanics/Molecular Mechanics \\
\hline $\mathrm{RDF}$ & Radial Distribution Function \\
\hline RHF & Restricted Hartree-Fock \\
\hline $\mathrm{S}-\mathrm{QM} / \mathrm{MM}$ & Sequential - Quantum Mechanics/Molecular Mechanics \\
\hline SOMO & Singly Occupied Molecular Orbital \\
\hline UHF & Unrestricted Hartree-Fock \\
\hline
\end{tabular}





\section{Lista de Figuras}

1.1 Reproduzido da referência [15]. O diagrama mostra a perda de energia de um pósitron, inicialmente com $150 \mathrm{eV}$, em função do tempo. O diagrama de cores indica a ocorrência dos diferentes processos elásticos e inelásticos, tal como descrito por uma simulação de Monte Carlo que leva em consideração a dependência das correspondentes seções de choque em relação à energia. . . . . . . . . . . . . . . . . . . . . . 2

1.2 Reproduzido da referência [4]. Mecanismos de aniquilação do Ps em água e os respectivos tempos de vida para cada forma de aniquilação. 3

1.3 Reproduzido da referência [4]. Ilustração da região chamada de spur formada na termalização do pósitron em líquidos, representamos em verde as moléculas, em azul os elétrons, em amarelo os radicais e em vermelho o pósitron. . . . . . . . . . . . . . . . . 4

2.1 Reproduzido da referência [32]. Ilustração da estrutura de um líquido sendo entendida através da $G(r) \ldots \ldots \ldots$. . . . . . . . . . 14

2.2 Reproduzido da referência [39]. Ilustração do método das imagens no qual a caixa de simulação é replicada em todas as direções. . . . . . . . 18 
2.3 Configuração típica utilizada em um cálculo sequencial QM/MM em que tratamos quanticamente um soluto pontual (átomo laranja) e as moléculas da primeira camada de solvatação, as demais moléculas do solvente são tratadas como cargas pontuais (pontos em azul). . . . . . . 21

2.4 Reproduzido da referência [41]. Ilustração do procedimento QM/MM sequencial. . . . . . . . . . . . . . . . . . . 23

2.5 Configuração gerada com ASEC para o caso de um soluto pontual, como um átomo ou partícula quântica. . . . . . . . . . . . . . . . 23

4.1 Gráfico do potencial LJ mostrando os comportamentos repulsivo e atrativo do potencial, e os parâmetros $\epsilon$ e $\sigma$. . . . . . . . . . . 45

4.2 Gráfico do potencial LJ representando a interação do Ps com a água usando o modelo I, os parâmetros do campo de força são $\epsilon_{\mathrm{PsO}}=0.050 \mathrm{kcal} / \mathrm{mol}$ e $\sigma_{\mathrm{PsO}}=3.82 \AA . \ldots \ldots \ldots \ldots \ldots \ldots$

4.3 Gráfico dos potenciais LJ representando a interação do Ps com a água para as duas propostas de modelo do campo de força do Ps. . . . . . . 48

4.4 Caixa de simulação usada nas simulações clássicas, no centro da caixa temos o átomo de positrônio representado em verde. . . . . . . . . . . . 49

4.5 Entalpia configuracional por molécula na etapa de termalização no gráfico A, e na etapa de produção no gráfico $\mathrm{B}$, em ambos os gráficos os valores da entalpia estão em kcal/mol. . . . . . . . . . . . . . . . 50

4.6 Histograma dos valores da densidade do líquido amostrados durante a simulação. . . . . . . . . . . . . . . . . . . . . 50 50

4.7 Ajuste da função de autocorrelação estatística $C(t) \ldots$. . . . . . . . . . 51

4.8 Comparação entre as RDF Ps-O e elétron-O. . . . . . . . . . . . . . . 52 
4.9 Sobreposição da primeira camada de solvatação das configurações descorrelacionadas do elétron (A) e do Ps (B) hidratados, em ambos os casos o soluto está representado por um ponto no centro da cavidade. . 53

4.10 Comparação entre as RDF Ps-O e O-O da água-água. . . . . . . . . . . 53

4.11 Entalpia configuracional por molécula nas etapas de termalização (A) e produção (B) obtida com os parâmetros do modelo II, em ambos os gráficos os valores da entalpia estão em kcal/mol. . . . . . . . . . . . 55

4.12 Comparação entre os histogramas da densidade e das RDF Ps-O, ambos obtidos com os parâmetros dos modelos I e II. . . . . . . . . . . . . . 55

4.13 Gráfico das pertubações sobre o parâmetro $\epsilon_{\mathrm{Ps}}$ do potencial de interação $\mathrm{Ps}_{\mathrm{s}} \mathrm{H}_{2} \mathrm{O}$. A parte repulsiva do potencial é afetada de maneira significativa. 58

$4.14 \mathrm{O}$ gráfico à esquerda representa a média acumulada da energia de interação Ps-água $\left(E_{\mathrm{Psw}}\right)$ em função do número de valores $(N)$ considerados na média, enquanto no gráfico da direita temos a média acumulada da energia de relaxação $\left(E_{\mathrm{R}}\right)$ em função do número de valores. . . . . . . 62

5.1 RDF entre o Ps e o centro de massa das moléculas de água, a região destacada abaixo da curva corresponde a parte do sistema considerada nos cálculos QM. O número de moléculas de água consideradas como cargas pontuais é dado pela integral da região destacada da RDF. . . . 67

5.2 Configurações A, B e C selecionadas para os testes compostas pelo Ps e dez moléculas de água consideradas explicitamente conforme o procedimento I. . . . . . . . . . . . . . . . . . . . . . . . . . . . . 68

5.3 Configurações A, B e C selecionadas para os testes compostas pelo Ps, dez moléculas de água consideradas explicitamente e 140 moléculas de água consideradas como cargas pontuais conforme o procedimento II. . 68 
5.4 Orbitais SOMO eletrônico em laranja e positrônico em roxo obtidos com a base $6-31 \mathrm{G}++(\mathrm{d}, \mathrm{p})$ e o procedimento $\mathbf{I}$, usamos o isovalor 0.03. . 70

5.5 Orbitais SOMO eletrônico em laranja e positrônico em roxo obtidos com a base $6-31 \mathrm{G}++(\mathrm{d}, \mathrm{p})$ e o procedimento II, usamos o isovalor 0.03 .71

5.6 Momento de dipolo total representado junto com os orbitais SOMO eletrônico (laranja) e positrônico (roxo), as densidades foram representadas com o isovalor 0.03. Esses resultados foram obtidos com a base $6-31 \mathrm{G}++(\mathrm{d}, \mathrm{p})$ e o procedimento $\mathbf{I} \ldots \ldots \ldots 72$

5.7 Momento de dipolo total representado junto com os orbitais SOMO eletrônico (laranja) e positrônico (roxo), as densidades foram representadas com o isovalor 0.03. Esses resultados foram obtidos com a base $6-31 \mathrm{G}++(\mathrm{d}, \mathrm{p})$ e o procedimento II. . . . . . . . . . . . . . .

5.8 Momento de dipolo total representado junto com os orbitais SOMO eletrônico (laranja) e positrônico (roxo) usando o isovalor 0.03. Esses resultados foram obtidos com a base $6-31 \mathrm{G}++(\mathrm{d}, \mathrm{p})$ para a configuração C considerando toda a primeira camada de solvatação explicitamente com o procedimento II. . . . . . . . . . . . . . . . . . . . . 73

5.9 Orbitais SOMO eletrônico em laranja e positrônico em roxo obtidos com a base $6-31 \mathrm{G}++(\mathrm{d}, \mathrm{p})$ e o procedimento $\mathbf{I}$, usamos o isovalor 0.03. . 77

5.10 Orbitais SOMO eletrônico em laranja e positrônico em roxo obtidos com a base $6-31 \mathrm{G}++(\mathrm{d}, \mathrm{p})$ e o procedimento II, usamos o isovalor 0.03. 77

5.11 Orbitais SOMO eletrônico em laranja e positrônico em roxo obtidos com a base $6-31 \mathrm{G}++(\mathrm{d}, \mathrm{p})$ e o procedimento $\mathbf{I}$, usamos o isovalor 0.03 .

5.12 Orbitais SOMO eletrônico em laranja e positrônico em roxo obtidos com a base $6-31 \mathrm{G}++(\mathrm{d}, \mathrm{p})$ e o procedimento II, usamos o isovalor 0.03 . 
5.13 Médias acumuladas do VDE eletrônico e positrônico, utilizamos a base 6-31G++ (d,p) com centros de expansão nos sítos atômicos e a aug-ccpVTZ com os centros de expansão posicionados sobre a origem. . . . . 83

5.14 Orbitais SOMO eletrônico em laranja e positrônico em roxo obtidos em um dos 60 cálculos quânticos realizados, a figura da direita mostra ambos os orbitais representados simultaneamente. Utilizamos o isovalor

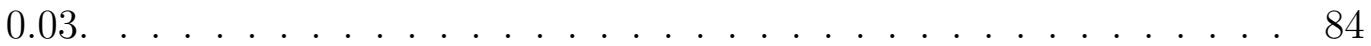





\section{Lista de Tabelas}

4.1 Comparação dos resultados clássicos obtidos com os modelos I e II. . . 56

4.2 Contribuições para o $\Delta G_{\epsilon}$ obtidas para cada pertubação feita sobre o parâmetro $\epsilon \ldots \ldots \ldots \ldots \ldots \ldots$

4.3 Contribuições para o $\Delta G_{\sigma}$ obtidas para cada pertubação feita sobre o parâmetro $\sigma_{\mathrm{Ps}} . \quad \ldots \ldots \ldots \ldots \ldots \ldots$

4.4 Resumo dos resultados obtidos envolvendo a variação na energia interna do sistema no processo de solvatação do Ps. . . . . . . . . . . . . . . 63

5.1 Energias do SOMO eletrônico do Ps calculadas utilizando os centros de expansão positrônico sobre os oxigênios, com os procedimentos I e II. As diferenças entre os resultados com as bases $6-311 \mathrm{G}++(\mathrm{d}, \mathrm{p})$ e 6-31G++(d,p) estão indicadas por $6311 \mathrm{G}-631 \mathrm{G}$, e para o caso da augcc-pVDZ e 6-311G++(d,p) indicamos por VDZ-6311G. . . . . . . . . . 69

5.2 Energias do SOMO positrônico do Ps calculadas utilizando os centros de expansão positrônico sobre os oxigênios, com os procedimentos I e II. As diferenças entre os resultados com as bases $6-311 \mathrm{G}++(\mathrm{d}, \mathrm{p})$ e 6-31G++(d,p) estão indicadas por $6311 \mathrm{G}-631 \mathrm{G}$, e para o caso da augcc-pVDZ e 6-311G++(d,p) indicamos por VDZ-6-311G. . . . . . . . . 70 
5.3 Momento de dipolo total obtido nos cálculos RHF para as configurações A, B e C com os procedimentos I e II ambos na ausência do Ps, usamos o isovalor $0.03 . \ldots \ldots \ldots \ldots \ldots$. . . . . . . . . . . . . . . . . . .

5.4 Energias do orbital SOMO eletrônico do Ps obtidas com o centro de expansão do pósitron na origem com os procedimentos I e II. As diferenças entre os resultados com as bases aug-cc-pVTZ e aug-cc-pVDZ estão indicadas por VTZ-VDZ, e para o caso da aug-cc-pVQZ e aug-ccpVTZ indicamos por VQZ-VTZ. . . . . . . . . . . . . . . 75

5.5 Energias do orbital SOMO positrônico do Ps obtidas com o centro de expansão do pósitron na origem com os procedimentos I e II. As diferenças entre os resultados com as bases aug-cc-pVTZ e aug-cc-pVDZ estão indicadas por VTZ-VDZ, e para o caso da aug-cc-pVQZ e aug-ccpVTZ indicamos por VQZ-VTZ. . . . . . . . . . . . . . 75

5.6 Energias totais das configurações A, B e C obtidas nos cálculos UHF com o centro de expansão do pósitron posicionado apenas na origem usando os procedimentos I e II. . . . . . . . . . . . . . . . . 7

5.7 Energias do SOMO eletrônico do Ps em eV calculadas utilizando o centro de expansão positrônico sobre a origem e nos oxigênios, com os procedimentos I e II. As diferenças entre os resultados com as bases 6$311 \mathrm{G}++(\mathrm{d}, \mathrm{p})$ e $6-31 \mathrm{G}++(\mathrm{d}, \mathrm{p})$ estão indicadas por $6311 \mathrm{G}-631 \mathrm{G}$, e para o caso da aug-cc-pVDZ e 6-311G++(d,p) indicamos por VDZ-6-311G. .

5.8 Energias do SOMO positrônico do Ps em eV calculadas utilizando o centro de expansão positrônico na origem e nos oxigênios, com os procedimentos I e II. As diferenças entre os resultados com as bases 6$311 \mathrm{G}++(\mathrm{d}, \mathrm{p})$ e $6-31 \mathrm{G}++(\mathrm{d}, \mathrm{p})$ estão indicadas por $6311 \mathrm{G}-631 \mathrm{G}$, e para o caso da aug-cc-pVDZ e 6-311G++(d,p) indicamos por VDZ-6-311G. . 78 
5.9 Energias totais obtidas com a base $6-31 \mathrm{G}++(\mathrm{d}, \mathrm{p})$ representando todo o sistema com os procedimentos I e II, usando o centro de expansão do pósitron nos oxigênios $\left(E_{1}\right)$, apenas na origem $\left(E_{2}\right)$ e usando centros na origem e nos oxigênios $\left(E_{3}\right) \ldots \ldots \ldots$. . . . . . . . . 80

5.10 Energias dos VDE eletrônico e positrônico do Ps obtidas com um cálculo UHF usando a configuração gerada com o procedimento ASEC. . . . . 84

5.11 Energias dos VDEs eletrônico e positrônico do Ps obtidas com cálculos UHF, MP2 e P2 usando a base aug-cc-pVTZ e a configuração gerada com o procedimento ASEC. . . . . . . . . . . . . . . . 85 



\section{Índice}

1 Introdução 1

2 Simulação de Líquidos Moleculares $\quad 7$

2.1 Método de Monte Carlo . . . . . . . . . . . . . . . . . . . . . . 8

2.2 Algoritmo de Metrópolis . . . . . . . . . . . . . . . . . . . . . . . . . 10

2.3 Potencial de Interação Molecular . . . . . . . . . . . . . . . . . . . . 12

2.4 Função de Distribuição Radial de Pares . . . . . . . . . . . . . . . . . . 13

2.5 Teoria da Pertubação Termodinâmica . . . . . . . . . . . . . . . . . 15

2.6 Simulação com o código DICE . . . . . . . . . . . . . . . . . 17

2.7 Métodos Híbridos . . . . . . . . . . . . . . . . . . . . 20

$2.7 .1 \mathrm{QM} / \mathrm{MM}$ Sequencial . . . . . . . . . . . . . 20

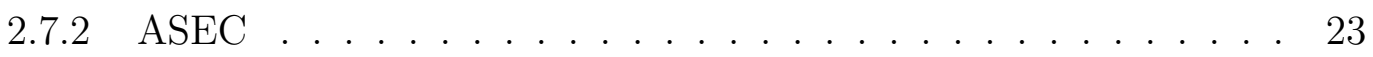

3 Métodos Quânticos de Estrutura Eletrônica 25

3.1 Aproximação de Born-Oppenheimer . . . . . . . . . . . . . . 26

3.1.1 Any Particle Molecular Orbital . . . . . . . . . . . . . . 30

3.2 Método de Hartree-Fock . . . . . . . . . . . . . . . . . . . . . . . . 32

3.3 Teoria de Perturbação de Møller Plesset . . . . . . . . . . . . . . . 35

3.4 Propagadores de Segunda Ordem . . . . . . . . . . . . . . . . . . 40 
4 Resultados das Simulações Clássicas $\quad 43$

4.1 Campo de Força do Átomo de Positrônio . . . . . . . . . . . . . . . . . 43

4.2 Simulações de Monte Carlo . . . . . . . . . . . . . . . . . . . . . . . . . 48

4.3 Análise da Estrutura do Líquido . . . . . . . . . . . . . . . . . 51

4.4 Comparação dos Resultados com Campos de Força Distintos . . . . . . 54

4.5 Energia Livre de Solvatação . . . . . . . . . . . . . . . . . . 56

4.6 Energia de Relaxação da Água . . . . . . . . . . . . . . . . . . . . . . 60

4.7 Contribuição Entrópica da Solvatação . . . . . . . . . . . . . . . . 63

5 Resultados das Simulações Quânticas $\quad 65$

5.1 Modelo de Coordenação . . . . . . . . . . . . . . . . . . 66

5.1.1 Centro de Expansão do Pósitron nos Oxigênios . . . . . . . . . 69

5.1.2 Centro de Expansão do Pósitron na Origem . . . . . . . . . . . 74

5.1.3 Centro de Expansão do Pósitron na Origem e nos Oxigênios . 77

5.1.4 Conclusões do Modelo de Coordenação . . . . . . . . . . . . . . 81

$5.2 \mathrm{QM} / \mathrm{MM}$ Sequencial . . . . . . . . . . . . . . . . . 82

5.3 ASEC . . . . . . . . . . . . . . . . . . . 84

6 Conclusões e Perspectivas $\quad 87$

$\begin{array}{lr}\text { Referências Bibliográficas } & 89\end{array}$ 


\section{Introdução}

A existência dos pósitrons foi prevista teoricamente em 1930 por Dirac [1], e somente em 1933 foi realizada a detecção experimental por Anderson [2]. Essa partícula elementar é a antipartícula do elétron, tendo as mesmas propriedades com exceção da carga que é oposta. Por ser a antipartícula do elétron, pósitrons são instáveis frente à aniquilação com elétrons que resulta na emissão de radiação gama. Existem diversas aplicações tecnológicas que exploram as propriedades do pósitron e sua interação com a matéria, e essas aplicações são feitas em áreas como a ciência de materiais, química, biologia, medicina entre outras. Uma importante aplicação no campo da medicina seria a Tomografia por Emissão de Pósitrons (PET) [3], enquanto no campo da ciência de materiais podemos citar a espectroscopia por aniquilação de pósitrons [4]. Além das características mencionadas anteriormente, pósitrons podem formar os chamados átomos de positrônio (Ps) dependendo das propriedades físico-químicas do meio. Esse átomo consiste em um estado ligado formado por um elétron e um pósitron, instável frente à aniquilação. A previsão teórica dos átomos de positrônio foi feita em 1945 por Mohorovic [5], e em 1951 foi determinada experimentalmente a formação do Ps em fase gasosa por Deutsch [6]. O átomo de positrônio possui dois estados de spin, sendo o caso do spin total (S) igual a 1 chamado de orto-positrônio (o-Ps) e o caso em que $\mathrm{S}=0$ é denominado para-positrônio (p-Ps). A multiplicidade de spin dada por $2 S+1$ indica que para o o-Ps temos um estado tripleto, enquanto para o p-Ps temos um estado singleto. Sobre o tempo de vida de cada um dos estados do Ps em fase 
gasosa, vale mencionar que o tempo de vida do estado fundamental do o-Ps é de 142 ns e 0.125 ns para o p-Ps [7]. O tempo de vida elevado do o-Ps favorece o estudo do seu comportamento em um meio material.

O avanço das técnicas experimentais para a acumulação e manipulação de pósitrons em baixas energias permitiu avanços importantes nesse campo [8, 9, 10], como a produção de moléculas de $\operatorname{Ps}_{2}[11,12]$ e estados atômicos de Rydberg [13, 14]. Paralelamente aos avanços relacionados aos processos fundamentais envolvendo pósitrons, é crescente o interesse pelo entendimento do comportamento dos pósitrons em meio biológico motivado pela PET. Em relação ao estudo do pósitron em meio biológico, resultados recentes obtidos através de simulações dos traços positrônicos em água [15], revelam a formação do Ps em diferentes estágios do caminho do pósitron na água conforme é ilustrado na figura (1.1).

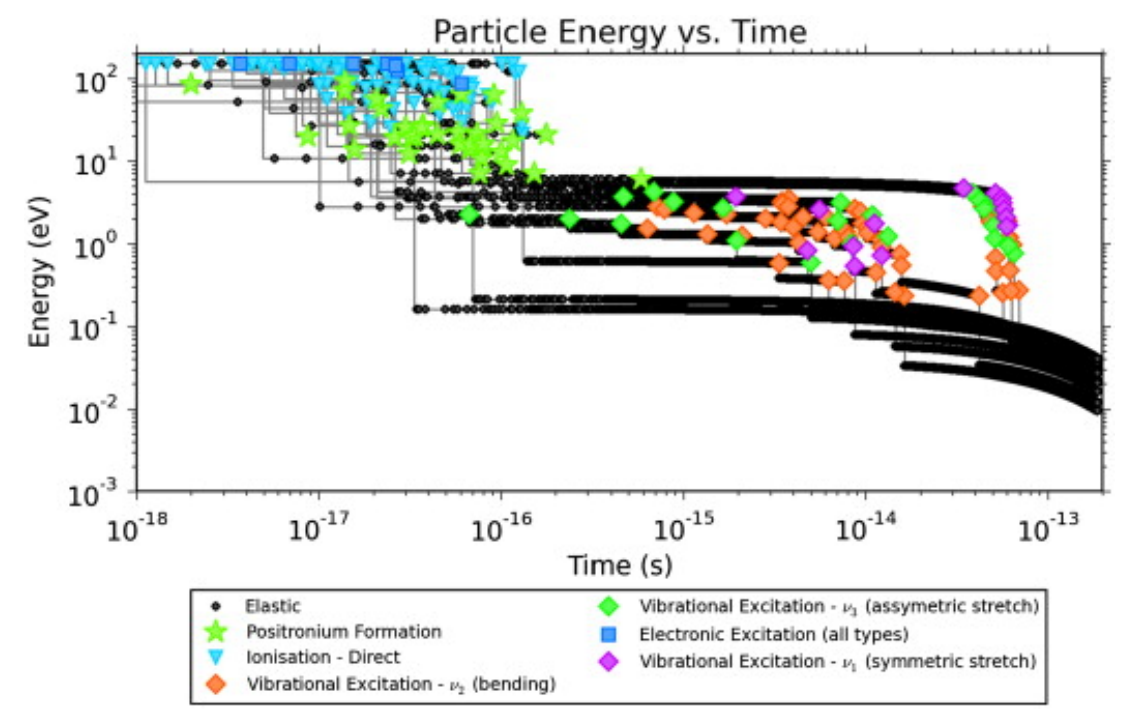

Figura 1.1: Reproduzido da referência [15]. O diagrama mostra a perda de energia de um pósitron, inicialmente com $150 \mathrm{eV}$, em função do tempo. O diagrama de cores indica a ocorrência dos diferentes processos elásticos e inelásticos, tal como descrito por uma simulação de Monte Carlo que leva em consideração a dependência das correspondentes seções de choque em relação à energia.

O diagrama da figura (1.1) sugere a formação do Ps principalmente entre $10^{-17} \mathrm{~s}$ 
e $10^{-16} \mathrm{~s}$, após a emissão dos pósitrons com energia de $150 \mathrm{eV}$. A etapa final dos traços positrônicos revela que os átomos de positrônio formados termalizam em baixas energias e na escala de tempo de $10^{-13} \mathrm{~s}$, inferior ao tempo de vida do o-Ps hidratado que é de $1.86 \times 10^{-9} \mathrm{~s}$ [16]. Essas conclusões corroboram com o que é conhecido experimentalmente sobre o tempo de vida do Ps hidratado, conforme indicamos no diagrama da figura (1.2). Com isso, podemos concluir que esses resultados sugerem a possibilidade da formação de estados de equilíbrio termodinâmico do Ps hidratado na etapa final dos traços positrônicos.

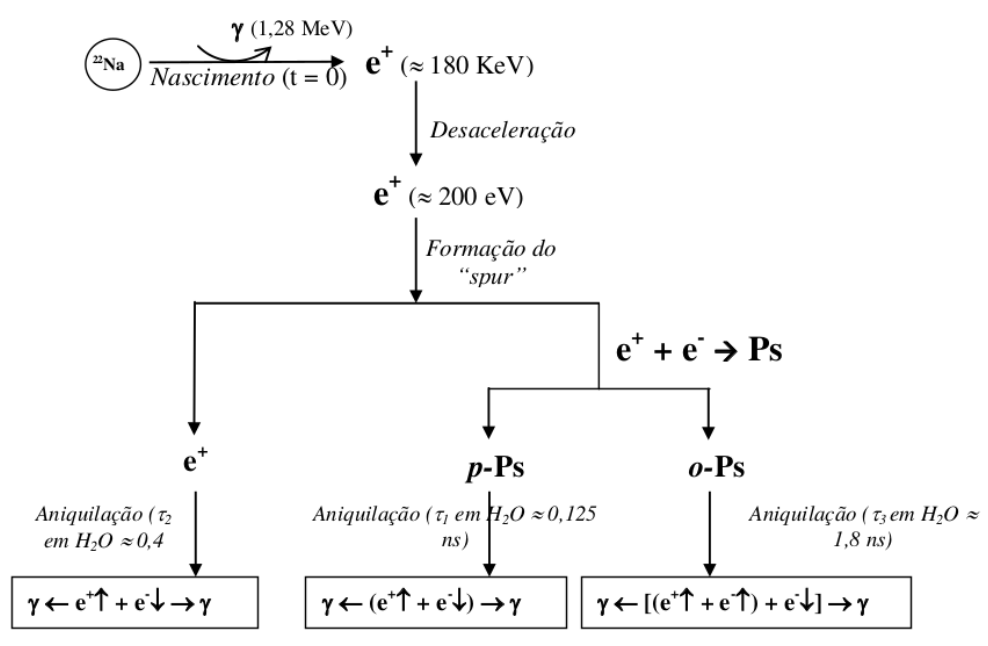

Figura 1.2: Reproduzido da referência [4]. Mecanismos de aniquilação do Ps em água e os respectivos tempos de vida para cada forma de aniquilação.

Uma forma de obtermos pósitrons seria através do decaimento $\beta$ de radionuclídeos, como por exemplo o $\mathrm{Na}^{22}$ [7]. Os pósitrons liberados nesses decaimentos têm energias da ordem de $\mathrm{MeV}$, e portanto são injetados na matéria com energias muito altas conforme indicado na figura (1.2). Após a injeção do pósitron na matéria, ocorre a perda da energia do mesmo através de colisões inelásticas com as moléculas do meio até que energias da ordem de dezenas de elétron-volts sejam atingidas. Então, o pósitron atinge uma faixa de energia entre $5 \mathrm{eV}$ e $10 \mathrm{eV}$, na qual pode formar um estado ligado com o elétron resultando em um átomo de positrônio [7, 17]. Alguns modelos buscam 
explicar a formação do Ps em líquidos e sólidos, para o caso dos líquidos podemos citar os modelos bolha [18], de spur [19] e ressonante [20].

O modelo bolha foi proposto em 1957 por Ferrel [18] com o intuito de explicar o tempo de vida do o-Ps no hélio líquido, o qual é inferior ao tempo de vida em fase gasosa em virtude do mecanismo de aniquilação pick-off. Esse processo consiste na aniquilação do pósitron com um elétron do meio que possui spin oposto, ocasionando a emissão de dois raios gama [7]. Essa abordagem considera a formação de uma bolha no líquido ocupada pelo Ps termalizado, e dentro desta cavidade o Ps poderia sofrer a aniquilação. Por outro lado, o modelo de spur proposto por Mogensen [19] em 1974 para o entendimento da formação do Ps em líquidos considera uma região chamada de spur, formada pelo conjunto de espécies reativas resultantes das colisões durante a termalização do pósitron no líquido.

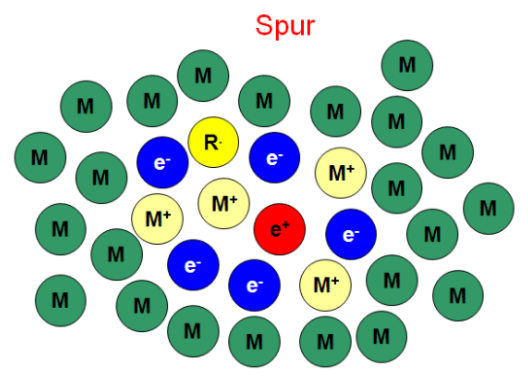

Figura 1.3: Reproduzido da referência [4]. Ilustração da região chamada de spur formada na termalização do pósitron em líquidos, representamos em verde as moléculas, em azul os elétrons, em amarelo os radicais e em vermelho o pósitron.

Na região do spur existe uma competição entre os diversos processos possíveis que podem ocorrer, como a recombinação cátion-elétron, difusão do pósitron no meio, reações do pósitron com íons ou moléculas e até mesmo a solvatação do elétron ou pósitron ambos pertencentes ao spur. Outro modelo importante para o entendimento da formação do positrônio em líquidos, seria o modelo ressonante proposto em 1990 por 
Zhang [20]. Neste modelo, a região chamada de spur também é considerada havendo diferenças apenas em relação ao intervalo de energia do pósitron em que ocorre a formação do Ps.

O desenvolvimento de modelos para tratar o Ps hidratado ainda permanece em discussão na literatura $[17,21,22]$, havendo uma lacuna a ser preenchida em relação ao desenvolvimento metodológico para o tratamento adequado do Ps solvatado. Essa lacuna pode ser preenchida utilizando metodologias bem estabelecidas para o estudo de sistemas moleculares e atômicos em solução. Este trabalho é destinado ao desenvolvimento de um procedimento capaz de permitir o estudo de propriedades termodinâmicas, estruturais e quânticas do Ps solvatado. Isso foi feito através de uma abordagem QM/MM do sistema, a qual foi viabilizada com a proposta pioneira de um campo de força para o Ps hidratado. Com a definição do campo de força, realizamos simulações clássicas de Monte Carlo seguidas de uma abordagem quântica do sistema. Desta forma, adotamos o procedimento sequencial QM/MM para o cálculo de propriedades quânticas do sistema. Cabe mencionar que essa abordagem permite o tratamento do Ps solvatado em diversos solventes, podendo também ser extendida para o estudo do Ps em materiais o qual tem atraído a atenção da comunidade de pesquisadores da área [23, 24, 25, 26].

O texto desta dissertação foi organizado da seguinte forma. No capítulo 2 é apresentada a técnica para a simulação de líquidos moleculares utilizada, os modelos de solvatação são brevemente discutidos e os procedimentos QM/MM são abordados. No capítulo 3 são tratados os métodos utilizados para os cálculos de estrutura eletrônica e a metodologia Any Particle Molecular Orbital. O campo de força proposto para o Ps hidratado é discutido no capítulo 4, assim como os resultados das simulações clássicas para o Ps hidratado. Os resultados das simulações quânticas são abordados no capítulo 5, e a conclusão do trabalho é feita no capítulo seguinte. 



\section{Simulação de Líquidos Moleculares}

O estado líquido apresenta características intermediárias em comparação aos estados gasoso e sólido. Enquanto para um gás podemos assumir a aproximação de não-interação entre seus constituintes, o mesmo não pode ser feito para um sólido, mas é possível simplificar essa interação através da periodicidade presente neste estado. Um líquido possui características que o tornam distinto dos sistemas em fase gasosa e sólida, e ao mesmo tempo mais complexo. A alta densidade de um líquido impede que seja desprezada a interação entre seus constituintes, e a grande mobilidade das moléculas leva a uma enorme possibilidade de configurações para esse estado da matéria [27]. Existem diversos processos na natureza que ocorrem em meio líquido, e algumas propriedades de sistemas moleculares são sensíveis à presença de um solvente. Com isso, as simulações de sistemas moleculares solvatados devem tratar de maneira adequada o efeito do solvente sobre o sistema que está sendo estudado.

O solvente pode ser representado de diferentes formas em uma simulação computacional, e essas maneiras de representar o solvente são em geral divididas em dois modelos. O primeiro compreende o conjunto de métodos baseados na descrição do solvente como um meio contínuo [28], enquanto o segundo realiza a descrição atomística do solvente utilizando o modelo discreto [29]. Existem algumas vantagens e desvantagens no uso de cada modelo, assim como abordagens em que o custo computacional é maior ou menor. A abordagem utilizada neste trabalho foi a do modelo discreto do solvente, o qual descreve bem a estrutura microscópica do solvente nas regiões mais próximas do 
soluto. Porém, é preciso frisar que a descrição atomística do solvente implica na necessidade de determinarmos todas as posições dos átomos compondo o líquido. Assim, precisamos lidar com um grande número de informações nas simulações resultando em um maior custo computacional. Uma importante complicação inerente ao uso do modelo discreto do solvente, seria o fato das moléculas mudarem suas posições constantemente devido a dinâmica do sistema. Deste modo, é importante considerar a natureza estatística do líquido molecular.

\subsection{Método de Monte Carlo}

A descrição de um líquido é feita através do formalismo da Mecânica Estatística, que permite a obtenção de propriedades termodinâmicas e estruturais destes sistemas. O estado termodinâmico de um líquido pode ser representado por algumas variáveis, como a pressão, volume, e temperatura, entre outras. Nesta descrição podemos manter fixas algumas variáveis, de forma a estabelecer um ensemble de configurações. Usualmente, a descrição de líquidos é feita através do ensemble canônico (NVT) em que o número de partículas $(\mathrm{N})$, volume $(\mathrm{V})$ e temperatura $(\mathrm{T})$ estão fixos. Alternativamente, pode ser utilizado o ensemble das pressões (NpT) no qual o número de partículas, pressão (p) e temperatura estão fixos [30]. Uma vez estabelecido o ensemble no qual será estudado o sistema, podemos efetuar o cálculo da média de uma propriedade termodinâmica $A$ através de uma integral contendo uma parte com uma dependência em relação às coordenadas espaciais das partículas, e outra com as coordenadas de momento. Independente da complexidade do sistema, a integral sobre as coordenadas de momento das partículas é resolvida analiticamente. Assim, a complexidade matemática está na resolução da integral contendo o potencial de interação intermolecular $(U(\mathbf{R}))$ que fornecerá uma média configuracional da propriedade por meio da expressão 


$$
\langle A\rangle=\frac{1}{Z} \int A(\mathbf{R}) \rho d \mathbf{R}
$$

em que $\rho / Z$ seria a distribuição de probabilidades do ensemble, $\mathbf{R}$ designa o conjunto das coordenadas dos contituintes representando uma configuração e $Z$ seria a função partição configuracional. Essa função partição funciona como o fator de normalização da distribuição de probabilidades, e para os ensembles NVT e NpT é dada (a função partição) por (2.2) e (2.3) respectivamente,

$$
Z_{\mathrm{NVT}}=\int e^{-U(\mathbf{R}) / k_{B} T} d \mathbf{R}
$$

e

$$
Z_{\mathrm{NpT}}=\iint e^{-[U(\mathbf{R})+p V] / k_{B} T} d \mathbf{R} d V
$$

No caso do ensemble canônico, a média de uma propriedade $A$ seria dada por

$$
\langle A\rangle=\frac{\int A(\mathbf{R}) e^{-U(\mathbf{R}) / k_{B} T} d \mathbf{R}}{\int e^{-U(\mathbf{R}) / k_{B} T} d \mathbf{R}}
$$

e para o ensemble NpT o valor médio de $A$ é

$$
\langle A\rangle=\frac{\iint A(\mathbf{R}) e^{-[U(\mathbf{R})+p V] / k_{B} T} d \mathbf{R} d V}{\iint e^{-[U(\mathbf{R})+p V] / k_{B} T} d \mathbf{R} d V}
$$

sendo $p$ a pressão, $T$ é a temperatura, $V$ é o volume e $k_{B}$ é a constante de Boltzmann [30].

Esse formalismo é utilizado em simulações computacionais através de alguns métodos. Os dois principais métodos são o Monte Carlo (MC) e a Dinâmica Molecular (DM) [31]. No caso das simulações com DM, são geradas configurações do líquido de forma determinística através da mecânica newtoniana. Com isso, existe uma evolução tempo- 
ral das configurações que permite a obtenção de propriedades dependentes do tempo. Por outro lado, o método Monte Carlo têm como principal característica o uso de amostragens aleatórias. Utilizamos neste trabalho o método Monte Carlo, e portanto vamos abordar na sequência os aspectos envolvidos na utilização deste método.

Como ponto de partida podemos sugerir a utilização do método MC para uma integração numérica, que pode ser útil para o cálculo das médias de propriedades termodinâmicas. Porém, para um líquido molecular simples temos integrais multidimensionais envolvidas nos cálculos das médias exigindo uma amostragem muito grande. Isso seria um dos obstáculo para a obtenção de soluções analíticas ou via simulações MC. Com o uso de potenciais sofisticados para a descrição da interação entre os constituintes do líquido, teremos dificuldades ainda maiores. Deste modo, para atingirmos nosso objetivo inicial de obter as propriedades termodinâmicas e estruturais de um líquido, é necessário realizarmos uma amostragem dos pontos do espaço de fase que são mais relevantes para a descrição do sistema. Além disso, é importante utilizarmos um potencial de interação que represente bem as interações entre as moléculas presentes no líquido.

\subsection{Algoritmo de Metrópolis}

Uma maneira adequada de realizar a amostragem dos pontos do espaço de fase em uma simulação MC, seria utilizando técnicas de amostragem média [32, 33]. Esse procedimento consiste em escrever uma integral de um valor médio da seguinte maneira,

$$
\langle A(x)\rangle=\int_{x_{1}}^{x_{2}} A(x) \rho(x) d x=\int_{x_{1}}^{x_{2}}\left[\frac{A(x) \rho(x)}{\rho_{\text {arb }}}\right] \rho_{\text {arb }} d x
$$

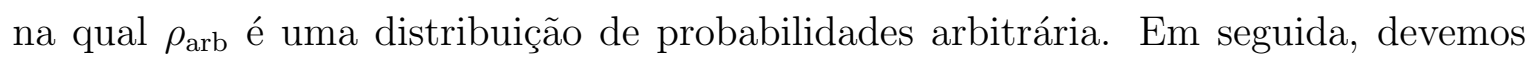
escolher $m$ pontos aleatórios $x_{i}$ no intervalo $\left[x_{1}, x_{2}\right]$ de acordo com a probabilidade 
$\rho_{\text {arb }}$ em questão. Com isso, a média de $A$ será dada por

$$
\langle A\rangle=\left\langle\frac{A(x) \rho(x)}{\rho_{\mathrm{arb}}}\right\rangle_{m}=\frac{1}{m} \sum_{i=1}^{m} \frac{A\left(x_{i}\right) \rho\left(x_{i}\right)}{\rho_{\mathrm{arb}}}
$$

e tomando $\rho_{\text {arb }}=\rho(x)$ temos $\langle A\rangle=\langle A\rangle_{m}$, então basta gerarmos pontos aleatórios $x_{i}$ dentro do intervalo $\left[x_{1}, x_{2}\right]$ obedecendo a distribuição de probabilidade $\rho(x)$. Para o caso das médias de ensemble (2.4) e (2.5), tornamos a probabilidade do ensemble $(\rho)$ igual a probabilidade arbitrária $\left(\rho_{\text {arb }}\right)$. Assim, o valor médio de A será determinado a partir de uma média aritmética dos valores desta propriedade conforme a equação

$$
\langle A\rangle=\langle A\rangle_{m}=\frac{1}{m} \sum_{i=1}^{m} A\left(\mathbf{R}_{i}\right) .
$$

No caso de um líquido molecular os pontos aleatórios que devem ser gerados pertencem ao espaço de fase configuracional, sobre o qual estamos calculando as médias. Então, esses $m$ pontos aleatórios consistem em configurações do líquido representadas por $\mathbf{R}$ que são amostradas de acordo com a distribuição de probabilidade do ensemble utilizado.

A geração e amostragem das configurações mencionadas aqui são realizadas através de um processo Markoviano com um critério de aceitação específico. Esse critério de aceitação é construído de acordo com as probabilidades de cada ensemble. Para o ensemble canônico definimos a probabilidade da transição da configuração $\mathbf{R}_{i}$ para a $\mathbf{R}_{j}$ como sendo igual a $\Pi_{i j}$ dada por

$$
\Pi_{i j}=e^{-\frac{U\left(\mathbf{R}_{j}\right)-U\left(\mathbf{R}_{i}\right)}{k_{B} T}},
$$

e para o ensemble das pressões a probabilidade de transição é

$$
\Pi_{i j}=e^{-\frac{U\left(\mathbf{R}_{j}\right)-U\left(\mathbf{R}_{i}\right)+p\left(V_{j}-V_{i}\right)}{k_{B} T}}
$$


sendo $U\left(\mathbf{R}_{i}\right)$ e $U\left(\mathbf{R}_{j}\right)$ as energias das configurações $\mathbf{R}_{i}$ e $\mathbf{R}_{j}$ respectivamente, $V_{i}$ e $V_{j}$ são os volumes das configurações $\mathbf{R}_{i}$ e $\mathbf{R}_{j}$. As expressões da probabilidade de transição são utilizadas para aceitarmos uma configuração gerada aleatoriamente de acordo com os seguintes critérios.

- Se $U\left(\mathbf{R}_{j}\right)<U\left(\mathbf{R}_{i}\right)$, então a configuração gerada é aceita.

- Se $U\left(\mathbf{R}_{j}\right)>U\left(\mathbf{R}_{i}\right)$, então um número aleatório $\zeta$ pertencente ao intervalo $[0,1]$ é gerado. Se $\zeta<\prod_{i j}$, a configuração é aceita e caso contrário é rejeitada.

Esse é o algoritmo proposto por Metrópolis [33] aplicado ao caso das simulações de líquidos moleculares, que evita a amostragem excessiva de configurações com pequena contribuição para o cálculo dos valores médios.

\subsection{Potencial de Interação Molecular}

Uma vez estabelecida a forma de realizar uma amostragem das regiões mais significativas do espaço de fase, ou seja, configurações com peso estatístico considerável, devemos estabelecer a forma do potencial de interação intermolecular utilizado nas simulações MC.

Sistemas na fase líquida são considerados densos e compostos por moléculas em constantes movimentos de rotação e translação, de modo que existe uma constante interação entre as moléculas. Para atingirmos nosso objetivo de determinar a interação molecular através de um potencial, utilizamos um nível de aproximação em que consideramos um potencial efetivo ajustado a dados experimentais ou curvas de energia potencial provenientes de cálculos quânticos. Neste caso, a energia de interação para uma configuração $\mathbf{R}$ é

$$
U(\mathbf{R})=U_{\text {intra }}(\mathbf{R})+U_{\text {inter }}(\mathbf{R})
$$


onde $U_{\text {intra }}$ consiste na contribuição intramolecular, e $U_{\text {inter }}$ é a contribuição intermolecular para a energia de interação.

Durante as simulações de MC consideramos as moléculas rígidas, e com isso não temos a contribuição intramolecular para o potencial de interação. Podemos escrever de maneira geral o potencial de interação intermolecular para um líquido a partir da equação (2.12), na qual consideramos apenas a contribuição de um potencial efetivo de pares $\left(U_{2}\right)$ com relação aos sítios atômicos

$$
U(\mathbf{R})=\sum_{j>i} U_{2}\left(\mathbf{r}_{i}, \mathbf{r}_{j}\right)
$$

Dadas as características das forças intermoleculares, o potencial de Lennard-Jones acrescido da interação coulombiana representa de forma satisfatória as contribuições atrativas e repulsivas da interação. Esse potencial de interação molecular é dado por

$$
U\left(r_{i j}\right)=\sum_{i} \sum_{j>i} 4 \epsilon_{i j}\left[\left(\frac{\sigma_{i j}}{r_{i j}}\right)^{12}-\left(\frac{\sigma_{i j}}{r_{i j}}\right)^{6}\right]+\frac{1}{4 \pi \epsilon_{0}} \frac{q_{i} q_{j}}{r_{i j}}
$$

onde $r_{i j}$ é a distância entre os sítios atômicos $i$ e $j, q_{i}$ e $q_{j}$ são as cargas parciais dos sítios atômicos $i$ e $j$, o parâmetro $\epsilon_{i j}$ é dado por $\sqrt{\epsilon_{i} \epsilon_{j}}$ e o parâmetro $\sigma_{i j}$ é dado por $\sqrt{\sigma_{i} \sigma_{j}}$. Através deste potencial calculamos a energia de interação entre os constituintes do líquido de uma configuração.

\subsection{Função de Distribuição Radial de Pares}

A análise da estrutura do líquido gerada na simulação é realizada com o auxílio da função de distribuição radial de pares (RDF). Essa função é associada a um par de átomos ou moléculas $i j$, e fornece a probabilidade de encontrar o par entre as distâncias $r$ e $r+d r$. A função de distribuição radial de pares $G(r)$ deve ser tal que, 


$$
N=\frac{4 \pi}{V} \int G(r) r^{2} d r
$$

de forma a garantir que a integral da $G(r)$ seja igual ao número total de moléculas $(N)$, e portanto normalizada.

Para um par de elementos $i j$, a função $G_{i j}(r)$ consiste na equação

$$
G_{i j}(r)=\frac{n_{i j}(r, r+d r)}{n_{i d}(r, r+d r)}
$$

sendo $n_{i j}(r, r+d r)$ o número de pares $i j$ separados por uma distância entre $r$ e $r+d r$, e $n_{i d}(r, r+d r)$ é o número de pares nessa mesma distância em um gás ideal com densidade $\rho$ conforme a equação

$$
n_{i d}(r, r+d r)=\frac{4 \pi}{3} \rho\left[(r+d r)^{3}-r^{3}\right]
$$

A estrutura do líquido é desvendada através da $G(r)$ associando os mínimos dessa função com as diferentes regiões da estrutura do líquido, esses mínimos locais da RDF definem as camadas de solvatação do líquido conforme vemos na figura (2.1).

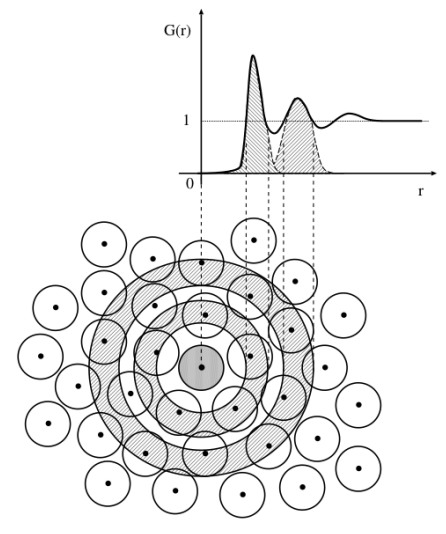

Figura 2.1: Reproduzido da referência [32]. Ilustração da estrutura de um líquido sendo entendida através da $G(r)$. 


\subsection{Teoria da Pertubação Termodinâmica}

A solvatação de um sistema molecular consiste em transferir o soluto da fase gasosa para a fase líquida em uma condição termodinâmica fixa. Esse processo pode ser analisado através da variação de algumas grandezas termodinâmicas do sistema, uma dessas grandezas seria a energia livre de Gibbs. A variação dessa grandeza no processo de solvatação fornece a energia livre de solvatação $\left(\Delta G_{\text {sol }}\right)$, a qual engloba contribuições da interação soluto-solvente, mudanças no soluto e também no solvente envolvidas no processo. De forma mais detalhada, podemos afirmar que a energia livre de solvatação é composta por uma contribuição das interações eletrostáticas e não eletrostáticas. A contribuição eletrostática reflete simplesmente a interação coulombiana entre os constituintes do sistema. Por outro lado, a contribuição não eletrostática pode ser dividida em uma parte referente à cavitação do solvente e outra referente à interação de van der Waals [34, 35].

A variação da energia livre de Gibbs envolvida na solvatação de uma molécula, átomo ou partícula quântica para o caso da solvatação explícita, pode ser determinada através das simulações MC com a teoria da pertubação termodinâmica. Na literatura essa metodologia é chamada de Free Energy Pertubation (FEP) [36].

As energias livres de Gibbs dos sistemas A e B seriam

$$
G_{A}=-k_{B} T \ln Z_{A}
$$

e

$$
G_{B}=-k_{B} T \ln Z_{B}
$$

sendo a variação da energia livre de Gibbs do sistema A para o B dada pela expressão 


$$
\Delta G_{B A}=G_{B}-G_{A}=-k_{B} T \ln \frac{Z_{B}}{Z_{A}}
$$

onde $T$ é a temperatura de ambos os sistemas, $Z_{A}$ e $Z_{B}$ são as funções partição dos sistemas A e B respectivamente. Como estamos tratando do caso do ensemble NpT podemos escrever a razão das funções de partição da seguinte forma

$$
\begin{gathered}
\frac{Z_{B}}{Z_{A}}=\frac{1}{Z_{A}} \iint e^{-\frac{U_{B}(\mathbf{R})+p V}{k_{B} T}} d \mathbf{R} d V \\
\frac{Z_{B}}{Z_{A}}=\frac{1}{Z_{A}} \iint e^{-\frac{H_{B}(\mathbf{R})-H_{A}(\mathbf{R})}{k_{B} T}} e^{-\frac{H_{A}(\mathbf{R})}{k_{B} T}} d \mathbf{R} d V, \\
\frac{Z_{B}}{Z_{A}}=\left\langle e^{-\frac{\Delta H_{B A}}{k_{B} T}}\right\rangle_{A}
\end{gathered}
$$

onde $H_{A}$ e $H_{B}$ são os valores da entalpia dos sistemas A e B respectivamente. Com isso, a variação da energia livre de Gibbs $\left(\Delta G_{B A}\right)$ é escrita como

$$
\Delta G_{B A}=-k_{B} T \ln \left\langle e^{-\frac{\Delta H_{B A}}{k_{B} T}}\right\rangle_{A} .
$$

A implementação computacional do cálculo da média dada por (2.20) exige o uso de estágios intermediários entre $\mathrm{A}$ e $\mathrm{B}$, caso contrário a variação $\Delta H$ será muito grande e a contribuição da exponencial desprezível. Essa é a ideia da metodologia FEP implementada nas simulações de Monte Carlo, ou seja, a variação da energia livre é avaliada em diversos estágios intermediários sucessivos entre os estados inicial e final. Esses estágios intermediários são dados pela pertubação do potencial intermolecular, sendo um estágio hipotético $\alpha_{i}$ definido pelo potencial com um dos parâmetros do campo de força pertubados. Como exemplo podemos citar um estágio intermediário em que a carga $(q)$ foi pertubada por um fator $\gamma q$, sendo $0<\gamma<1$. 
Assim, a variação da energia livre de Gibbs pode ser escrita como a soma da energia livre de $(N-1)$ estágios intermediários $\left(\alpha_{i}\right)$ entre A e B conforme a equação,

$$
\Delta G_{B A}=-k_{B} T \sum_{i=1}^{N-1} \ln \left\langle e^{-\frac{\Delta H_{\alpha_{i} \alpha_{i \pm 1}}}{k_{B} T}}\right\rangle_{\alpha_{i}} .
$$

Para um sistema intermediário $\alpha_{i}$, usando a equação (2.22) podemos escrever

$$
\Delta G_{\alpha_{i} \rightarrow \alpha_{i \pm 1}}=-k_{B} T \ln \left\langle e^{\frac{\Delta H_{\alpha_{i} \rightarrow \alpha_{i \pm 1}}}{k_{B} T}}\right\rangle_{\alpha_{i}}
$$

onde $\Delta H_{\alpha_{i} \rightarrow \alpha_{i \pm 1}}=H_{\alpha_{i \pm 1}}-H_{\alpha_{i}}$. Portanto, a partir do sistema $\alpha_{i}$ determinamos a variação da energia livre de Gibbs para dois sistemas intermediários $\left(\alpha_{i-1}\right.$ e $\left.\alpha_{i+1}\right)$. Essa é a técnica de amostragem de passo duplo, conhecida na literatura como doublewide [37].

Do ponto de vista prático, a FEP representa a diminuição sucessiva dos parâmetros do potencial resultando na aniquilação do soluto do líquido. Ao final do processo, temos a variação da energia livre de Gibbs associada a aniquilação do soluto $\left(\Delta G_{\text {ani }}\right)$. Portanto, o $\Delta G_{\text {sol }}$ corresponde ao inverso do $\Delta G_{\text {ani }}$ conforme a equação seguinte

$$
\Delta G_{\mathrm{sol}}=-\Delta G_{\mathrm{ani}}
$$

\subsection{Simulação com o código DICE}

As simulações clássicas de Monte Carlo com o algoritmo de Metrópolis realizadas neste trabalho foram feitas com o código DICE [32, 38]. O objetivo desta seção é fazer uma descrição geral da simulação computacional utilizando esse código.

O método de Monte Carlo tem como principal característica a geração de números aleatórios para o estudo de problemas determinísticos. Os números aleatórios gerados permitem a geração de configurações aleatórias do líquido ao longo da simulação. Do 
ponto de vista prático, em uma simulação na qual estamos solvatando uma molécula, átomo ou partícula quântica utilizamos uma caixa cúbica na qual estão as moléculas do solvente e o soluto. O sistema contido na caixa de simulação tem volume $V$, pressão $p$ e temperatura $T$ que estão fixos ou não dependendo do ensemble utilizado (NVT ou NpT). Quando confinamos o sistema em uma caixa cúbica, introduzimos efeitos de superfície que surgem da interação das moléculas com as paredes da caixa. Esses efeitos são contornados por meio do uso conjunto do método das imagens com condições periódicas de contorno. O método das imagens consiste em replicar a caixa de simulação em cada direção, e com isso as moléculas interagem com outras de uma das caixas replicadas ao invés de interagir com as paredes. As moléculas nas caixas replicadas se movem da mesma forma que na caixa original, assim uma molécula que sai por uma das faces da caixa original será introduzida novamente pela face oposta. Ilustramos o método das imagens na figura (2.2).

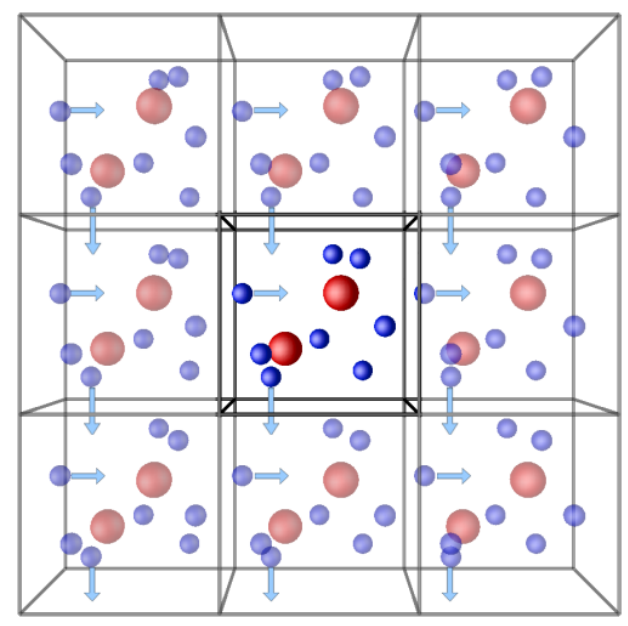

Figura 2.2: Reproduzido da referência [39]. Ilustração do método das imagens no qual a caixa de simulação é replicada em todas as direções.

Além de replicarmos a caixa de simulação, utilizamos um raio de corte para a interação entre as moléculas de modo que as mesmas não podem interagir com outras moléculas situadas a distâncias maiores que o raio de corte. Essa distância corresponde 
à metade do comprimento do lado da caixa de simulação $\left(r_{c}=L / 2\right)$. Deste modo, a energia de interação de uma molécula com as demais ao seu redor será calculada através da equação (2.13) apenas para distâncias menores ou iguais a metade do comprimento da caixa $\left(r \leq r_{c}\right)$.

O início da simulação ocorre com a geração de uma configuração aleatória, e as demais são geradas a partir do sorteio de uma das moléculas da caixa que sofrerá um movimento de translação e rotação. Vale destacar que as configurações aleatórias são geradas através de uma dinâmica estocástica, de modo que as sucessivas configurações geradas não são necessariamente consecutivas ou próximas temporalmente. Dada uma nova configuração, esta será aceita ou não de acordo com o critério de Metrópolis discutido na seção (2.2). O pontecial de interação utilizado no critério de aceitação consiste no potencial Lennard-Jones acrescido da contribuição coulombiana, conforme discutimos na seção (2.3). As moléculas do solvente e o próprio soluto estão rígidos durante toda a simulação, sendo permitido apenas movimentos de translação e rotação de uma molécula sorteada durante a geração de uma nova configuração.

A configuração inicial geralmente possui energia muito maior do que a energia média de equilíbrio da simulação. Com isso, no início da simulação não usamos o critério de aceitação de Metrópolis. O critério utilizado consiste em aceitar somente novas configurações em que a energia diminuiu, e isso é feito até a energia do sistema começar a oscilar em torno de um valor médio. Logo, temos dois estágios para a simulação sendo o inicial referente à fase de termalização do sistema com diminuição sucessiva da energia. O segundo estágio seria aquele no qual o sistema atingiu o equilíbrio, então o critério de aceitação de Metrópolis passa a ser utilizado e as propriedades termodinâmicas e estruturais são calculadas nessa etapa. 


\subsection{Métodos Híbridos}

Nas seções anteriores discutimos o uso de simulações clássicas de Monte Carlo para o estudo das propriedades de líquidos, e nessa abordagem consideramos o modelo discreto do solvente. Além das propriedades termodinâmicas e estruturais do solvente, essas simulações fornecem configurações do líquido com as quais podemos realizar simulações quânticas. Neste caso, estaremos fazendo o uso dos chamados métodos híbridos que consistem na combinação da mecânica quântica (QM) e mecânica clássica ou mecânica molecular (MM). O uso dos métodos híbridos é de enorme importância, sendo inclusive a temática do prêmio Nobel de Química de 2013. Esses métodos permitem a obtenção de diversas propriedades de um sistema em solução de natureza quântica, como espectros de absorção e emissão, energias de ionização e tantas outras. Porém, existem limitações para o tamanho do sistema tratado via QM. Com isso, a ideia principal dos métodos híbridos é tratar uma parte do sistema pela abordagem MM e outra com a QM.

Os métodos híbridos também são chamados de métodos QM/MM, e podem ser divididos em convencional e sequencial. No método QM/MM convencional, fazemos simultâneamente o tratamento quântico de uma parte do sistema e clássico da outra parte. Por outro lado, o QM/MM sequencial funciona com a abordagem clássica de todo o sistema inicialmente sendo seguida da abordagem quântica da região de interesse. Utilizamos neste trabalho o QM/MM sequencial, proposto por Canuto e Coutinho $[29,40]$.

\subsubsection{QM/MM Sequencial}

Conforme descrito no início desta seção, o tratamento de sistemas atômicos ou moleculares em solução via QM/MM sequencial consiste primeiramente em realizar simulações MC ou DM tratando todo o sistema classicamente. Em seguida, utilizando 
as configurações geradas nas simulações clássicas realizamos cálculos quânticos tratando uma parte do sistema classicamente e outra quanticamente. Na figura (2.3) apresentamos uma configuração típica utilizada em uma cálculo quântico, neste caso estamos tratando as moléculas da primeira camada de solvatação e o soluto quanticamente enquanto as demais moléculas do solvente são consideradas cargas pontuais.

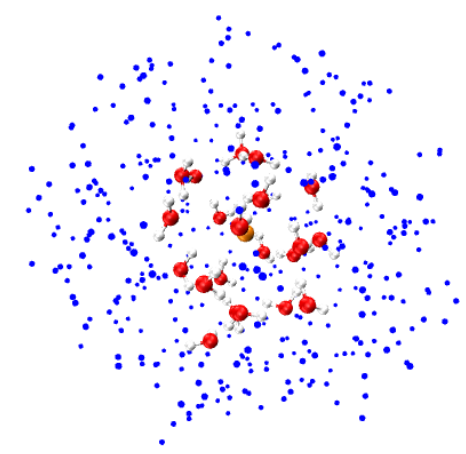

Figura 2.3: Configuração típica utilizada em um cálculo sequencial QM/MM em que tratamos quanticamente um soluto pontual (átomo laranja) e as moléculas da primeira camada de solvatação, as demais moléculas do solvente são tratadas como cargas pontuais (pontos em azul).

Um ponto forte da utilização do QM/MM sequencial é a obtenção do valor da propriedade estudada por meio de uma média estatisticamente convergida. Isso ocorre porque durante o tratamento clássico geramos configurações, que posteriormente são separadas em um conjunto de configurações descorrelacionadas e somente com essas realizamos simulações quânticas. Assim, evitamos cálculos quânticos em configurações próximas as quais sofreram poucas alterações durante a simulação MC. Definimos quais são as configurações descorrelacionadas analisando a correlação estatística entre as configurações, isso é feito com o auxílio da função de autocorrelação. Ao final da simulação clássica de Monte Carlo, calculamos a função de autocorrelação e com ela determinamos o intervalo de passos MC entre configurações ditas descorrelacionadas. Essa função de autocorrelação $(C(n))$ da energia é dada por [32], 


$$
C(n)=\frac{\left\langle\delta E_{i} \delta E_{i+n}\right\rangle}{\left\langle\delta E^{2}\right\rangle}=\frac{\sum_{i}\left(E_{i}-\langle E\rangle\right)\left(E_{i+n}-\langle E\rangle\right)}{\sum_{i}\left(E_{i}-\langle E\rangle\right)^{2}}
$$

onde $E_{i}$ é a energia de uma configuração $i$ e $E_{i+n}$ é a energia da configuração gerada após n passos MC.

Com $C(n)=1$ temos $100 \%$ de correlação entre as configurações, e evidentemente essas configurações estariam correlacionadas e a realização de cálculos quânticos sobre as mesmas seria um desperdício. Por outro lado, configurações infinitamente separadas teriam correlação nula e portanto $C(n)=0$. O comportamento de $C(n)$ para processos markovianos, que é justamente o caso das simulações MC, seria o de um decaimento exponencial $e^{-\frac{n}{\tau}}$ onde $\tau$ é o tempo de correlação. No ajuste da função de autocorrelação, usamos uma função composta por duas exponenciais conforme a equação

$$
C(n)=a_{1} e^{-\frac{n}{\tau_{1}}}+a_{2} e^{-\frac{n}{\tau_{2}}}
$$

O tempo de correlação $\tau$ será a integral da função de autocorrelação $C(n)$

$$
\tau=\int C(n) d n=a_{1} \tau_{1}+a_{2} \tau_{2}
$$

e o intervalo de passos MC entre configurações consideradas descorrelacionadas será igual à ineficiência estatística $(s)$, que corresponde ao dobro do tempo de correlação $(s=2 \tau)[32]$.

Umas vez determinadas as configurações descorrelacionadas, realizamos um cálculo quântico da propriedade desejada em cada configuração e a média dos valores obtidos será o valor da propriedade calculado via QM/MM sequencial conforme a ilustração feita na figura (2.4). 


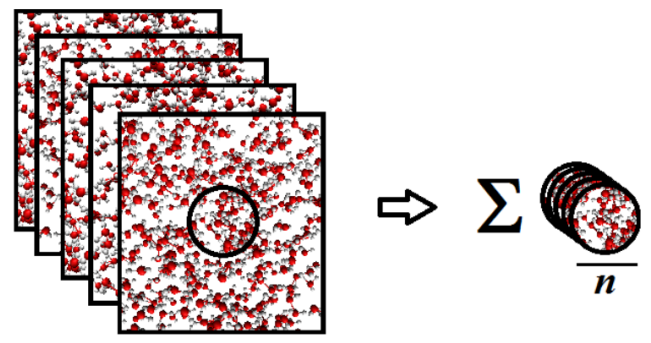

Figura 2.4: Reproduzido da referência [41]. Ilustração do procedimento QM/MM sequencial.

\subsubsection{ASEC}

Outra alternativa dentro dos métodos híbridos para o estudo de sistemas moleculares em solução seria o ASEC, que é o acrônimo de Average Solvent Eletrostatic Configuration [42]. Através desse procedimento geramos uma única configuração média a partir das configurações descorrelacionadas, com a qual realizamos um único cálculo quântico da propriedade de interesse. Para gerarmos ASEC realizamos a sobreposição de todas as configurações descorrelacionadas, considerando todas as moléculas de água das configurações como cargas pontuais. Após a sobreposição, as cargas pontuais sobrepostas são escalonadas pelo número de configurações usada na sobreposição. Na figura (2.5) apresentamos uma configuração gerada com ASEC.

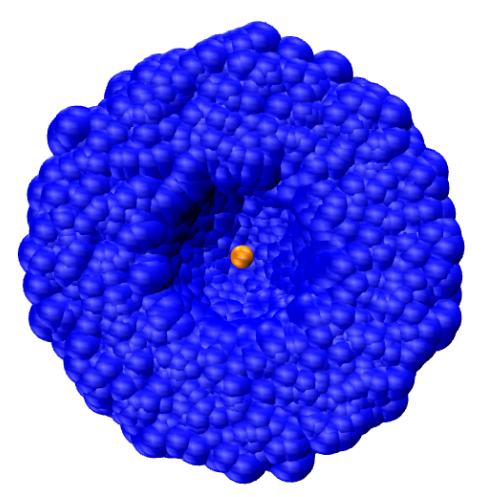

Figura 2.5: Configuração gerada com ASEC para o caso de um soluto pontual, como um átomo ou partícula quântica. 



\section{Métodos Quânticos de Estrutura Eletrônica}

A Física Molecular teórica tem como objetivo central o desenvolvimento de modelos e métodos computacionais para o estudo das propriedades de átomos e moléculas, de modo que os resultados experimentais possam ser interpretados adequadamente. Como ponto de partida temos o desafio de buscar soluções aproximadas para a equação de Schrödinger, uma vez que a solução exata da mesma para sistemas com mais de dois corpos não é factível. Existem diversos métodos destinados a obtenção de soluções aproximadas propostos na literatura que foram e continuam sendo desenvolvidos [43]. Aliado aos métodos mencionados, o modelo adiabático de uma molécula fornece a interpretação dos resultados experimentais espectroscópicos e físico-químicos. Segundo este modelo, os elétrons leves e rápidos adaptariam seu estado (posições e velocidades) quase instantaneamente à distribuição dos núcleos que são pesados e lentos. Os núcleos sentiriam um campo médio devido aos elétrons e suas repulsões mútuas, esse potencial ao qual os núcleos estão sujeitos constitui a chamada Superfície de Energia Potencial (SEP). Com isso, torna-se possível o entendimento dos espectros eletrônico, vibracional e rotacional de uma molécula obtidos experimentalmente. Do ponto de vista teórico, esse modelo resulta na separação dos movimentos eletrônico e nuclear através da Aproximação Adiabática (AA) seguida da definição de um hamiltoniano eletrônico com a Aproximação de Born-Oppenheimer (ABO) [44]. 


\subsection{Aproximação de Born-Oppenheimer}

Vamos iniciar nossa discussão sobre a estrutura eletrônica de sistemas moleculares a partir do desenvolvimento da aproximação de Born-Oppenheimer, discutiremos brevemente a validade da mesma e faremos a extensão desses conceitos para sistemas contendo elétrons e pósitrons.

A equação de Schrödinger independente do tempo para uma molécula poliatômica composta por N elétrons e M núcleos é dada por [40, 45, 46],

$$
\hat{H} \Psi(\mathbf{r}, \mathbf{R})=E \Psi(\mathbf{r}, \mathbf{R})
$$

onde $\hat{H}$ é o operador hamiltoniano total não relativístico, $\Psi(\mathbf{r}, \mathbf{R})$ é a função de onda do sistema, $\mathbf{r}=\left(\mathbf{r}_{1}, \mathbf{r}_{2}, \ldots, \mathbf{r}_{\mathbf{N}}\right)$ e $\mathbf{R}=\left(\mathbf{R}_{1}, \mathbf{R}_{2}, \ldots, \mathbf{R}_{\mathbf{M}}\right)$ são as coordenadas eletrônicas e nucleares respectivamente. O operador hamiltoniano é escrito em unidades atômicas da seguinte forma,

$$
\hat{H}=-\sum_{A=1}^{M} \frac{\nabla_{A}^{2}}{2 M_{A}}-\sum_{i=1}^{N} \frac{\nabla_{i}^{2}}{2}-\sum_{\mu=1}^{N} \sum_{A=1}^{M} \frac{Z_{A}}{r_{\mu A}}+\sum_{\mu=1}^{N} \sum_{\nu<\mu}^{N} \frac{1}{r_{\mu \nu}}+\sum_{A=1}^{M} \sum_{B<A}^{M} \frac{Z_{A} Z_{B}}{R_{A B}}
$$

onde $M_{A}$ é a massa do núcleo $A, Z_{A}$ e $Z_{B}$ representam as cargas dos núcleos $A$ e $B$ respectivamente, os termos $r_{\mu A}, r_{\mu \nu}$ e $R_{A B}$ representam as distâncias elétron-núcleo, elétron-elétron e núcleo-núcleo respectivamente.

Considerando a razão entre as massas do elétron e do núcleo suficientemente pequena, podemos considerar os núcleos fixos durante o movimento dos elétrons e assim o termo de energia cinética dos núcleos pode ser desprezado no hamiltoniano total.

$$
\hat{H}=\hat{T}_{N}+\hat{T}_{e}+\hat{V}_{N e}+\hat{V}_{e}+\hat{V}_{N} \rightarrow \hat{T}_{e}+\hat{V}_{N e}+\hat{V}_{e}+\hat{V}_{N}
$$




$$
\hat{H}=\hat{H}_{\text {ele }}+\hat{V}_{N}
$$

Na equação (3.3) indicamos os operadores de energia cinética dos núcleos e elétrons por $\hat{T}_{N}$ e $\hat{T}_{e}$ respectivamente, as energias potenciais de interação elétron-núcleo são indicadas por $\hat{V}_{N e}$, elétron-elétron por $\hat{V}_{e}$ e núcleo-núcleo por $\hat{V}_{N}$. Após desprezarmos a energia cinética do núcleos, reescrevemos o hamiltoniano na equação (3.4) como a soma do hamiltoniano eletrônico $\left(\hat{H}_{\text {ele }}\right)$ com a energia de interação núcleo-núcleo. Este hamiltoniano comuta com as coordenadas nucleares $\mathbf{R}$, com isso ambos podem ser diagonalizados simultaneamente e os autovalores de $\hat{H}_{\text {ele }}$ podem ser determinados para posições nucleares fixas conforme a equação

$$
\hat{H}_{e l e} \Phi_{m}(\mathbf{r} ; \mathbf{R})=\epsilon_{m}(\mathbf{R}) \Phi_{m}(\mathbf{r} ; \mathbf{R}) .
$$

A função de onda eletrônica possui uma dependência paramétrica em relação às coordenadas nucleares sendo simbolizada por $\Phi(\mathbf{r} ; \mathbf{R})$, enquanto $\epsilon_{m}(\mathbf{R})$ é a energia eletrônica com a mesma dependência nas coordenadas nucleares. O autovalor de $\hat{H}$ para uma molécula com os núcleos fixos é fornecido por (3.6), essa energia seria um ponto da hipersuperfície de energia potencial para um estado eletrônico $m$

$$
E_{m}(\mathbf{R})=\epsilon_{m}(\mathbf{R})+\sum_{A=1}^{M} \sum_{B<A}^{M} \frac{Z_{A} Z_{B}}{R_{A B}} .
$$

Podemos expandir a função de onda $\Psi(\mathbf{r}, \mathbf{R})$ através de um conjunto completo de autofunções do $\hat{H}_{\text {ele }}$,

$$
\Psi(\mathbf{r}, \mathbf{R})=\sum_{m} \chi_{m}(\mathbf{R}) \Phi_{m}(\mathbf{r} ; \mathbf{R})
$$

onde $\chi_{m}(\mathbf{R})$ são os coeficientes da expansão que representam a função de onda nuclear. Subtituindo a expansão (3.7) em (3.1), encontramos a equação seguinte 


$$
\left[-\sum_{A=1}^{M} \frac{\nabla_{A}^{2}}{2 M_{A}}+\hat{H}_{e l e}+\sum_{A=1}^{M} \sum_{B<A}^{M} \frac{Z_{A} Z_{B}}{R_{A B}}\right] \sum_{m} \chi_{m}(\mathbf{R}) \Phi_{m}(\mathbf{r} ; \mathbf{R})=E \sum_{m} \chi_{m}(\mathbf{R}) \Phi_{m}(\mathbf{r} ; \mathbf{R})
$$

que pode ser escrita como

$$
\sum_{m}\left[-\sum_{A=1}^{M} \frac{\nabla_{A}^{2}}{2 M_{A}}+\left(E_{m}(\mathbf{R})-E\right)\right] \chi_{m}(\mathbf{R}) \Phi_{m}(\mathbf{r} ; \mathbf{R})=0 .
$$

Substituímos o resultado de (3.6) em (3.8) para encontrarmos a equação (3.9). Multiplicando (3.9) à esquerda por $\Phi_{n}^{*}$ e integrando sobre todas as coordenadas eletrônicas temos,

$$
\begin{gathered}
{\left[-\sum_{A=1}^{M} \frac{\nabla_{A}^{2}}{2 M_{A}}+E_{n}(\mathbf{R})\right] \chi_{n}(\mathbf{R})=E \chi_{n}(\mathbf{R})+} \\
\sum_{m} \sum_{A=1}^{M} \frac{1}{2 M_{A}}\left[2 \int \Phi_{n}^{*}(\mathbf{r} ; \mathbf{R}) \nabla_{A} \Phi_{m}(\mathbf{r} ; \mathbf{R}) d^{3} r . \nabla_{A}+\int \Phi_{n}^{*}(\mathbf{r} ; \mathbf{R}) \nabla_{A}^{2} \Phi_{m}(\mathbf{r} ; \mathbf{R}) d^{3} r\right] \chi_{m}(\mathbf{R}) .
\end{gathered}
$$

Afim de simplificarmos (3.10) e reescrevermos esta equação de uma maneira propícia para a discussão da AA, definimos

$D_{n m}(\mathbf{R}, \nabla)=\sum_{A=1}^{M} \frac{1}{M_{A}}\left[\int \Phi_{n}^{*}(\mathbf{r} ; \mathbf{R}) \nabla_{A} \Phi_{m}(\mathbf{r} ; \mathbf{R}) d^{3} r . \nabla_{A}+2 \int \Phi_{n}^{*}(\mathbf{r} ; \mathbf{R}) \nabla_{A}^{2} \Phi_{m}(\mathbf{r} ; \mathbf{R}) d^{3} r\right]$

em que $D_{n n}$ e $D_{n m}$ são os chamados termos de acoplamento adiabáticos e não adiabáticos respectivamente. Substituindo (3.11) em (3.10) temos,

$$
\left[-\sum_{A=1}^{M} \frac{\nabla_{A}^{2}}{2 M_{A}}+E_{n}(\mathbf{R})-D_{n n}(\mathbf{R}, \nabla)\right] \chi_{n}(\mathbf{R})=E \chi_{n}(\mathbf{R})+\sum_{m} D_{n m}(\mathbf{R}, \nabla) \chi_{m}(\mathbf{R}) .
$$

Neste ponto podemos estabelecer a chamada aproximação adiabática, que considera 
os estados eletrônicos desacoplados levando a uma função de onda da molécula dada por

$$
\Psi(\mathbf{r} ; \mathbf{R})=\chi_{n}(\mathbf{R}) \Phi_{n}(\mathbf{r} ; \mathbf{R})
$$

Com isso, estamos considerando os termos de acoplamento não adiabáticos $D_{n m}(n \neq$ $m$ ) nulos e a equação (3.12) sem os termos $D_{n m}$ representa a equação de Schödinger para o movimento dos núcleos sujeitos a um potencial efetivo $\left(V_{e f}\right)$ dado por

$$
V_{e f}(\mathbf{R})=E_{n}(\mathbf{R})-D_{n n}(\mathbf{R}, \nabla)
$$

No contexto da AA, fazemos a escolha do hamiltoniano eletrônico que estabelecerá a base de $\Phi_{n}$ definindo assim uma representação. Uma das representações mais utilizadas é a Born-Oppenheimer, em que os termos de acoplamento são considerados nulos. O hamiltoniano eletrônico por sua vez será dado por $H_{\text {ele }}$, de modo que a energia cinética nuclear seja desprezada na resolução do problema eletrônico. Portanto, o potencial efetivo ao qual os núcleos estão sujeitos na $\mathrm{ABO}$ será fornecido por

$$
V_{e f}(\mathbf{R})=E_{n}(\mathbf{R})
$$

e as equações para o movimento nuclear e eletrônico são (3.16) e (3.17) respectivamente,

$$
\left[\hat{T}_{N}+E_{n}(\mathbf{R})\right] \chi_{n m}(\mathbf{R})=E_{n m} \chi_{n m}(\mathbf{R})
$$

e

$$
\left[\hat{T}_{e}+\hat{V}_{N e}+\hat{V}_{e}\right] \Phi_{n}(\mathbf{R})=E_{n} \Phi_{n}(\mathbf{R})
$$


Um aspecto importante da ABO seria a validade desta aproximação. Essa discussão é feita com base na análise dos termos de acoplamento $D_{n m}$ desprezados, e permite concluir que a AA e ABO são válidas em situações sem acoplamento significativo entre diferentes estados eletrônicos $\left(D_{n m} \sim 0\right)$. Essa condição é garantida quando a separação entre estados eletrônicos é significativa, isto é, fora das regiões de cruzamento das curvas de energia potencial, e também para o estado fundamental em torno do mínimo de energia potencial onde tipicamente os estados excitados estão distantes do nível fundamental.

\subsubsection{Any Particle Molecular Orbital}

Apesar da grande importância da ABO para a descrição de propriedades moleculares, existem inúmeros fenômenos moleculares que não podem ser analisados adequadamente empregando a ABO considerando apenas os elétrons quanticamente [47, 48, 49, 50]. Uma alternativa para essas deficiênias seria o uso de metodologias multicomponente, as quais são inspiradas na extensão dos métodos de estrutura eletrônica para a resolução simultânea da equação de Schrödinger independente do tempo para elétrons e outras espécies quânticas. A primeira proposta de abordagem multi-componente foi feita por Thomas em 1961, para a obtenção de funções de onda protônicas [51]. Algumas décadas depois, Nakai e Tachikawa propuseram a extensão da teoria do orbital molecular eletrônico para a obtenção dos estados quânticos dos elétrons e núcleos de moléculas [52], e nos últimos anos outras abordagens multi-componente foram propostas $[53,54,55]$. A abordagem utilizada em nossos estudos é a Any Particle Molecular Orbital (APMO), que foi proposta por Reyes e colaboradores [56]. A APMO generaliza métodos de estrutura eletrônica para descrever simultaneamente múltiplas espécies quânticas, e para o seu desenvolvimento escrevemos o hamiltoniano molecular no contexto da $\mathrm{ABO}$ contendo $N$ elétrons, $M$ núcleos e um pósitron em unidades atômicas 
da seguinte forma

$\hat{H}=-\sum_{i=1}^{N}\left[\frac{\nabla_{i}^{2}}{2}+\sum_{A=1}^{M} \frac{Z_{A}}{r_{i A}}\right]+\left[-\frac{\nabla_{k}^{2}}{2}+\sum_{A}^{M} \frac{Z_{A}}{r_{k A}}\right]+\sum_{i=1}^{N} \sum_{j>i}^{N} \frac{1}{r_{i j}}-\sum_{i=1}^{N} \frac{1}{r_{i k}}+\sum_{A}^{M} \sum_{B>A}^{M} \frac{Z_{A} Z_{B}}{R_{A B}}$

onde os índices $i$ e $j$ são referentes aos elétrons, $k$ é referente ao pósitron, $A$ e $B$ são referentes aos núcleos, $Z_{A}$ e $Z_{B}$ são as cargas dos núcleos $A$ e $B$ respectivamente. De acordo com a Aproximação de Partícula Independente, construímos a função de onda de $N$ elétrons a partir de funções de onda de um elétron. No formalismo APMO essa construção é estendida para o caso dos pósitrons de modo que as funções de onda de um único elétron e pósitron são dadas por

$$
\chi^{e-}\left(\mathbf{r}_{i}\right)=\psi^{e-}\left(\mathbf{r}_{i}\right) \omega\left(s_{i}\right) \quad \text { e } \quad \chi^{e+}\left(\mathbf{r}_{k}\right)=\psi^{e+}\left(\mathbf{r}_{k}\right) \omega\left(s_{k}\right)
$$

onde $\chi^{e-}\left(\mathbf{r}_{i}\right)$ e $\chi^{e+}\left(\mathbf{r}_{k}\right)$ são os spin-orbitais dos elétrons e pósitrons respectivamente, $\psi^{e-}\left(\mathbf{r}_{i}\right)$ e $\psi^{e+}\left(\mathbf{r}_{k}\right)$ são as funções de onda espaciais, $\omega(s)$ são as funções de spin que podem assumir $2 s+1$ valores para um partícula de spin $s$. Elétrons e pósitrons possuem spin $1 / 2$, logo existem dois estados de spin possíveis $(+1 / 2$ ou $-1 / 2)$ para os mesmos comumente chamados de up e down. As funções de onda de $N$ elétrons e um pósitron são construídas através do produto dos respectivos spin-orbitais antisimetrizados de forma a atender o Princípio da Exclusão de Pauli, o qual estabelece que a função de onda de férmions idênticos deve ser antisimétrica em relação a troca das coordenadas das partículas. Logo, a função de onda para um sistema composto por $N$ elétrons e um pósitron será dada pelo produto das funções de onda eletrônica $\left(\Phi^{e^{-}}\right)$e positrônica $\left(\Phi^{e^{+}}\right)$ambas antisimétricas conforme a equação

$$
\Psi_{0}=\Phi^{e^{-}} \Phi^{e^{+}}
$$


Através da função de onda (3.20) realizamos a generalização dos métodos de estrutura estrutura eletrônica, como Hartree-Fock, Teoria de Pertubação e Propagadores Eletrônicos entre outros para sistemas contendo $N$ elétrons e um pósitron [56].

\subsection{Método de Hartree-Fock}

Vamos iniciar a discussão dos métodos para a resolução da equação de Schrödinger independente do tempo (ES) pela aproximação de Hartree-Fock (HF) [57], que constitui a base para as demais metodologias abordadas na sequência. Dentro do formalismo APMO, essa aproximação consiste em considerar uma função de onda dada por um produto de determinantes de Slater referentes a cada espécie quântica conforme a equação (3.20) [56]. Esses determinantes são construídos a partir dos spin-orbitais moleculares $\chi_{i}^{\alpha}$, os quais são obtidos através da resolução das equações de Fock dadas por

$$
F^{\alpha}(1) \chi^{\alpha}(1)=\epsilon^{\alpha}(1) \chi^{\alpha}(1), \quad \alpha=e^{-}, e^{+}
$$

sendo $F^{\alpha}(1)$ os operadores de Fock dos elétrons e pósitron, $\epsilon^{\alpha}(1)$ são as energias orbitais eletrônicas e positrônicas. Os operadores de Fock são dados pelas expressões (3.22) e (3.23),

$$
F^{e^{-}}(1)=h^{e^{-}}(1)+\sum_{i}^{N^{e^{-}}}\left[J^{e^{-}}(i)-K^{e^{-}}(i)\right]-J^{e^{+}}(1)
$$

e

$$
F^{e^{+}}(1)=h^{e^{+}}(1)-\sum_{i}^{N^{e^{-}}} J^{e^{-}}(i) .
$$

Os hamiltonianos de caroço, presentes nos operadores de Fock definidos acima, são escritos como 


$$
h^{e^{-}}(1)=-\frac{1}{2} \nabla_{1}^{2}-\sum_{A}^{M} \frac{Z_{A}}{r_{1 A}} \quad h^{e^{+}}(1)=-\frac{1}{2} \nabla_{1}^{2}+\sum_{A}^{M} \frac{Z_{A}}{r_{1 A}},
$$

em que $Z_{A}$ é a carga do núcleo $A$. Definimos os operadores de Coulomb $(J)$ e de Troca $(K)$ para ambas as espécies quânticas conforme as equações

$$
\begin{gathered}
J_{j}^{\alpha}(1) \psi_{i}^{\alpha}(1)=\left[\int d \mathbf{r}_{2} \psi_{j}^{\alpha *}(2) \frac{1}{r_{12}} \psi_{j}^{\alpha}(2)\right] \psi_{i}^{\alpha}(1), \\
J_{j}^{\alpha}(1) \psi_{i}^{\beta}(1)=-\left[\int d \mathbf{r}_{2} \psi_{j}^{\alpha *}(2) \frac{1}{r_{12}} \psi_{j}^{\alpha}(2)\right] \psi_{i}^{\beta}(1) \quad \alpha \neq \beta
\end{gathered}
$$

e

$$
K_{j}^{\alpha}(1) \psi_{i}^{\alpha}(1)=\left[\int d \mathbf{r}_{2} \psi_{j}^{\alpha}(2) \frac{1}{r_{12}} \psi_{i}^{\alpha}(2)\right] \psi_{j}^{\alpha}(1) \quad \alpha, \beta=e^{-}, e^{+}
$$

Os operadores de Troca e de Coulomb possuem uma interpretação análoga à usual da teoria de Hartree-Fock para sistemas puramente eletrônicos, ou seja, o operador de Coulomb representa a interação coulombiana entre as nuvens eletrônicas e entre as densidades de carga definidas pelos orbitais moleculares eletrônicos e positrônicos [57]. Enquanto para o operador de Troca não há interpretação em termos clássicos, cabendo dizer apenas que ele resulta da imposição do Princípio da Exclusão de Pauli.

A parte espacial dos spins orbitais dados por (3.19) é escrita como a combinação linear de orbitais atômicos de acordo com a equação

$$
\psi_{i}^{\alpha}(\mathbf{r})=\sum_{\mu} C_{\mu i}^{\alpha} \phi_{\mu}^{\alpha}\left(\mathbf{r}, \mathbf{r}_{\mathbf{0}}\right)
$$

sendo $\left\{\phi_{\mu}^{\alpha}\left(\mathbf{r}, \mathbf{r}_{0}\right)\right\}$ o conjunto de funções base. Usualmente utilizamos conjuntos de funções de base gaussianas, e a coordenada $\mathbf{r}_{0}$ corresponde ao centro de expansão das funções sendo geralmente a posição dos sítios atômicos [57]. 
Através da formulação matricial proposta por Roothaan [58], a solução das equações de Fock correspondem ao problema matricial representado por

$$
\mathbf{F}^{\alpha} \mathbf{C}^{\alpha}=\epsilon^{\alpha} \mathbf{S}^{\alpha} \mathbf{C}^{\alpha} \quad \alpha=e^{-}, e^{+}
$$

em que $\mathbf{F}$ é a matriz de Fock, $\mathbf{C}$ é a matriz dos coeficientes da expansão (3.28), $\mathbf{S}$ é a matriz de overlap e $\epsilon$ é a matriz das energias orbitais. As equações (3.29) são resolvidas simultaneamente para cada espécie quântica através do procedimento iterativo SCF, até que ocorra a convergência da energia total Hartree-Fock $\left(E^{A P M O / H F}\right)$ dada pela expressão

$E^{A P M O / H F}=\left\langle\Psi_{0}|\hat{H}| \Psi_{0}\right\rangle=\left\langle k\left|h^{e^{+}}(k)\right| k\right\rangle+\sum_{i=1}^{N}\left\langle i\left|h_{i}^{e^{-}}\right| i\right\rangle+\frac{1}{2} \sum_{i=1}^{N} \sum_{j=1}^{N}\langle i j \| i j\rangle-\frac{1}{2} \sum_{i=1}^{N}\langle i k \mid i k\rangle$

onde $|k\rangle=\left|\psi_{k}\right\rangle$ é o orbital positrônico ocupado, $|i\rangle=\left|\psi_{i}\right\rangle$ e $|j\rangle=\left|\psi_{j}\right\rangle$ são os orbitais eletrônicos ocupados. Usamos a notação $\langle a b|| a b\rangle=\langle a b \mid a b\rangle-\langle a b \mid b a\rangle$ na equação (3.30).

Além da energia total, outra grandeza importante que diz respeito à estrutura eletrônica do sistema são as energias dos orbitais ocupados determinadas no cálculo HF. As expressões dessas energias são dadas pelas equações,

$$
\epsilon^{e^{-}}(i)=\left\langle i\left|F^{e^{-}}(i)\right| i\right\rangle=\left\langle i\left|h^{e^{-}}(i)\right| i\right\rangle-\langle i k \mid i k\rangle+\sum_{j=1}^{N}\langle i j \| i j\rangle
$$

$\mathrm{e}$

$$
\epsilon^{e^{+}}(k)=\left\langle k\left|F^{e^{+}}(k)\right| k\right\rangle=\left\langle k\left|h^{e^{+}}(k)\right| k\right\rangle-\langle k i \mid k i\rangle .
$$

As energias orbitais calculadas possuem uma interpretação física importante a partir do teorema de Koopmans, que é extendido para sistemas com mais de uma espécie 
quântica dentro do formalismo APMO. Com isso, as energias de ionização eletrônica e positrônica são calculadas considerando este teorema a partir do negativo da energia do orbital de mais alta energia da espécie quântica em questão.

\subsection{Teoria de Perturbação de Møller Plesset}

Além do método de Hartree-Fock existem outros que procuram incluir as chamadas energias de correlação, sendo conhecidos como métodos pós Hartree-Fock [45, 57]. A Teoria de Pertubação de Møller Plesset [59] constitui um destes métodos, especificamente a correção de segunda ordem fornece uma correção ao resultado Hartree-Fock para a energia total. Vamos descrever brevemente a Teoria de Pertubação de RayleighSchrödinger [60], a partir da qual podemos tratar o caso de muitos corpos.

Como ponto de partida supomos que nosso sistema seja descrito por um hamiltoniano independente do tempo $(H)$, para o qual não somos capazes de resolver a ES

$$
H\left|\Psi_{0}\right\rangle=E\left|\Psi_{0}\right\rangle
$$

Outra suposição seria em relação a existência de um hamiltoniano $\left(H^{(0)}\right)$ que difere pouco do hamiltoniano completo $H$, sendo as soluções da ES para o mesmo conhecidas. Assim, o hamiltoniano é escrito como a soma de $H^{(0)}$ com uma pertubação $(W)$

$$
H=H^{(0)}+W
$$

Deste modo, os autovalores e autofunções de $H$ podem ser obtidos a partir dos autovalores e autofunções conhecidos de $H^{(0)}$ e dos elementos de matriz de $W$ na base das autofunções de $H^{(0)}$. Consideramos a expansão da energia e da função de onda do sistema introduzindo um parâmetro $\lambda$ da seguinte forma, 


$$
E_{0}=E_{0}^{(0)}+\lambda E_{0}^{(1)}+\lambda^{2} E_{0}^{(2)}+\ldots
$$

$\mathrm{e}$

$$
\left|\Psi_{0}\right\rangle=\left|\Psi_{0}^{(0)}\right\rangle+\lambda\left|\Psi_{0}^{(1)}\right\rangle+\lambda^{2}\left|\Psi_{0}^{(2)}\right\rangle+\ldots
$$

onde $E_{0}^{(n)}$ e $\left|\Psi_{0}^{(n)}\right\rangle$ são as correções de ordem $n$ da energia e função de onda respectivamente. Vamos considerar o estado não pertubado, $\left|\Psi_{0}^{(0)}\right\rangle$, como sendo não degenerado e consideraremos ainda que

$$
W=W^{\dagger}, \quad H^{(0)}=H^{(0) \dagger} \quad\left\langle\Psi_{i}^{(0)} \mid \Psi_{j}^{(0)}\right\rangle=\delta_{i j} .
$$

Substituindo (3.34), (3.35) e (3.36) na ES (3.33) temos

$$
\begin{gathered}
\lambda^{0} \rightarrow H^{(0)}\left|\Psi_{0}^{(0)}\right\rangle=E_{0}^{(0)}\left|\Psi_{0}^{(0)}\right\rangle, \\
\lambda^{1} \rightarrow\left(H^{(0)}-E_{0}^{(0)}\right)\left|\Psi_{0}^{(1)}\right\rangle=\left(E_{0}^{(1)}-W\right)\left|\Psi_{0}^{(0)}\right\rangle, \\
\lambda^{2} \rightarrow\left(H^{(0)}-E_{0}^{(0)}\right)\left|\Psi_{0}^{(2)}\right\rangle=\left(E_{0}^{(1)}-W\right)\left|\Psi_{0}^{(1)}\right\rangle+E_{0}^{(2)}\left|\Psi_{0}^{(0)}\right\rangle
\end{gathered}
$$

onde as equações (3.38) representam os termos da expansão até segunda ordem. Multiplicando a terceira equação (3.38) à esquerda por $\left\langle\Psi_{0}^{(0)}\right|$, e usando o resultado

$$
\left\langle\Psi_{0}^{(0)}\right|\left(H^{(0)}-E_{0}^{(0)}\right)=0
$$

junto com a condição de normalização intermediária

$$
\left\langle\Psi^{(0)} \mid \Psi_{0}\right\rangle=1 \rightarrow\left\langle\Psi_{0}^{(0)} \mid \Psi_{0}^{(n)}\right\rangle=\delta_{n 0},
$$

obtemos a equação para a correção de segunda ordem na energia dada por 


$$
E_{0}^{(2)}=\left\langle\Psi_{0}^{(0)}|W| \Psi_{0}^{(1)}\right\rangle
$$

Uma vez determinada a equação da correção da energia de segunda ordem, utilizamos uma expansão de $\left|\Psi_{0}^{(n)}\right\rangle$ através do conjunto completo formado pelas soluções do problema não pertubado $\left\{\left|\Psi_{i}^{(0)}\right\rangle\right\}$ para obtermos uma forma fechada de $E_{0}^{(2)}$. Expandindo $\left|\Psi_{0}^{(1)}\right\rangle$ com o conjunto completo mencionado encontramos,

$$
\left|\Psi_{0}^{(1)}\right\rangle=\sum_{i \neq 0} c_{i}^{(1)}\left|\Psi_{i}^{(0)}\right\rangle
$$

onde a restrição feita no somatório $(i \neq 0)$ resulta da condição de normalização intermediária (3.40) imposta à expansão da função de onda. Substituindo (3.42) na segunda equação (3.38) temos,

$$
\sum_{i \neq 0} c_{i}^{(1)}\left(H^{(0)}-E_{0}^{(0)}\right)\left|\Psi_{i}^{(0)}\right\rangle=\left(E^{(1)}-W\right)\left|\Psi_{0}^{(0)}\right\rangle
$$

Multiplicando a equação (3.43) à esquerda por $\left\langle\Psi_{j}^{(0)}\right|$ e usando a condição de ortonormalidade (3.37) temos

$$
c_{i}^{(1)}=\frac{\left\langle\Psi_{i}^{(0)}|W| \Psi_{0}^{(0)}\right\rangle}{E_{0}^{(0)}-E_{i}^{(0)}},
$$

e com isso determinamos a correção de primeira ordem da função de onda conforme a equação seguinte

$$
\left|\Psi_{0}^{(1)}\right\rangle=\sum_{i \neq 0} \frac{\left\langle\Psi_{i}^{(0)}|W| \Psi_{0}^{(0)}\right\rangle}{E_{0}^{(0)}-E_{i}^{(0)}}\left|\Psi_{i}^{(0)}\right\rangle .
$$

Usando a correção da função de onda (3.45) na equação (3.41) encontramos uma expressão para a correção de segunda ordem da energia dada por 


$$
E_{0}^{(2)}=\sum_{i \neq 0} \frac{\left|\left\langle\Psi_{0}^{(0)}|W| \Psi_{i}^{(0)}\right\rangle\right|^{2}}{E_{0}^{(0)}-E_{i}^{(0)}}
$$

A correção de segunda ordem para um sistema molecular será obtida a partir da generalização da partição de Moller-Plesset do hamiltoniano molecular para um sistema contendo $N$ elétrons e um pósitron cujo hamiltoniano é dado por (3.18). Assim, consideramos a seguinte partição para o mesmo

$$
H^{(0)}=F^{e^{+}}(1)+\sum_{i=1}^{N} F^{e^{-}}(i)
$$

onde $F^{e^{+}}(1)$ e $F^{e^{-}}(1)$ são os operadores de Fock positrônicos e eletrônicos definidos na seção anterior por (3.22) e (3.23). Atuando o operador hamiltoniano não pertubado $H^{(0)}$ sobre a função de onda HF para um sistema contendo $N$ elétrons e um pósitron temos,

$$
H^{(0)}\left|\Psi_{0}\right\rangle=\left(F^{e^{+}}(k)+\sum_{i=1}^{N} F^{e^{-}}(i)\right)\left|\Phi_{0}^{e^{+}}\right\rangle\left|\Phi_{0}^{e^{-}}\right\rangle=\left(\epsilon^{e^{+}}(k)+\sum_{i=1}^{N} \epsilon^{e^{-}}(i)\right)\left|\Phi_{0}^{e^{+}}\right\rangle\left|\Phi_{0}^{e^{-}}\right\rangle
$$

mostrando que a solução da parte não pertubada do hamiltoniano corresponde a soma das energias orbitais positrônica $\left(\epsilon^{e^{+}}(k)\right)$ e eletrônica $\left(\epsilon^{e^{-}}(i)\right)$.

A definição do hamiltoniano não pertubado dada por (3.47), resulta na seguinte definição para a pertubação

$$
\begin{gathered}
W=H-H^{(0)}=h^{e^{+}}(k)+\sum_{i=1}^{N} h^{e^{-}}(i)+\sum_{i=1}^{N} \frac{1}{r_{i k}}+\sum_{j>i}^{N} \frac{1}{r_{i j}}-F^{e^{+}}(k)-\sum_{i=1}^{N} F^{e^{-}}(i), \\
W=\left[\sum_{j>i}^{N} \frac{1}{r_{i j}}-\sum_{i=1}^{N} \nu_{e^{-} e^{-}}^{H F}(i)\right]-\left[\sum_{i=1}^{N} \frac{1}{r_{i k}}+\sum_{i=1}^{N} \nu_{e^{-}}^{H F} e^{+}\right]
\end{gathered}
$$


onde $\nu_{e^{-} e^{-}}^{H F}(i)$ e $\nu_{e^{-} e^{+}}^{H F}(i)$ são dados pelas equações,

$$
\nu_{e^{-} e^{-}}^{H F}(i)=\sum_{a=1}^{N}\left[J_{a}^{e^{-}}(i)-K_{a}^{e^{-}}(i)\right]
$$

e

$$
\nu_{e^{-} e^{+}}^{H F}(i)=\sum_{b=1}^{N} J_{b}^{e^{+}}(i)
$$

Com isso, a correção de segunda ordem na energia do sistema será dada pelas correções $E_{e^{-} e^{-}}^{(2)}$ e $E_{e^{-} e^{+}}^{(2)}$ referentes à correlação elétron-elétron e elétron-pósitron conforme as equações

$$
\begin{gathered}
E_{0}^{(2)}=E_{e^{-} e^{-}}^{(2)}+E_{e^{-} e^{+}}^{(2)}=\sum_{i \neq 0} \frac{\left|\left\langle\Psi_{0}^{(0)}|W| \Psi_{i}^{(0)}\right\rangle\right|^{2}}{E_{0}^{(0)}-E_{i}^{(0)}}, \\
E_{e^{-} e^{-}}^{(2)}=\frac{1}{4} \sum_{a^{e^{-}}}^{O^{e^{-}}} \sum_{b^{e^{-}}}^{O^{e^{-}}} \sum_{r^{e^{-}}} \sum_{s^{e^{-}}} \frac{\left|\left\langle a^{e^{-}} b^{e^{-}} \mid r^{e^{-}} s^{e^{-}}\right\rangle-\left\langle a^{e^{-}} b^{e^{-}} \mid s^{e^{-}} r^{e^{-}}\right\rangle\right|^{2}}{\epsilon_{a}^{e^{-}}+\epsilon_{b}^{e^{-}}-\epsilon_{r}^{e^{-}}-\epsilon_{s}^{e^{-}}}
\end{gathered}
$$

e

$$
E_{e^{-} e^{+}}^{(2)}=\sum_{a^{e^{+}}}^{O^{e^{+}}} \sum_{a^{e^{-}}}^{O^{e^{-}}} \sum_{r^{e^{+}}}^{V^{e^{+}}} \sum_{r^{e^{-}}} \frac{\left|\left\langle a^{e^{+}} a^{e^{-}} \mid r^{e^{+}} r^{e^{-}}\right\rangle\right|^{2}}{\epsilon_{a}^{e^{+}}+\epsilon_{a}^{e^{-}}-\epsilon_{r}^{e^{+}}-\epsilon_{r}^{e^{-}}}
$$

onde os índices $a^{e^{ \pm}}$e $b^{e^{ \pm}}$referem-se aos orbitais ocupados, $r^{e^{ \pm}}$e $s^{e^{ \pm}}$aos virtuais, $O^{e^{ \pm}}$ e $V^{e^{ \pm}}$são os números de orbitais ocupados e virtuais respectivamente. Portanto, a energia total do sistema obtida considerando a correção de segunda ordem fornece a energia $E^{A P M O / M P 2}$ dada pela equação

$$
E^{A P M O / M P 2}=E^{A P M O / H F}+E_{e^{-} e^{-}}^{(2)}+E_{e^{-} e^{+}}^{(2)}
$$




\subsection{Propagadores de Segunda Ordem}

As energias orbitais HF podem ser corrigidas através dos propagadores de segunda ordem generalizados para sistemas contendo $N$ elétrons e um pósitron. A formulação deste método, baseado em operadores de Green de muitos corpos, pode ser encontrada nas referências $[56,61,62]$.

A energia do $p$-ésimo orbital da espécie quântica $\alpha, \epsilon_{p}^{\alpha}$, pode ser melhorada através das correções de relaxação e correlação com a inclusão das auto-energias $\Sigma_{p p}^{\alpha}\left(\omega_{p}^{\alpha}\right)$. Com isso, as energias dos orbitais eletrônico e positrônico incluindo a correção de segunda ordem serão dadas por (3.57) e (3.58) e podem ser interpretadas como correções ao Teorema de Koopmans,

$$
\omega_{p}^{e^{-}}=\epsilon_{p}^{e^{-}}+\Sigma_{p p}^{e^{-} e^{-}(2)}\left(\omega_{p}^{e^{-}}\right)+\Sigma_{p p}^{e^{-} e^{+}(2)}\left(\omega_{p}^{e^{-}}\right)
$$

e

$$
\omega_{p}^{e^{+}}=\epsilon_{p}^{e^{+}}+\Sigma_{p p}^{e^{+} e^{-}(2)}\left(\omega_{p}^{e^{+}}\right)
$$

As expressões acima constituem aproximações de quase-partícula, uma vez que apenas os elementos de matriz diagonais das auto-energias são levados em consideração. Os termos de correção de relaxação e correlação para os casos eletrônico e positrônico são dados por

$$
\Sigma_{p p}^{e^{-} e^{-}(2)}\left(\omega_{p}^{e^{-}}\right)=\sum_{r^{e^{-}}}^{V^{e^{-}}} \sum_{a^{e^{-}}>b^{e^{-}}}^{O^{e^{-}}} \frac{\left|\left\langle p^{e^{-}} r^{e^{-}} \| a^{e^{-}} b^{e^{-}}\right\rangle\right|^{2}}{\omega_{p}^{e^{-}}+\epsilon_{r}^{e^{-}}-\epsilon_{a}^{e^{-}}-\epsilon_{b}^{e^{-}}}+\sum_{a^{e^{-}}}^{O^{e^{-}}} \sum_{r^{-}>s^{e^{-}}}^{V^{e^{-}}} \frac{\left|\left\langle p^{e^{-}} a^{e^{-}} \| r^{e^{-}} s^{e^{-}}\right\rangle\right|^{2}}{\omega_{p}^{e^{-}}+\epsilon_{a}^{e^{-}}-\epsilon_{r}^{e^{-}}-\epsilon_{s}^{e^{-}}}
$$


$\Sigma_{p p}^{e^{-} e^{+}(2)}\left(\omega_{p}^{e^{-}}\right)=\sum_{a^{e^{+}}} \sum_{r^{e^{+}}} \sum_{r^{e^{-}}}^{V^{e^{+}}} \frac{\left|\left\langle p^{e^{-}} a^{e^{+}} \mid r^{e^{-}} r^{e^{+}}\right\rangle\right|^{2}}{\omega_{p}^{e^{-}}+\epsilon_{a}^{e^{-}}-\epsilon_{r}^{e^{+}}-\epsilon_{r}^{e^{-}}}+\sum_{a^{e^{+}}}^{O^{e^{+}}} \sum_{r^{e^{+}}}^{V^{e^{+}}} \sum_{a^{e^{-}}}^{O^{e^{-}}} \frac{\left|\left\langle p^{e^{-}} r^{e^{+}} \mid a^{e^{-}} a^{e^{+}}\right\rangle\right|^{2}}{\omega_{p}^{e^{-}}+\epsilon_{r}^{e^{+}}-\epsilon_{a}^{e^{-}}-\epsilon_{a}^{e^{+}}}$

$\mathrm{e}$

$\Sigma_{p p}^{e^{+} e^{-}(2)}\left(\omega_{p}^{e^{+}}\right)=\sum_{a^{e^{-}}} \sum_{r^{e^{-}}} \sum_{r^{e^{+}}}^{V^{e^{-}}} \frac{\left|\left\langle p^{e^{+}} a^{e^{-}} \mid r^{e^{+}} r^{e^{-}}\right\rangle\right|^{2}}{\omega_{p}^{e^{+}}+\epsilon_{a}^{e^{+}}-\epsilon_{r}^{e^{-}}-\epsilon_{r}^{e^{+}}}+\sum_{a^{e^{-}}}^{O^{e^{-}}} \sum_{r^{e^{-}}}^{V^{e^{-}}} \sum_{a^{e^{+}}}^{O^{e^{+}}} \frac{\left|\left\langle p^{e^{+}} r^{e^{-}} \mid a^{e^{+}} a^{e^{-}}\right\rangle\right|^{2}}{\omega_{p}^{e^{+}}+\epsilon_{r}^{e^{-}}-\epsilon_{a}^{e^{+}}-\epsilon_{a}^{e^{-}}}$

onde $a^{e^{ \pm}}$e $b^{e^{ \pm}}$correspondem aos orbitais ocupados, $r^{e^{ \pm}}$e $s^{e^{ \pm}}$representam orbitais virtuais. As equações (3.57) e (3.58) são resolvidas iterativamente, e as energias de ionização eletrônicas e positrônicas podem ser obtidas em um único cálculo (não é necessário obter diferenças entre energias de sistemas com números de partículas diferentes). Essas energias de ionização refletem energias de ligação verticais (vertical detachment energies). Em geral, propagadores de segunda ordem fornecem melhores energias de ligação positrônicas em comparação ao método MP2 [61]. 



\section{Resultados das Simulações Clássicas}

Neste capítulo apresentaremos as simulações clássicas de Monte Carlo para o átomo de positrônio solvatado, discutiremos os resultados obtidos para as propriedades termodinâmicas e estruturais do Ps hidratado estabelecendo comparações com sistemas moleculares relevantes. Foram feitas simulações clássicas análogas para o elétron hidratado e água pura, sendo os resultados utilizados para comparações com o caso do Ps hidratado. Como ponto de partida, vamos discutir a proposta de um modelo para o campo de força desenvolvido neste trabalho para o Ps em solução e em seguida discutiremos as simulações utilizando este campo de força.

\subsection{Campo de Força do Átomo de Positrônio}

O primeiro passo para a realização de uma simulação clássica de Monte Carlo seria determinar o campo de força para a interação do soluto e o solvente. O conjunto de parâmetros $\left\{\epsilon_{i}, \sigma_{i}, q_{i}\right\}$ constitui o campo de força que representa a molécula, átomo ou partícula quântica $i$. Estamos interessados em estudar o Ps solvatado em água, e para este solvente existem diversos campos de força propostos na literatura [63, 64, 65]. Embora a descrição clássica de partículas leves como o Ps pareça inadequada, o procedimento S-QM/MM utilizando simulações MC para a descrição clássica do líquido no caso do elétron hidratado produziu excelentes resultados para o espectro de absorção do mesmo em um estudo anterior [66, 67]. Neste trabalho a descrição das moléculas de água foi feita através do campo de força SPC/E [63], enquanto os 
parâmetros da interação $e^{-}-\mathrm{O}$ foram ajustados para reproduzir dados experimentais sobre a estrutura da água em torno da partícula solvatada. Logo, como ponto de partida para a determinação do campo de força do Ps adotamos o modelo SPC/E para a descrição das moléculas de água. Para os parâmetros do Ps não há na literatura trabalhos em que alguma proposta de campo de força para solvatação tenha sido feita, havendo uma lacuna importante a ser preenchida.

Dentre os parâmetros do campo de força do soluto, a carga representando a interação coulombiana é nula para o Ps. Com isso, nosso foco esta na determinação dos parâmetros $\left\{\epsilon_{\mathrm{Ps}}, \sigma_{\mathrm{Ps}}\right\}$ que descrevem a interação Ps-água através do potencial Lennard-Jones utilizado nas simulações. A construção do campo de força é realizada através da análise da interação soluto-oxigênio, como sugere o próprio campo de força SPC/E utilizado para a água (a interação do soluto com os átomos de hidrogênio se faz exclusivamente pelo termo de Coulomb). Portanto, é necessário determinar os parâmetros da interação do átomo de positrônio com o oxigênio. O potencial de interação intermolecular discutido na seção (2.3), está implementado no código DICE da seguinte forma

$$
U\left(r_{i j}\right)=\sum_{i} \sum_{j>i}\left[\frac{q_{i} q_{j}}{r_{i j}}+4 \epsilon_{i j}\left(\left(\frac{\sigma_{i j}}{r_{i j}}\right)^{12}-\left(\frac{\sigma_{i j}}{r_{i j}}\right)^{6}\right)\right]
$$

onde $q_{i}$ e $q_{j}$ são as cargas dos sítios atômicos $i$ e $j, r_{i j}=\left|\mathbf{r}_{j}-\mathbf{r}_{i}\right|, \epsilon_{i j}=\sqrt{\epsilon_{i} \epsilon_{j}}$ e $\sigma_{i j}=\sqrt{\sigma_{i} \sigma_{j}}$. Reescrevendo apenas a contribuição do potencial Lennard-Jones (LJ) para a interação,

$$
U_{\mathrm{LJ}}\left(r_{i j}\right)=\frac{C_{12}}{r_{i j}^{12}}-\frac{C_{6}}{r_{i j}^{6}}
$$

onde o termo $C_{6}$ representa o coeficiente de dipersão da interação de van der Waals entre o Ps e o oxigênio. A contribuição atrativa de longo alcance deste potencial é 
representada pelo termo $\left(-C_{6} / r_{i j}^{6}\right)$, enquanto a contribuição repulsiva para distâncias pequenas seria representada por $\left(C_{12} / r_{i j}^{12}\right)$. Vale destacar que o termo repulsivo, no caso dos elétrons, incorpora o efeito do Princípio de Pauli (que efetivamente exclui o elétron solvatado das regiões de alta densidade eletrônica), enquanto no caso dos pósitrons a repulsão resulta da interação com os núcleos. O potencial da equação (4.2) e os comportamentos repulsivo e atrativo mencionados estão ilustrados na figura (4.1).

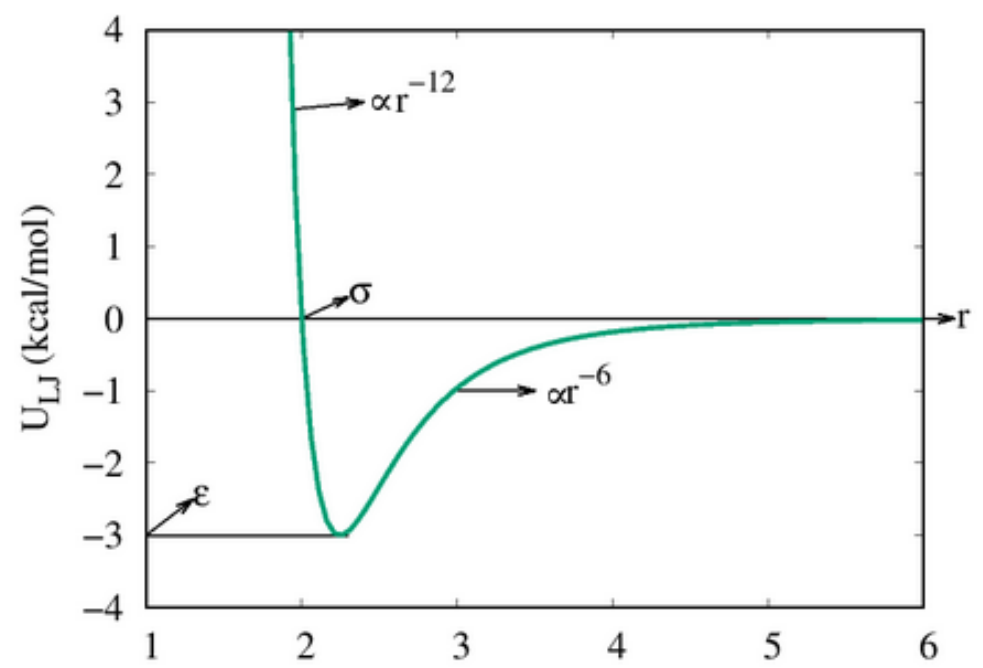

Figura 4.1: Gráfico do potencial LJ mostrando os comportamentos repulsivo e atrativo do potencial, e os parâmetros $\epsilon$ e $\sigma$.

O coeficiente $C_{6}$ possui expressão conhecida em termos das forças de oscilador e energias de excitação dos pares de átomos [68], podendo ainda ser determinado pela Fórmula de London [69]. Com esta fórmula o coeficiente de dispersão é dado por uma expressão simplificada em termos das polarizabilidades e potenciais de ionização, a qual fornece bons resultados para a interação entre o Ps e átomos de polarizabilidade relativamente baixa [70]. Existem na literatura cálculos precisos para o coeficiente de dispersão $C_{6}$ referente à interação Ps-átomo [70, 71], assim como modelos para a determinação dos mesmos [72]. Segundo o modelo de Tkatchenko e Scheffler [72], o 
coeficiente $C_{6}$ pode ser obtido em termos das propriedades atômicas individuais pela fórmula

$$
C_{6}^{A B}=\frac{2 C_{6}^{A A} C_{6}^{B B}}{\frac{\alpha_{B}}{\alpha_{A}} C_{6}^{A A}+\frac{\alpha_{A}}{\alpha_{B}} C_{6}^{B B}}
$$

em que o índice $A B$ denota a interação entre as espécies $A$ e $B, \alpha_{A}$ e $\alpha_{B}$ são as polarizabilidades estáticas dos átomos $A$ e $B$ respectivamente. As quantidades de interesse para o uso do modelo de Tkatchenko e Scheffler são bem conhecidas, sendo que para o Ps em vácuo temos $C_{6}^{\mathrm{PsPs}}=207.97$ Hartree.$a_{0}^{6}[70,71]$ e $\alpha_{\mathrm{Ps}}=36 a_{0}^{3}[70]$. Para o oxigênio, $\alpha_{\mathrm{O}}=5.41 a_{0}^{3}[73]$ e $C_{6}^{\mathrm{OO}}=12.6$ Hartree.$a_{0}^{6}$ foi obtido da interação entre os oxigênios em um dímero da água [72]. Usando os valores mencionados na fórmula de Tkatchenko e Scheffler, obtemos o seguinte valor para o coeficiente de dispersão

$$
C_{6}^{\mathrm{PsO}}=\epsilon \sigma^{6}=45.5 \text { Hartree } . a_{0}^{6}
$$

Com a conclusão sobre o coeficiente de dispersão, resta apenas determinarmos o comportamento repulsivo da interação entre o Ps e o oxigênio representada no potencial $U_{\mathrm{LJ}}$ pelo termo $C_{12} / r_{i j}^{12}$. O modelo fenomenológico de Eldrup para a aniquilação do Ps em polímeros, indica que o termo repulsivo da interação do Ps com um átomo tem grande contribuição da interação eletrônica em decorrência do Princípio de Exclusão de Pauli [74]. Logo, podemos assumir que o termo $C_{12} / r_{i j}^{12}$ é dado pela interação entre o elétron do Ps e o oxigênio. Essa interação foi ajustada anteriormente para a construção do campo de força do elétron hidratado por Ludwig e colaboradores [66, 67]. A carga do elétron seria $q_{e^{-}}=-1$, enquanto os parâmetros LJ foram determinados com base nos resultados experimentais de ressonância magnética nuclear ENDOR (Electron Nuclear Double Ressonance) [75]. Neste experimento, Kevan e colaboradores 
determinaram o raio e o número de moléculas de água compondo a cavidade na qual o elétron hidratado estaria presente. Logo, os parâmetros $\epsilon$ e $\sigma$ do potencial foram ajustados para reproduzir a estrutura do elétron solvatado obtida experimentalmente. O campo de força determinado para o elétron hidratado é composto pela carga $q_{e^{-}}=-1$, $\epsilon_{e-}=0.08 \mathrm{kcal} / \mathrm{mol}$ e $\sigma_{e-}=4.04 \AA$. Vale ressaltar que o campo de força da água utilizado para o elétron também foi o SPC/E. A interação repulsiva do potencial LJ obtida com esses parâmetros e com os do campo de força SPC/E fornece,

$$
C_{12}^{\mathrm{PsO}}=\epsilon \sigma^{12}=1.61 \times 10^{6} \text { Hartree } . a_{0}^{12} .
$$

Portanto, uma vez determinados os comportamentos atrativo e repulsivo fornecidos pelas equações (4.4) e (4.5) podemos construir um campo de força para o átomo de positrônio respeitando ambos os comportamentos. Tomando a razão dos valores dos coeficientes obtidos em (4.4) e (4.5), encontramos os parâmetros

$$
\epsilon_{\mathrm{Ps}}=0.016 \mathrm{kcal} / \mathrm{mol} \quad \sigma_{\mathrm{Ps}}=4.61 \AA
$$

que seriam nossa principal proposta de parâmetros para representar o Ps nas simulações clássicas a qual chamaremos de modelo I. O gráfico do potencial de interação do Ps com a água obtido com o campo de força proposto é apresentado na figura (4.2).

Para a obtenção desses parâmetros utilizamos o coeficiente $C_{6}^{\mathrm{OO}}=12.6$ Hartree.$a_{0}^{6}$, mas o modelo de Tkatchenko e Scheffler fornece valores máximo e mínimo para $C_{6}^{\text {OO }}$ dados por 14.7 e 11.7 (em unidades atômicas) respectivamente [72]. Deste modo, podemos obter parâmetros $\epsilon_{\mathrm{Ps}}$ e $\sigma_{\mathrm{Ps}}$ alternativos aos obtidos inicialmente. Utilizando o valor $C_{6}^{\mathrm{OO}}=14.7$ Hartree. $a_{0}^{6}$, encontramos $\epsilon_{\mathrm{Ps}}=0.019 \mathrm{kcal} / \mathrm{mol}$ e $\sigma_{\mathrm{Ps}}=4.55 \AA$ definindo assim o modelo II. Os últimos valores de $\epsilon_{\mathrm{Ps}}$ e $\sigma_{\mathrm{Ps}}$ obtidos nesta seção, foram usados como uma segunda opção em relação as escolhas de parâmetros do modelo I 


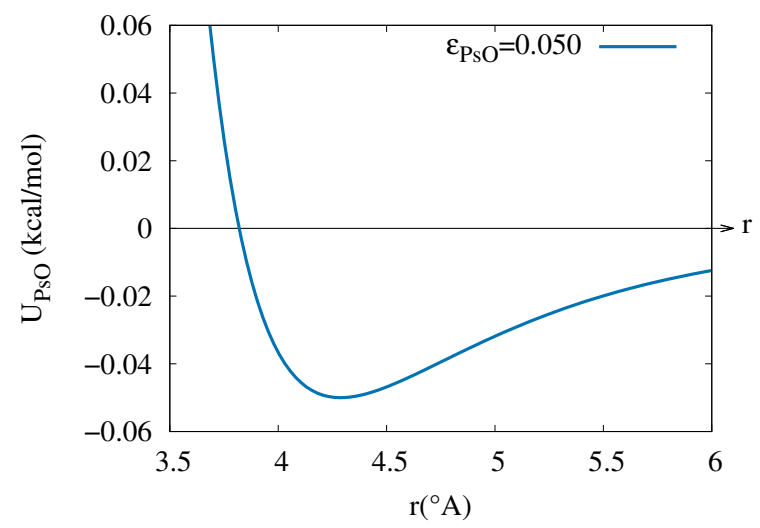

Figura 4.2: Gráfico do potencial LJ representando a interação do Ps com a água usando o modelo I, os parâmetros do campo de força são $\epsilon_{\mathrm{PsO}}=0.050 \mathrm{kcal} / \mathrm{mol} \mathrm{e}$ $\sigma_{\mathrm{PsO}}=3.82 \AA$.

$\left(\epsilon_{\mathrm{Ps}}=0.016\right.$ e $\left.\sigma_{\mathrm{Ps}}=4.61\right)$. Na figura (4.3) apresentamos os potenciais de interação do Ps com a água para os dois modelos propostos de campo de força do Ps.

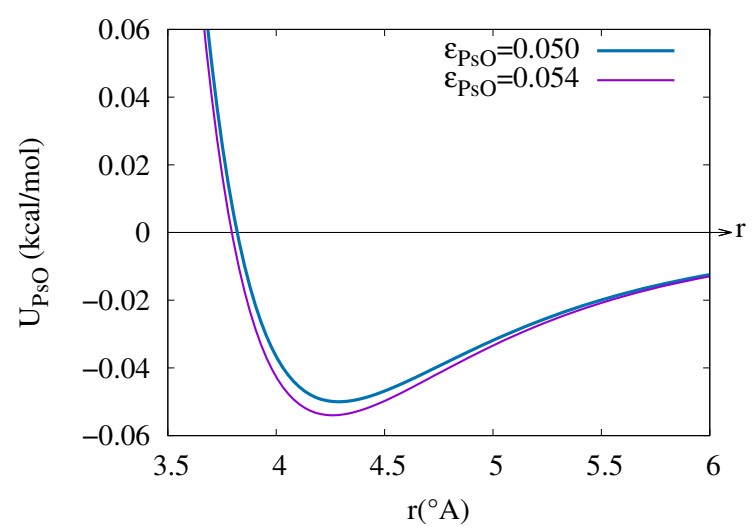

Figura 4.3: Gráfico dos potenciais LJ representando a interação do Ps com a água para as duas propostas de modelo do campo de força do Ps.

\subsection{Simulações de Monte Carlo}

Após a definição do campo de força para a interação do soluto e do solvente, iniciamos a simulação de Monte Carlo no ensemble NPT usando o código DICE [38]. A caixa de simulação tem formato cúbico com 500 moléculas de água e o átomo de 
positrônio, pressão igual a 1.0 atm e temperatura de 293.15 K. O comprimento inicial das arestas da caixa de simulação foi de $24.55 \AA$ A. Utilizamos o modelo I para os parâmetros LJ da interação $\mathrm{Ps}_{\mathrm{s}} \mathrm{H}_{2} \mathrm{O}$, conforme descrito na seção (4.1), que consiste em $\epsilon_{\mathrm{Ps}}=0.016 \mathrm{kcal} / \mathrm{mol}$ e $\sigma_{\mathrm{Ps}}=4.61 \AA$. Foram realizados 80000 e 200000 ciclos MC respectivamente, nas etapas de termalização e produção. É importante esclarecer a diferença entre ciclos MC e passos MC, consideramos que um ciclo MC corresponde a um total de passos MC igual ao número de moléculas da caixa de simulação. Portanto, 80000 e 200000 ciclos MC correspondem a $4 \times 10^{7}$ e $10^{8}$ passos MC respectivamente.

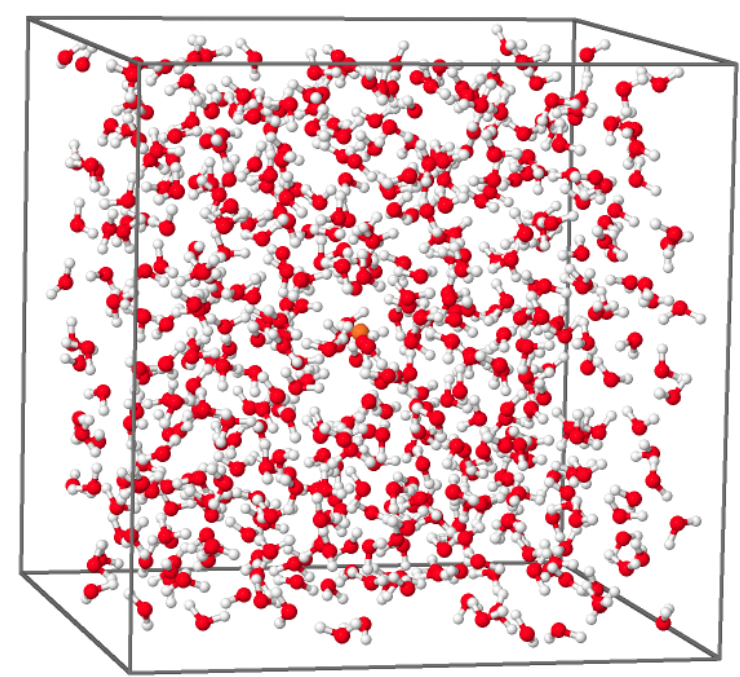

Figura 4.4: Caixa de simulação usada nas simulações clássicas, no centro da caixa temos o átomo de positrônio representado em verde.

Após 80000 ciclos MC observamos a variação do valor da entalpia configuracional por molécula flutua em torno de um valor médio, indicando que o sistema atingiu o equilíbrio. Observamos também, que a densidade média obtida está de acordo com o valor experimental da densidade da água conforme esperado. A entalpia configuracional por molécula média encontrada foi de $\left\langle H_{c} / N\right\rangle=-11.45 \pm 0.08 \mathrm{kcal} / \mathrm{mol}$, e a densidade média $\langle\rho\rangle=1.02 \pm 0.01 \mathrm{~g} / \mathrm{cm}^{3}$.

Em seguida, determinamos o intervalo de ciclos $\mathrm{MC}$ a partir do qual obtemos con- 
(A)

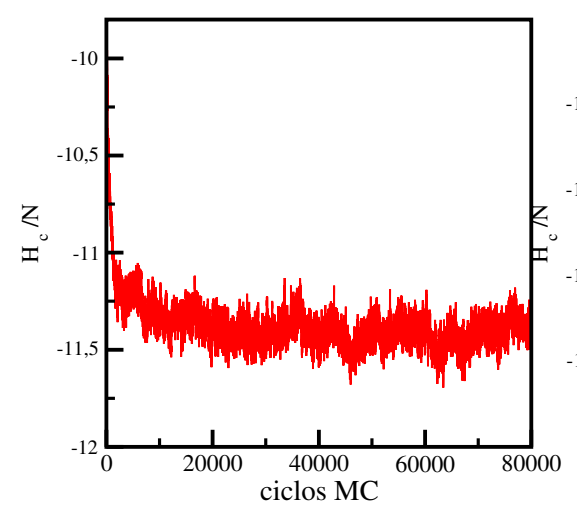

(B)

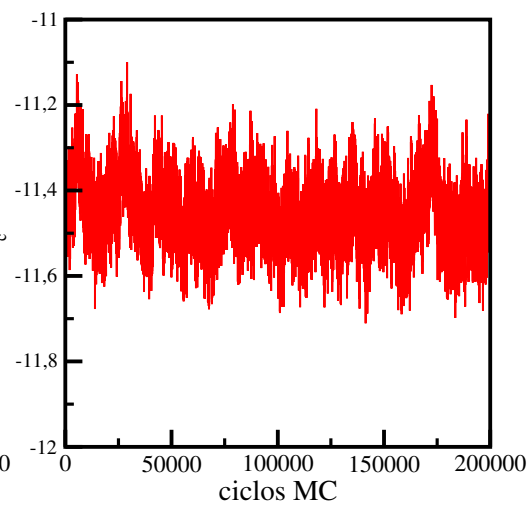

Figura 4.5: Entalpia configuracional por molécula na etapa de termalização no gráfico A, e na etapa de produção no gráfico $\mathrm{B}$, em ambos os gráficos os valores da entalpia estão em $\mathrm{kcal} / \mathrm{mol}$.

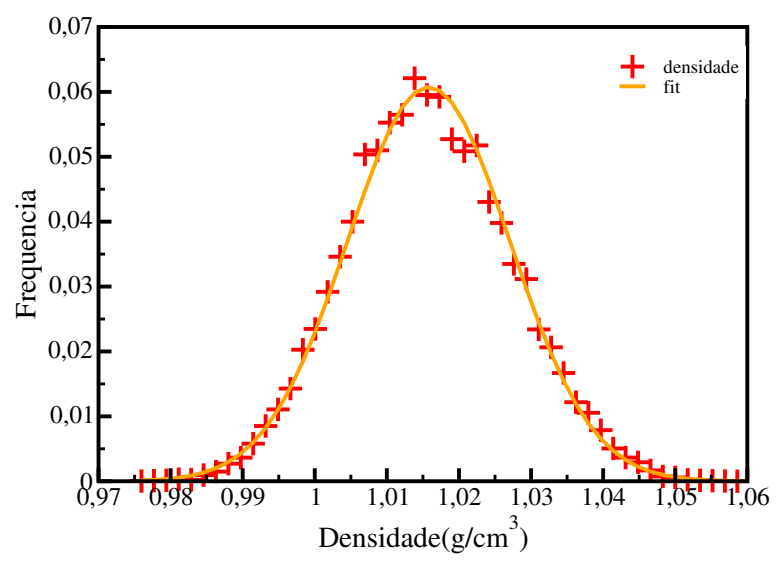

Figura 4.6: Histograma dos valores da densidade do líquido amostrados durante a simulação.

figurações estatisticamente descorrelacionadas. Foram geradas 200000 configurações durante a simulação na etapa de produção, e apenas 2000 configurações foram salvas. O tempo de correlação e a ineficiência estatística foram calculados através do ajuste descrito na seção (2.7), usamos 3\% dos dados da simulação que equivalem a 6000 ciclos MC no ajuste. A ineficiência estatística calculada foi de aproximadamente 2583 ciclos, com isso podemos estabelecer que configurações separadas por 2500 ciclos estão descorrelacionadas. Logo, em uma simulação com 200000 ciclos temos 80 
configurações estatisticamente descorrelacionadas. Na figura (4.7) apresentamos o resultado do ajuste da função de autocorrelação.

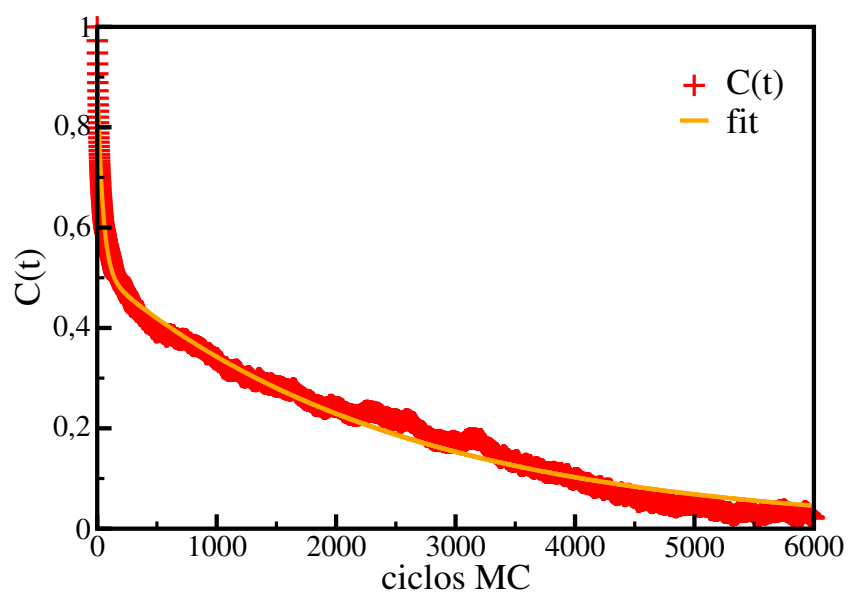

Figura 4.7: Ajuste da função de autocorrelação estatística $C(t)$.

\subsection{Análise da Estrutura do Líquido}

A análise da estrutura do líquido gerada na simulação foi realizada com o auxílio da função de distribuição radial de pares (RDF), discutida na seção (2.4). Apresentamos a RDF entre o Ps e os oxigênios das moléculas de água na figura (4.8), que permite determinar a primeira camada de solvatação. Podemos observar um pico em $3.75 \AA$ e um mínimo local em $5.45 \AA$ os quais definem a primeira camada de solvatação. A integração da RDF até $5.45 \AA$ indica que em média 22 moléculas de água formam a primeira camada de solvatação. Em seguida, fizemos uma comparação entre as estruturas do Ps e do elétron hidratados. Para isso realizamos uma simulação MC do elétron solvatado usando o campo de força mencionado na seção (4.1), com 80000 e 40000 ciclos MC nas etapas de termalização e produção respectivamente. Na figura (4.8) também apresentamos a RDF entre o elétron e os oxigênios das moléculas de água. 


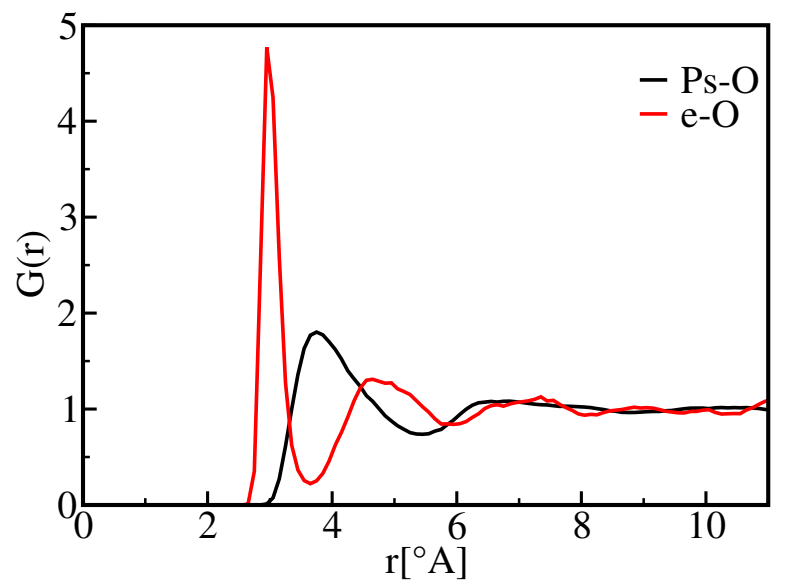

Figura 4.8: Comparação entre as RDF Ps-O e elétron-O.

A RDF entre o elétron e os oxigênios das moléculas de água apresenta um pico em $2.95 \AA$ e um mínimo local em $3.65 \AA$, definindo a primeira camada de solvatação do elétron hidratado. A primeira camada de solvatação do elétron é composta em média por 7 moléculas de água. A comparação feita na figura (4.8) evidencia a grande contribuição coulombiana para a formação da estrutura do líquido, e também para a orientação das moléculas de água em torno do soluto. É interessante observar a sobreposição da primeira camada de solvatação de cada uma das configurações descorrelacionadas para os casos do Ps e do elétron hidratados. As sobreposições representadas na figura (4.9) mostram que para o caso do elétron hidratado os hidrogênios apontam para o centro da cavidade ocupada pelo elétron, enquanto para o Ps a sobreposição não indica uma tendência em relação à orientação dos hidrogênios ou oxigênios.

Portanto, podemos concluir que o Ps hidratado ocupa uma cavidade significativamente maior que a do elétron solvatado com moléculas de água distribuídas nessa cavidade sem uma orientação predominante em relação ao soluto.

Outra comparação interessante em relação a estrutura do Ps em solução seria com o caso da água pura. Para isso realizamos uma simulação análoga a do Ps hidratado para a água pura, ou seja, uma molécula de água na presença de outras 500 águas. 
(A)

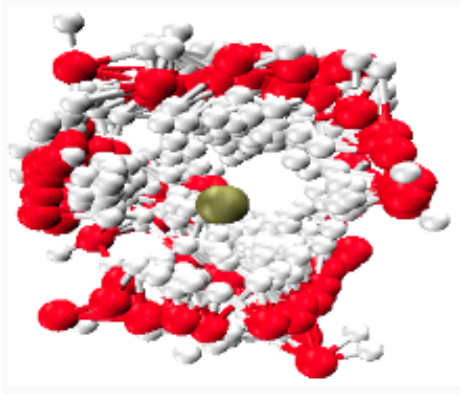

(B)

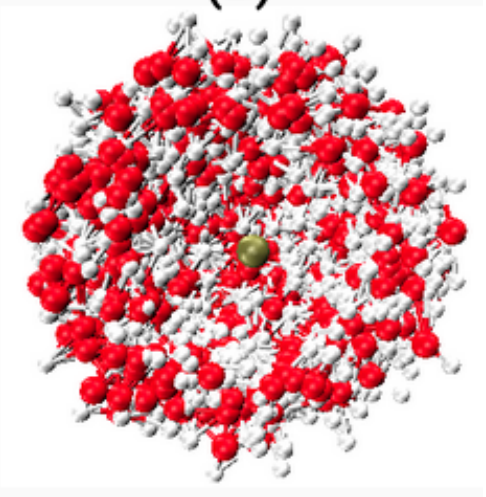

Figura 4.9: Sobreposição da primeira camada de solvatação das configurações descorrelacionadas do elétron (A) e do Ps (B) hidratados, em ambos os casos o soluto está representado por um ponto no centro da cavidade.

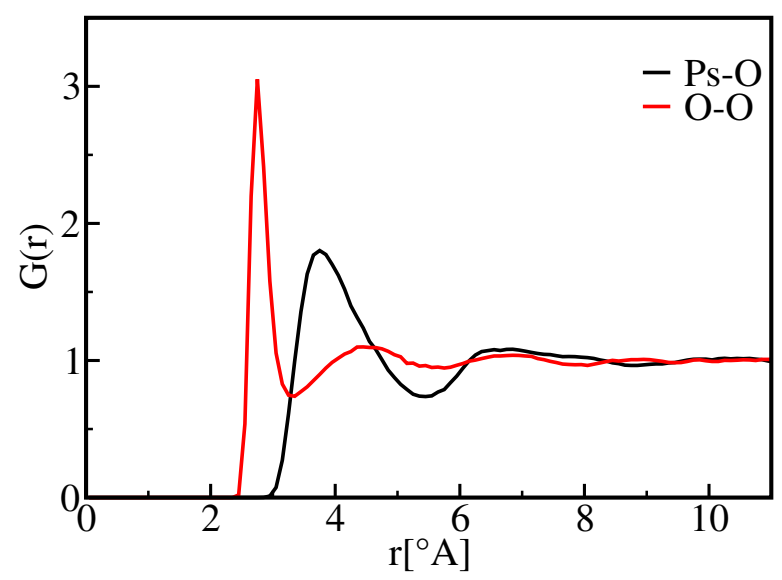

Figura 4.10: Comparação entre as RDF Ps-O e O-O da água-água.

A RDF entre os oxigênios das moléculas de água para a simulação da água pura, é apresentada na figura (4.10). Observamos um mínimo local em 3.35 Åcom a primeira camada de solvatação composta por cinco moléculas de água conforme é reportado experimentalmente para a estrutura da água [76]. Podemos concluir que a solvatação do Ps em água altera significativamente a estrutura do líquido, de modo que o Ps possa ocupar uma cavidade relativamente grande no interior do líquido. Por outro lado, a estrutura do Ps hidratado obtida apresenta um comportamento distante daquele 
reportado no chamado modelo bolha (bubble model) no qual o Ps habita uma cavidade com raio entre $3.2 \AA$ e $3.55 \AA$ na água [21]. Essa diferença pode ser atribuída ao fato desses modelos tratarem de forma bastante idealizada e simples a interação do Ps com a água.

\subsection{Comparação dos Resultados com Campos de Força Distintos}

As propriedades termodinâmicas de equilíbrio obtidas até agora resultaram de simulações utilizando os parâmetros do modelo $\mathbf{I}$, determinados utilizando valores do coeficiente $C_{6}^{\mathrm{OO}}$ mais representativos para a interação O-O em dímeros da água conforme discutido na seção (4.1). No modelo de Tkatchenko e Scheffler os valores mínimo e máximo propostos para o coeficiente são 11.7 e 14.7 (em unidades atômicas), e a maior variação possível dos parâmetros $\epsilon_{\mathrm{Ps}}$ e $\sigma_{\mathrm{Ps}}$ é obtida com o $C_{6}^{\mathrm{OO}}=14.7$ usado para determinarmos o modelo II. Utilizando $C_{6}^{\mathrm{OO}}=11.7$, encontramos uma variação desprezível sobre os parâmetros $\epsilon_{\mathrm{Ps}}$ e $\sigma_{\mathrm{Ps}}$. Portanto, avaliamos a estabilidade dos resultados clássicos frente a uma variação dos parâmetros do campo de força obtida usando o modelo II que consiste em $\epsilon_{\mathrm{Ps}}=0.019 \mathrm{kcal} / \mathrm{mol}$ e $\sigma_{\mathrm{Ps}}=4.55 \AA$. Foram realizados novamente 80000 e 200000 ciclos MC respectivamente, nas etapas de termalização e produção. O comprimento inicial da caixa de simulação foi de 24.47 A. Após 80000 ciclos MC observamos a variação do o valor da entalpia configuracional por molécula flutua em torno de um valor médio, indicando que o sistema atingiu o equilíbrio como anteriormente. A entalpia configuracional média por molécula encontrada foi de $\left\langle H_{c} / N\right\rangle=-11.48 \pm 0.08 \mathrm{kcal} / \mathrm{mol}$. A densidade média obtida também está de acordo com o valor experimental da densidade da água, e foi de $\langle\rho\rangle=1.02 \pm 0.01 \mathrm{~g} / \mathrm{cm}^{3}$. Nas figuras (4.11) e (4.12) são apresentados o gráfico da entalpia configuracional por molécula e o histograma da densidade respectivamente. 
(A)

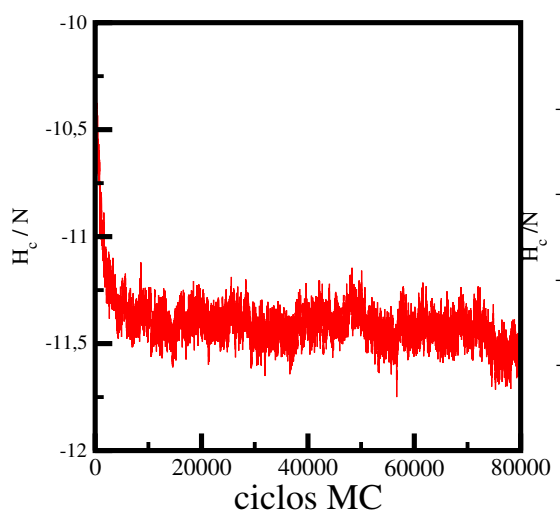

(B)

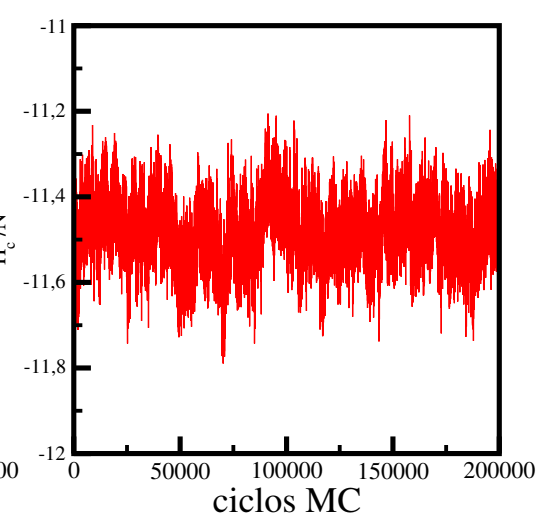

Figura 4.11: Entalpia configuracional por molécula nas etapas de termalização (A) e produção (B) obtida com os parâmetros do modelo II, em ambos os gráficos os valores da entalpia estão em $\mathrm{kcal} / \mathrm{mol}$.
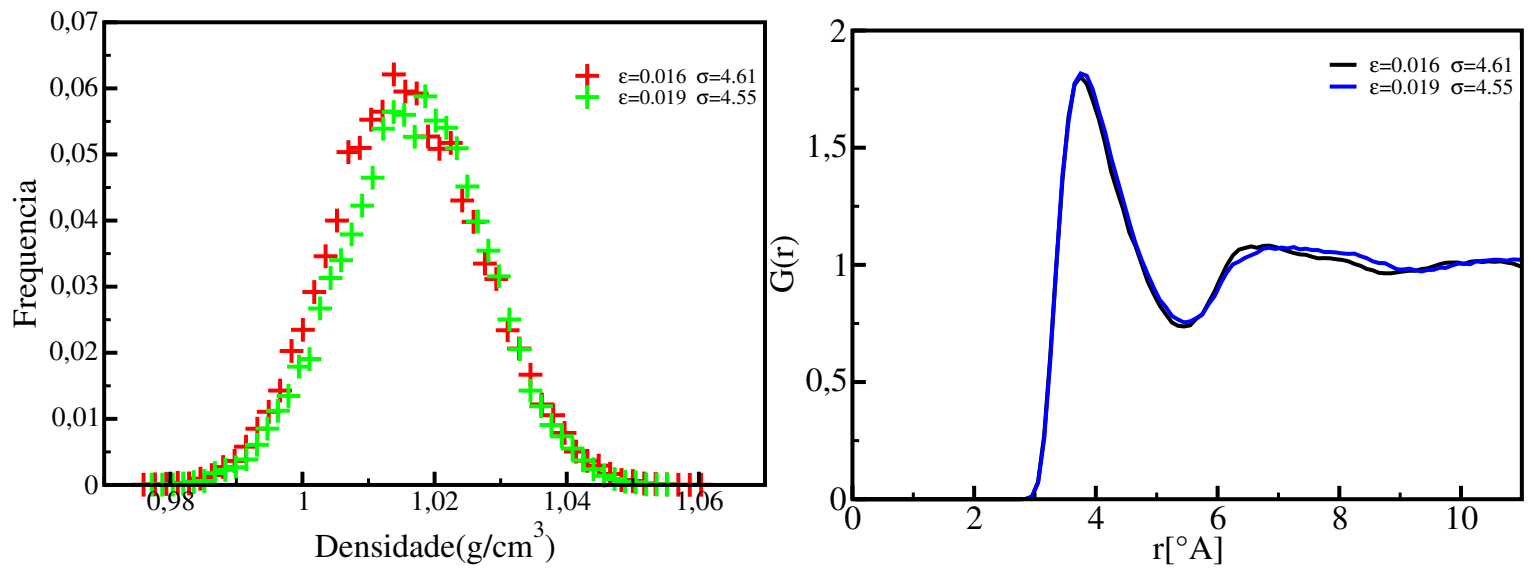

Figura 4.12: Comparação entre os histogramas da densidade e das RDF Ps-O, ambos obtidos com os parâmetros dos modelos I e II.

Em relação a estrutura do líquido, observamos através da comparação das RDF para o Ps-O que o mínimo da primeira camada permanece em $5.45 \AA$ sendo a mesma formada por 22 moléculas de água em ambos os casos. Na tabela (4.1) apresentamos as propriedades termodinâmicas de equilíbrio, número de moléculas da primeira camada e raio da cavidade ocupada pelo Ps obtidos com os parâmetros dos modelos I e II. 


\begin{tabular}{|c|c|c|}
\hline Modelos: & I & II \\
\hline$\left\langle H_{c} / N\right\rangle$ & $-11.45 \pm 0.08 \mathrm{kcal} / \mathrm{mol}$ & $-11.48 \pm 0.08 \mathrm{kcal} / \mathrm{mol}$ \\
\hline$\langle\rho\rangle$ & $1.02 \pm 0.01 \mathrm{~g} / \mathrm{cm}^{3}$ & $1.02 \pm 0.01 \mathrm{~g} / \mathrm{cm}^{3}$ \\
\hline $\mathrm{N}^{\circ}$ de moléculas & 22 & 22 \\
\hline Raio da cavidade & $5.45 \AA$ & $5.45 \AA$ \\
\hline
\end{tabular}

Tabela 4.1: Comparação dos resultados clássicos obtidos com os modelos I e II.

Portanto, podemos concluir que o aumento do parâmetro $\epsilon_{\mathrm{Ps}}$ em $19 \%$ no modelo II em relação ao I não alterou significativamente as propriedades termodinâmicas de equilíbrio do Ps solvatado. Dada a estabilidade encontrada nas propriedades, variações inferiores a essa do modelo II não foram testadas.

\subsection{Energia Livre de Solvatação}

A abordagem clássica do Ps hidratado através de simulações MC permite que outra grandeza importante e acessível experimentalmente para sistemas moleculares [77] seja calculada, a energia livre de solvatação $\left(\Delta G_{\text {sol }}\right)$. Essa energia é igual ao valor da variação da energia livre de Gibbs envolvida no processo de solvatação do átomo de positrônio. O caráter hidrofóbico de um soluto apolar como o Ps pode ser analisado a partir dessa grandeza, a qual deve ser positiva indicando que o soluto é hidrofóbico. O cálculo da energia livre de solvatação foi feito a partir do inverso da variação envolvida no processo de aniquilação do soluto $\left(\Delta G_{\text {ani }}\right)$, determinada com a teoria da pertubação termodinâmica usando a técnica double-wide discutida na seção (2.5) e implementada no código DICE.

É importante ressaltar que estamos tratando de um soluto neutro, e com isso a energia livre de solvatação diz respeito às contribuições não-eletrostáticas. Essas contribuições por sua vez são constituídas por um termo de cavitação $\left(\Delta G_{\text {cav }}\right)$, referente à formação da cavidade ocupada pelo Ps e à parte repulsiva do potencial intermolecular, e um termo associado às forças de van der Waals $\left(\Delta G_{\mathrm{vdw}}\right)$ entre o soluto e o solvente 
relacionado à parte atrativa do potencial. A formação da cavidade no interior do solvente envolve a quebra de ligações entre as moléculas do mesmo, logo esse processo em geral é desfavorável para o sistema $\left(\Delta G_{\text {cav }}>0\right)$. Por outro lado, uma vez formada a cavidade, o soluto e o solvente estabelecerão interações coesivas através das forças de van der Waals sendo este um processo favorável para o sistema $\left(\Delta G_{\mathrm{vdw}}<0\right)$.

As simulações necessárias para o estudo dessa propriedade são tipicamente maiores, tendo em vista a dificuldade na convergência dessa grandeza. Cada simulação foi feita com 100000 ciclos MC na etapa de termalização, e 600000 ciclos MC na etapa de produção onde calculamos de fato a energia livre de solvatação. Como a interação entre o Ps e a água é dada apenas pelo potencial LJ, usando a técnica double-wide o procedimento consiste em calcular primeiramente a variação da energia livre pertubando o parâmetro $\epsilon_{\mathrm{Ps}}$ do soluto conforme a equação

$$
\Delta G_{\epsilon}=\Delta G_{100 \% \epsilon \rightarrow 75 \% \epsilon}+\Delta G_{75 \% \epsilon \rightarrow 50 \% \epsilon}+\Delta G_{50 \% \epsilon \rightarrow 25 \% \epsilon}+\Delta G_{25 \% \epsilon \rightarrow 1 \% \epsilon} .
$$

Em uma única simulação podemos realizar duas pertubações a partir de um valor de referência do parâmetro que está sendo pertubado, ou seja, a partir da condição na qual o $\epsilon_{\mathrm{Ps}}$ vale $75 \%$ do seu valor original fazemos uma pertubação para $100 \%$ e outra para 50\% em uma única simulação. E com isso, obtemos os dois primeiros termos da equação (4.7). Portanto, para obtermos a variação da energia livre correspondente a (4.7) são necessárias apenas duas simulações MC. Na tabela (4.2) estão os resultados de cada parcela da equação (4.7), com os quais obtemos o $\Delta G_{\epsilon}$.

As pertubações sobre $\epsilon_{\mathrm{Ps}}$ representam justamente a redução das interações de van der Waals entre o Ps e a água, contribuindo diretamente para $\Delta G_{\mathrm{vdw}}$. Assim, esperamos que o processo inverso ao de redução do parâmetro $\epsilon_{\mathrm{Ps}}$ seja favorável ao sistema resultando em $\Delta G_{\mathrm{vdw}}<0$. Porém, os resultados da tabela (4.2) não exibem esse 


\begin{tabular}{|c|c|c|}
\hline Pertubação do $\epsilon_{\mathrm{Ps}}$ & $\epsilon_{\text {pertubado }}(\mathrm{kcal} / \mathrm{mol})$ & $\Delta G_{\epsilon}(\mathrm{kcal} / \mathrm{mol})$ \\
\hline $100 \% \epsilon \rightarrow 75 \% \epsilon$ & $0.016 \rightarrow 0.012$ & $-0.03 \pm 0.00$ \\
\hline $75 \% \epsilon \rightarrow 50 \% \epsilon$ & $0.012 \rightarrow 0.008$ & $-0.07 \pm 0.01$ \\
\hline $50 \% \epsilon \rightarrow 25 \% \epsilon$ & $0.008 \rightarrow 0.004$ & $-0.17 \pm 0.02$ \\
\hline $25 \% \epsilon \rightarrow 1 \% \epsilon$ & $0.004 \rightarrow 0.00016$ & $-1.23 \pm 0.06$ \\
\hline aniquilação: & $\sum \Delta G_{\epsilon}$ & $-1.50 \pm 0.09 \mathrm{kcal} / \mathrm{mol}$ \\
\hline solvatação: & $-\sum \Delta G_{\epsilon}$ & $1.50 \pm 0.09 \mathrm{kcal} / \mathrm{mol}$ \\
\hline
\end{tabular}

Tabela 4.2: Contribuições para o $\Delta G_{\epsilon}$ obtidas para cada pertubação feita sobre o parâmetro $\epsilon$.

comportamento. Isso é entendido analisando a forma do potencial LJ da interação Ps$\mathrm{H}_{2} \mathrm{O}$, que apresenta um poço atrativo raso devido ao fato de $\epsilon_{\mathrm{Ps}}$ ser pequeno. Logo, as pertubações sobre $\epsilon_{\mathrm{Ps}}$ afetam fortemente a parte repulsiva do potencial conforme vemos na figura (4.14).

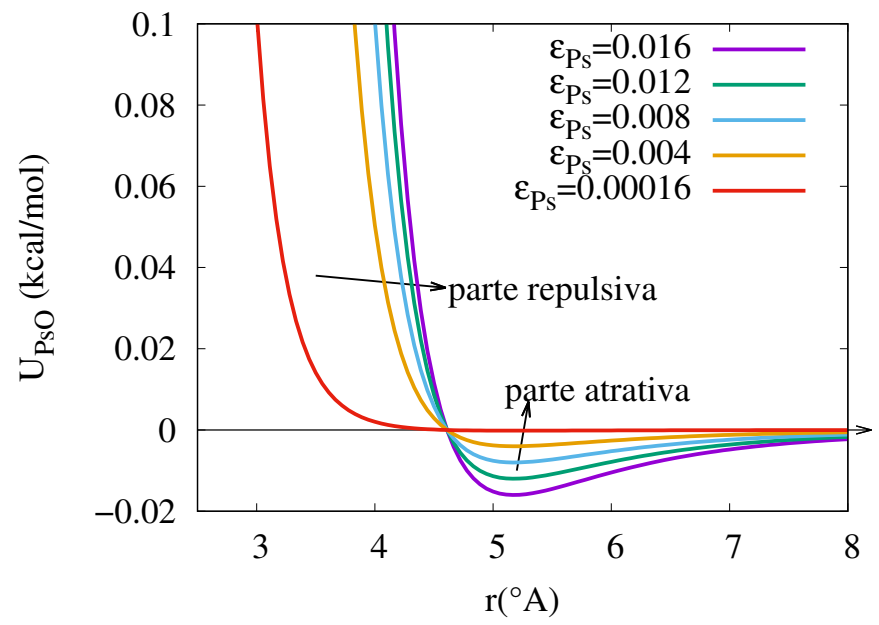

Figura 4.13: Gráfico das pertubações sobre o parâmetro $\epsilon_{\mathrm{Ps}}$ do potencial de interação $\mathrm{Ps}_{\mathrm{S}} \mathrm{H}_{2} \mathrm{O}$. A parte repulsiva do potencial é afetada de maneira significativa.

Portanto, como a parte repulsiva também está sendo afetada a contribuição líquida com as perturbações no parâmetro $\epsilon_{\mathrm{Ps}}$ são negativas representando também parte da contribuição de cavitação.

Em seguida, realizamos as simulações referentes à pertubação do parâmetro $\sigma_{\mathrm{Ps}}$ partindo da situação final da última simulação realizada, ou seja, com o parâmetro $\epsilon_{\mathrm{Ps}}$ 
igual a $1 \%$ de seu valor original. Pertubamos o parâmetro $\sigma_{\mathrm{Ps}}$ sucessivamente até seu valor ser nulo, representando o desaparecimento do Ps da água conforme a equação

$\Delta G_{\sigma}=\Delta G_{100 \% \sigma \rightarrow 75 \% \sigma}+\Delta G_{75 \% \sigma \rightarrow 50 \% \sigma}+\Delta G_{50 \% \sigma \rightarrow 25 \% \sigma}+\Delta G_{25 \% \sigma \rightarrow 5 \% \sigma}+\Delta G_{5 \% \sigma \rightarrow 0 \% \sigma}$.

Na tabela (4.3) estão os resultados de cada contribuição da equação (4.8), com as quais encontramos $\Delta G_{\sigma}$.

\begin{tabular}{|c|c|c|}
\hline Pertubação do $\sigma_{\mathrm{Ps}}$ & $\sigma_{\text {pertubado }}(\AA)$ & $\Delta G_{\sigma}(\mathrm{kcal} / \mathrm{mol})$ \\
\hline $100 \% \sigma \rightarrow 75 \% \sigma$ & $4.61 \rightarrow 3.4575$ & $-1.94 \pm 0.00$ \\
\hline $75 \% \sigma \rightarrow 50 \% \sigma$ & $3.4575 \rightarrow 2.305$ & $-1.16 \pm 0.09$ \\
\hline $50 \% \sigma \rightarrow 25 \% \sigma$ & $2.305 \rightarrow 1.1525$ & $-0.76 \pm 0.06$ \\
\hline $25 \% \sigma \rightarrow 5 \% \sigma$ & $1.1525 \rightarrow 0.2305$ & $-0.22 \pm 0.02$ \\
\hline $5 \% \sigma \rightarrow 0 \% \sigma$ & $0.2305 \rightarrow 0$ & $-0.01 \pm 0.00$ \\
\hline aniquilação: & $\sum \Delta G_{\sigma}$ & $-4.09 \pm 0.17$ \\
\hline solvatação: & $-\sum \Delta G_{\sigma}$ & $4.09 \pm 0.17$ \\
\hline
\end{tabular}

Tabela 4.3: Contribuições para o $\Delta G_{\sigma}$ obtidas para cada pertubação feita sobre o parâmetro $\sigma_{\mathrm{Ps}}$.

Os resultados da tabela (4.3) seguem o esperado do ponto de vista físico, ou seja, a diminuição do $\sigma_{\mathrm{Ps}}$ reduz a contribuição repulsiva do potencial LJ permitindo que as moléculas de água ocupem gradativamente a cavidade ocupada pelo Ps. O processo inverso referente à solvatação envolveria a quebra de ligações coesivas entre as moléculas de água, devendo resultar em uma contribuição positiva para $\Delta G_{\text {sol }}$ sendo portanto desfavorável para o sistema.

Com os resultados anteriores podemos obter a energia livre de solvatação do Ps como sendo igual ao inverso da variação da energia livre envolvida na aniquilação do Ps da água conforme a equação

$$
\Delta G_{\text {sol }}=-\Delta G_{\text {ani }}=-\sum \Delta G_{\epsilon}-\sum \Delta G_{\sigma}=5.59 \pm 0.26 \mathrm{kcal} / \mathrm{mol} .
$$


O fato da energia livre de solvatação do Ps ser positiva indica que a solvatação deste átomo não é um processo espontâneo. Esse comportamento era esperado, tendo em vista o fato do Ps ser neutro. A interpretação deste resultado é feita através de comparações com sistemas próximos do Ps, como os citados a seguir. O elétron hidratado possui energia livre de solvatação estimada igual à $-36.3 \mathrm{kcal} / \mathrm{mol}$ [78, 79], para a molécula de água essa energia seria de -6.01 kcal/mol [80] enquanto para gases nobres como o neônio e xenônio temos 2.48 e $1.45 \mathrm{kcal} / \mathrm{mol}$ respectivamente [81]. Esses resultados permitem concluir que a energia livre de solvatação do Ps é semelhante ao caso do neônio, e ao mesmo tempo seria oposta à energia livre da molécula de água. Sistemas carregados como o elétron e íons, ambos solvatados em água, apresentam tipicamente energias inferiores a $-30 \mathrm{kcal} / \mathrm{mol}$ [77] e portanto tem comportamento oposto e bastante favorável a solvatação em comparação com o Ps.

\subsection{Energia de Relaxação da Água}

Durante o processo de solvatção do Ps temos uma variação na energia interna do sistema $(\Delta E)$, a qual pode ser determinada classicamente com as simulações MC. A variação mencionada consiste na diferença da energia entre dois sistemas, o primeiro seria formado pelo átomo de Ps isolado e pela água infinitamente separados, e o segundo seria composto pelo Ps solvatado na água sendo as energias internas dos respectivos sistemas dadas por $E_{\text {sol }}$ e $E_{\text {gás }}$, Logo, a variação da energia interna será

$$
\Delta E=E_{\mathrm{sol}}-E_{\text {gás }}
$$

As contribuições cinéticas para as energias dos dois sistemas serão canceladas, e com isso $\Delta E$ pode ser escrito em termos das contribuições potenciais conforme a equação seguinte 


$$
\Delta E=\left(E_{\mathrm{Psw}}+E_{\mathrm{ww}}^{\mathrm{Ps}}\right)-\left(E_{\mathrm{ww}}^{\mathrm{bulk}}\right)
$$

onde $E_{\mathrm{Psw}}$ é a energia de interação Ps-água, $E_{\mathrm{ww}}^{\mathrm{Ps}}$ consiste na energia de interação entre moléculas de água na presença do Ps e $E_{\mathrm{ww}}^{\mathrm{bulk}}$ seria a energia de interação entre moléculas de água na ausência do Ps. Essas parcelas da energia são calculadas considerando o raio de corte conforme discutido na seção (2.6). Uma das partes da variação da energia corresponde a energia de relaxação da água $\left(E_{\mathrm{R}}\right)$, que ocorre na solvatação do Ps e é dada por

$$
E_{\mathrm{R}}=E_{\mathrm{ww}}^{\mathrm{Ps}}-E_{\mathrm{ww}}^{\mathrm{bulk}}
$$

Portanto, a variação da energia interna do sistema envolvida na solvatação do Ps pode ser reescrita em função da energia de interação Ps-água e da energia de relaxação conforme a equação

$$
\Delta E=E_{\mathrm{Psw}}+E_{\mathrm{R}}
$$

A fim de calcularmos a energia de relaxação da água em questão, realizamos uma simulação MC para o Ps na presença de 500 moléculas de água com 100000 ciclos MC na etapa de termalização e 2000000 ciclos MC na etapa de produção divididos em 20 simulações independentes com 100000 ciclos MC cada. Com isso, obtivemos a parcela da energia $E_{\mathrm{ww}}^{\mathrm{Ps}}$ através da média dos valores dessa propriedade em cada simulação com 100000 ciclos MC. Também realizamos o mesmo procedimento para um sistema composto por uma molécula de água na presença de outras 500 moléculas de água, assim encontramos $E_{\mathrm{ww}}^{\mathrm{bulk}}$. Esse procedimento fornece valores estatisticamente independentes destas grandezas, com os quais calculamos a média acumulada dos valores da energia de relaxação obtidos com a fórmula (4.12). As médias acumuladas 
dos valores de $E_{\mathrm{R}}$ e $E_{\text {Psw }}$ resultaram em $-9.30 \pm 1.88 \mathrm{kcal} / \mathrm{mol}$ e $-0.04 \pm 0.03 \mathrm{kcal} / \mathrm{mol}$ respectivamente. Apresentamos os gráficos das médias acumuladas de $E_{\mathrm{Psw}}$ e $E_{\mathrm{R}}$ na figura (4.14).
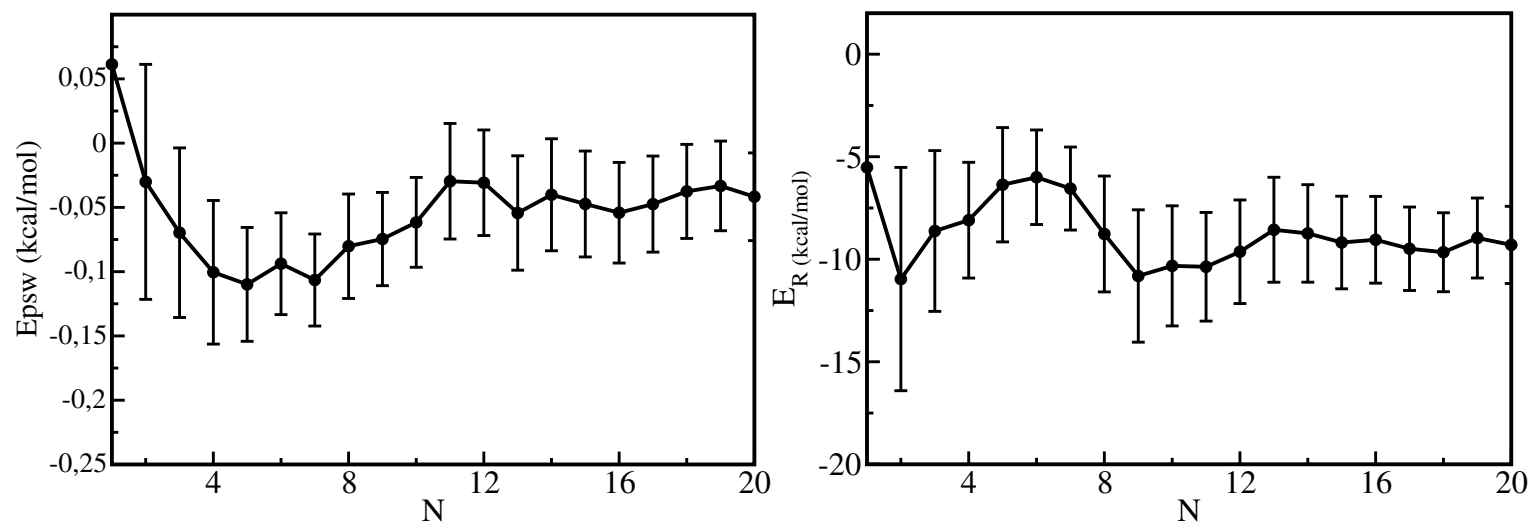

Figura 4.14: $\mathrm{O}$ gráfico à esquerda representa a média acumulada da energia de interação Ps-água $\left(E_{\mathrm{Psw}}\right)$ em função do número de valores $(N)$ considerados na média, enquanto no gráfico da direita temos a média acumulada da energia de relaxação $\left(E_{\mathrm{R}}\right)$ em função do número de valores.

A energia de interação entre o soluto e o solvente $\left(E_{\mathrm{Psw}}\right)$ calculada é pequena em comparação às demais parcelas de $\Delta E$, e isso deve ser interpretado levando em conta o valor do potencial de interação Ps-água na região do pico da RDF Ps-cm. O primeiro pico desta RDF está em $3.75 \AA$, e a interação Ps-água para distâncias inferiores a coordenada do ponto do pico é altamente repulsiva enquanto as contribuições para coordenadas maiores são tipicamente muito próximas de zero. Logo, o valor médio da energia de interação entre o soluto e o solvente será muito pequeno conforme obervamos.

Portanto, a variação da energia interna do sistema durante a solvatação do átomo de positrônio foi de $-9.34 \pm 1.91 \mathrm{kcal} / \mathrm{mol}$ e os resultados das parcelas da variação da energia interna estão dispostos na tabela (4.4). 


\begin{tabular}{|c|l|}
\hline$E_{\mathrm{R}}$ & $-9.30 \pm 1.88 \mathrm{kcal} / \mathrm{mol}$ \\
\hline$E_{\mathrm{Psw}}$ & $-0.04 \pm 0.03 \mathrm{kcal} / \mathrm{mol}$ \\
\hline$\Delta E$ & $-9.34 \pm 1.91 \mathrm{kcal} / \mathrm{mol}$ \\
\hline
\end{tabular}

Tabela 4.4: Resumo dos resultados obtidos envolvendo a variação na energia interna do sistema no processo de solvatação do Ps.

\subsection{Contribuição Entrópica da Solvatação}

Ainda resta uma grandeza termodinâmica envolvida no processo de solvatação do Ps que fornece uma interpretação física importante. A grandeza em questão seria a entropia, ou seja, podemos determinar contribuição entrópica envolvida na solvatação. Encontramos a variação da entropia a partir da equação seguinte,

$$
\Delta G_{\mathrm{sol}}=\Delta H-T \Delta S
$$

onde $\Delta H$ e $\Delta S$ são as variações da entalpia e entropia respectivamente. Reescrevendo a variação da entalpia em termos das variações da energia interna $(\Delta E)$ e do volume $(\Delta V)$ encontramos,

$$
\Delta G_{\mathrm{sol}}=\Delta E+P \Delta V-T \Delta S
$$

e sendo a contribuição $P \Delta V$ muito pequena tendo em vista a variação ínfima do volume entre os sistemas inicial e final, podemos reescrever a equação (4.15) como

$$
\Delta S=\frac{1}{T}\left(\Delta E-\Delta G_{\text {sol }}\right)
$$

Com os resultados obtidos anteriormente, encontramos uma contribuição entrópica na solvatação do Ps igual a $-213.23 \pm 30.99 \mathrm{~J} / \mathrm{mol} . K$. A contribuição entrópica negativa pode ser entendida a partir da quebra de ligações de hidrogênio da água para a formação da cavidade ocupada pelo soluto, as moléculas de água por sua vez estaram 
orientadas sobre a primeira camada de solvatação formando ligações de hidrogênio tangencialmente à superfície e terão uma mobilidade reduzida. Com isso, os movimentos de translação e rotação das moléculas de água serão retardados levando a uma perda de entropia translacional e rotacional das moléculas de água. Esse processo foi observado experimentalmente por Halselmeier e colaboradores [82] para a solvatação do xenônio, e portanto corrobora com a comparação feita na seção (4.5). 


\section{Resultados das Simulações Quânticas}

Neste capítulo vamos apresentar a abordagem quântica realizada no estudo do átomo de positrônio hidratado. A propriedade de interesse neste estudo é a energia de ionização vertical (Vertical Detachment Energy, VDE), que seria a energia necessária para ionizarmos o Ps retirando o elétron ou o pósitron do mesmo. Iniciamos a discussão apresentando um modelo para o Ps hidratado com o qual faremos testes utilizando diferentes formas de representar este átomo exótico em um cálculo quântico. Paralelamente, também utilizamos diferentes conjuntos de funções base nestes cálculos quânticos com diferentes formas de representar o Ps analisando a influência das bases sobre os resultados da propriedade desejada. Durante esses testes observamos as densidades eletrônicas e positrônicas, onde foi possível observar o efeito das diferentes maneiras de representar o Ps sobre a distribuição das densidades na cavidade ocupada pelo Ps na água. Buscamos através da abordagem quântica (QM) determinar as energias dos orbitais de mais alta energia ocupados por um único elétron ou pósitron, que seriam os orbitais SOMO (Singly Occupied Molecular Orbital) do elétron e do pósitron pertencentes ao Ps. Após a definição do conjunto de funções base adequado ao cálculo dessa propriedade, o valor do VDE eletrônico e positrônico foi determinado através dos procedimentos S-QM/MM e ASEC. 


\subsection{Modelo de Coordenação}

Cálculos de estrutura eletrônica para átomos ou moléculas realizados com métodos que utilizam a expansão da função de onda através de um conjunto de funções de base, na grande maioria dos casos ocorrem com o centro de expansão dessas funções de base posicionados sobre a coordenada nuclear do átomo em questão. Portanto, para o caso de funções de base dadas por gaussianas, o centro de expansão das gaussianas será a posição do átomo em questão. Para o caso de um átomo exótico como o positrônio, o qual não possui um núcleo sendo composto apenas por duas partículas leves, não há uma forma bem estabelecida para representar o Ps na presença de outras moléculas. A abordagem utilizada neste trabalho para sistemas contendo elétrons e pósitrons consiste em tratar ambas as partículas por meio de funções de onda, e deste modo é necessária a discussão sobre onde os centros de expansão das funções da base de cada espécie quântica devem ser posicionados na cavidade do Ps hidratado. Com isso, a forma de representar o positrônio pode influenciar nos valores da propriedade calculada e na distribuição das densidades eletrônica e positrônica do Ps dentro da cavidade. Cabe ainda ressaltar que os cálculos de estrutura eletrônica são realizados através de simulações computacionais e portanto estão sujeitos a algumas limitações de natureza técnica, como os limites de mémoria RAM , tempo de cálculo, número de processadores e espaço de disco rígido. Portanto, o ponto de partida da abordagem quântica foi a realização de testes utilizando diferentes formas de representar esse átomo e diferentes conjuntos de funções base.

As simulações MC discutidas na seção (4.2) geraram 80 configurações descorrelacionadas compostas pelo Ps na presença de 500 moléculas de água. Vale mencionar que na abordagem QM com as configurações do líquido, consideramos o soluto e uma quantidade específica de moléculas de água selecionada a partir da função de distri- 
buição radial de pares entre o Ps e o centro de massa das moléculas de água. O critério adotado nessa seleção consiste em considerar todas as moléculas do solvente até uma coordenada radial a partir da qual a $G(r)$ possui valor em torno de 1 e não oscila significativamente. Com isso, estamos considerando a região em que ocorre a formação de estruturas do líquido como a primeira e segunda camada de solvatação. Portanto, a análise da RDF entre o Ps e o centro de massa das águas (Ps-cm) permite concluir que devemos considerar todas as moléculas do solvente até a coordenada $r=10 \AA$. A integral da RDF Ps-cm até $10 \AA$ fornece 150 moléculas de água, logo para os cálculos QM consideramos até 150 moléculas de água sendo uma parte tratada explicitamente (quanticamente) e outra implicitamente (cargas pontuais). Na figura (5.1) mostramos a definição da região considerada em cada configuração.

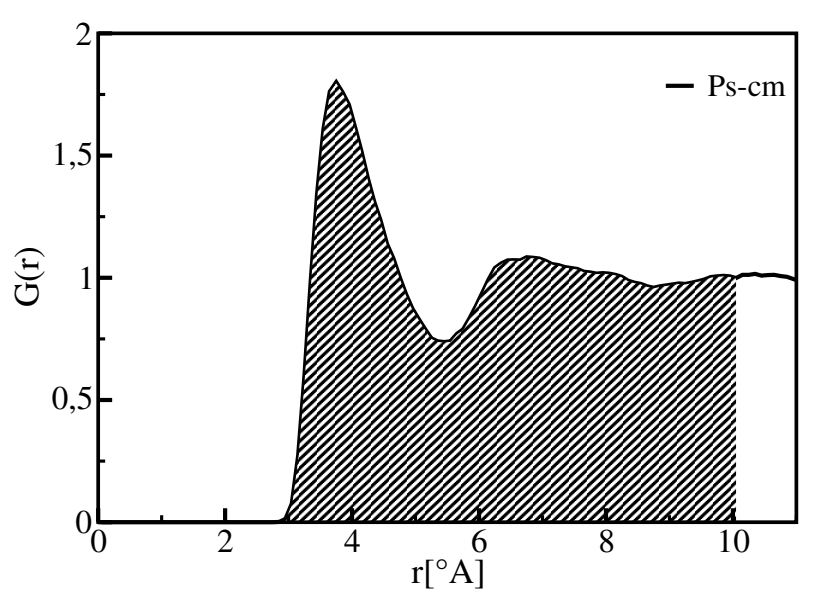

Figura 5.1: RDF entre o Ps e o centro de massa das moléculas de água, a região destacada abaixo da curva corresponde a parte do sistema considerada nos cálculos QM. O número de moléculas de água consideradas como cargas pontuais é dado pela integral da região destacada da RDF.

Os testes com os diferentes modelos de representação do Ps no cálculo quântico, utilizaram diferentes conjuntos de funções base, além de utilizarem configurações obtidas a partir de um modelo de coordenação representativo do sistema e viável computacionalmente para os cálculos QM. Esse modelo de coordenação foi definido a partir de três configurações (A, B e C) selecionadas aleatoriamente do conjunto de configurações 
descorrelacionadas, e em cada configuração escolhida tratamos quanticamente o Ps e dez moléculas de água. As 140 moléculas do solvente restantes são tratadas como cargas pontuais nos cálculos quânticos, constituindo um banho eletrostático. Adotamos dois procedimentos nos cálculos quânticos, sendo o I aquele no qual consideramos as configurações do modelo de coordenação na ausência do banho eletrostático e o II na presença do banho. Na figura (5.2) apresentamos as configurações A, B e C na ausência do banho eletrostático conforme o procedimento I, enquanto na figura (5.3) estão dispostas as mesmas configurações na presença do banho de acordo com o procedimento II.

(A)

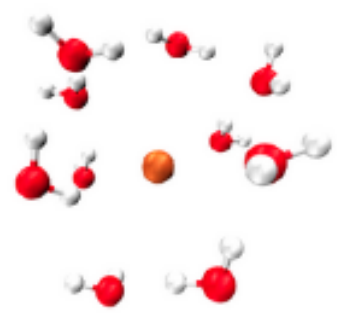

(B)

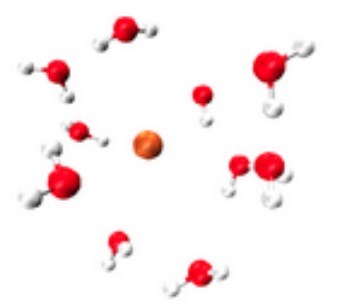

(C)

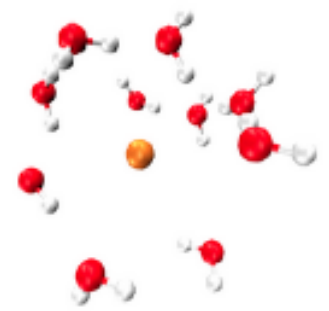

Figura 5.2: Configurações A, B e C selecionadas para os testes compostas pelo Ps e dez moléculas de água consideradas explicitamente conforme o procedimento I.

(A)

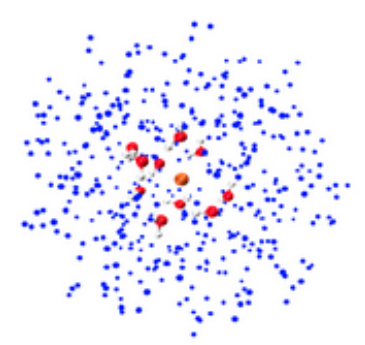

(B)

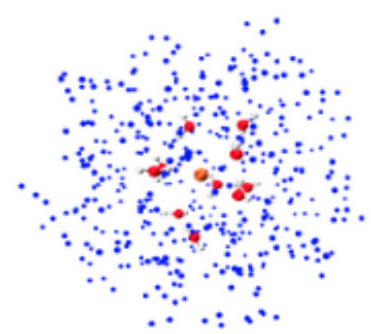

(C)

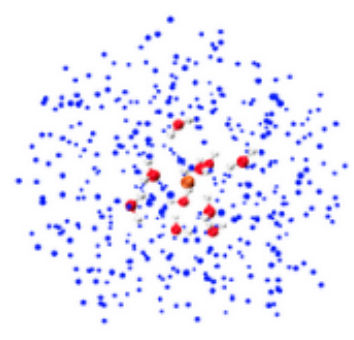

Figura 5.3: Configurações A, B e C selecionadas para os testes compostas pelo Ps, dez moléculas de água consideradas explicitamente e 140 moléculas de água consideradas como cargas pontuais conforme o procedimento II. 


\subsubsection{Centro de Expansão do Pósitron nos Oxigênios}

Uma vez definido o modelo de coordenação e os procedimentos adotados nos cálculos quânticos necessários para os testes, realizamos simulações quânticas com as diferentes configurações usando o método Hartree-Fock de Camada Aberta (Unrestricted Hartree-Fock, UHF) com as bases 6-31G++(d,p), 6-311G++(d,p) e aug-cc-pVDZ. A maneira usada para representar o Ps quanticamente nesses cálculos consiste em posicionar o centro de expansão da base positrônica sobre os átomos de oxigênio das moléculas de água, enquanto para a base eletrônica não foram acrescentados centros extras de expansão além dos sítios atômicos. Essa escolha para o centro de expansão positrônico leva em conta a tendência do pósitron de interagir com os oxigênios, e evita induzir artificialmente a localização do Ps na cavidade, sob potencial risco de exigir bases mais robustas para representação adequada da cavidade sem adição de centros extras. Os resultados para as energias dos orbitais SOMO eletrônico e positrônico do Ps estão dispostos nas tabelas (5.1) e (5.2).

\begin{tabular}{|l|l|l|l|l|l|l|l|}
\hline Configurações: & \multicolumn{2}{l|}{ A $(\mathrm{eV})$} & \multicolumn{2}{l|}{$\mathrm{B}(\mathrm{eV})$} & \multicolumn{2}{l|}{$\mathrm{C}(\mathrm{eV})$} & \\
\hline & I & II & I & II & I & II & \\
\hline SOMO $e^{-}$ & -3.06 & -3.74 & -2.69 & -2.67 & -2.97 & -2.89 & $6-31 \mathrm{G}++(\mathrm{d}, \mathrm{p})$ \\
\hline SOMO $e^{-}$ & -3.05 & -3.18 & -2.69 & -2.69 & -3.03 & -2.94 & $6-311 \mathrm{G}++(\mathrm{d}, \mathrm{p})$ \\
\hline SOMO $e^{-}$ & -2.95 & -3.13 & -2.70 & -2.96 & -3.01 & -3.08 & aug-cc-pVDZ \\
\hline 6311G-631G & 0.01 & 0.56 & 0.00 & -0.02 & -0.06 & -0.05 & \\
\hline VDZ-6311G & 0.10 & 0.05 & -0.01 & -0.27 & 0.02 & -0.14 & \\
\hline
\end{tabular}

Tabela 5.1: Energias do SOMO eletrônico do Ps calculadas utilizando os centros de expansão positrônico sobre os oxigênios, com os procedimentos I e II. As diferenças entre os resultados com as bases 6-311G++(d,p) e 6-31G++(d,p) estão indicadas por 6311G-631G, e para o caso da aug-cc-pVDZ e 6$311 \mathrm{G}++(\mathrm{d}, \mathrm{p})$ indicamos por VDZ-6311G.

Os resultados apresentados acima demonstram uma variação típica de $0.40 \mathrm{eV}$ das energias dos orbitais SOMO positrônico com as diferentes bases utilizadas, enquanto para o caso eletrônico as variações estão em torno de $0.10 \mathrm{eV}$ na maior parte dos 


\begin{tabular}{|l|l|l|l|l|l|l|l|}
\hline Configurações: & \multicolumn{2}{l|}{$\mathrm{A}(\mathrm{eV})$} & \multicolumn{2}{l|}{$\mathrm{B}(\mathrm{eV})$} & \multicolumn{2}{l|}{$\mathrm{C}(\mathrm{eV})$} & \\
\hline & I & II & I & II & I & II & \\
\hline SOMO $e^{+}$ & -2.08 & -2.54 & -2.80 & -3.43 & -3.10 & -2.67 & $6-31 \mathrm{G}++(\mathrm{d}, \mathrm{p})$ \\
\hline SOMO $e^{+}$ & -2.09 & -3.01 & -2.82 & -3.42 & -3.21 & -2.74 & $6-311 \mathrm{G}++(\mathrm{d}, \mathrm{p})$ \\
\hline SOMO $e^{+}$ & -2.30 & -3.42 & -3.03 & -3.96 & -3.68 & -3.32 & aug-cc-pVDZ \\
\hline 6311G-631G & -0.01 & -0.47 & -0.02 & 0.01 & -0.11 & -0.07 & \\
\hline VDZ-6311G & -0.21 & -0.41 & -0.21 & -0.54 & -0.47 & -0.58 & \\
\hline
\end{tabular}

Tabela 5.2: Energias do SOMO positrônico do Ps calculadas utilizando os centros de expansão positrônico sobre os oxigênios, com os procedimentos I e II. As diferenças entre os resultados com as bases $6-311 \mathrm{G}++(\mathrm{d}, \mathrm{p})$ e 6 $31 \mathrm{G}++(\mathrm{d}, \mathrm{p})$ estão indicadas por $6311 \mathrm{G}-631 \mathrm{G}$, e para o caso da aug-ccpVDZ e 6-311G++(d,p) indicamos por VDZ-6-311G.

casos. Em seguida, apresentamos os orbitais SOMO eletrônico e positrônico do Ps obtidos nestes cálculos nas figuras (5.4) e (5.5). São apresentados apenas os orbitais obtidos com a base 6-31G++(d,p), tendo em vista que o caráter e o comportamento dos demais orbitais obtidos com as outras bases foi semelhante.
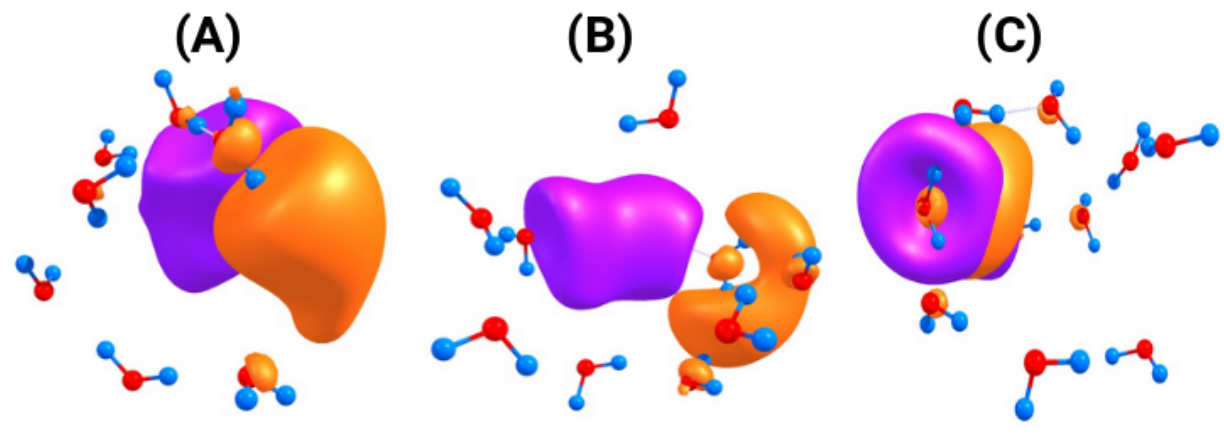

Figura 5.4: Orbitais SOMO eletrônico em laranja e positrônico em roxo obtidos com a base $6-31 \mathrm{G}++(\mathrm{d}, \mathrm{p})$ e o procedimento $\mathbf{I}$, usamos o isovalor 0.03 .

É possível notar que em todos os casos ambos os orbitais estão situados em uma das extremidades das configurações, logo as densidades apresentadas não ocupam o centro da cavidade onde o Ps está nas simulações clássicas. Em relação à comparação dos resultados com os procedimentos I e II (com e sem o banho eletrostático), observamos que o efeito do banho sobre as densidades seria a sobreposição das mesmas quando consideramos as cargas pontuais no cálculo. Aglomerados de moléculas de água como 
(A)

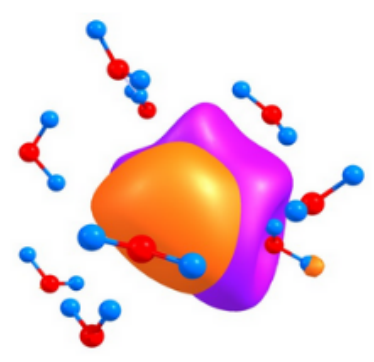

(B)

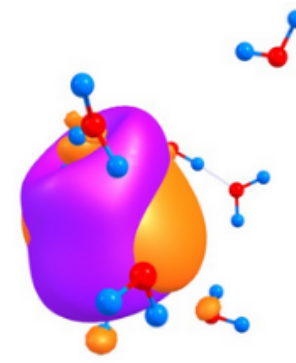

(C)

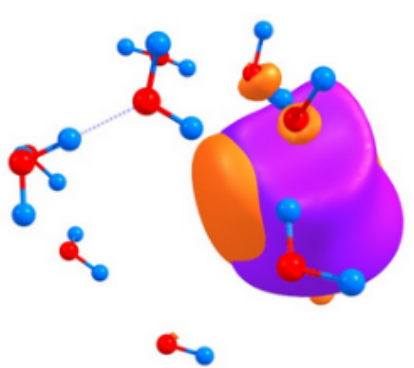

Figura 5.5: Orbitais SOMO eletrônico em laranja e positrônico em roxo obtidos com a base $6-31 \mathrm{G}++(\mathrm{d}, \mathrm{p})$ e o procedimento II, usamos o isovalor 0.03 .

estes tipicamente apresentam elevado momento de dipolo e a densidade de carga do Ps deve ser influenciada pela direcionalidade da distribuição de carga dos aglomerados de água neutros. Com isso, também foram feitos cálculos com o método Hartree-Fock Restrito (Restricted Hartree-Fock, RHF) do momento de dipolo das configurações A, B e C usando os procedimentos I e II na ausência do Ps afim de observarmos se as densidades estão distribuídas sob influência significativa do dipolo ou não. Os resultados do momento de dipolo estão dispostos na tabela (5.3). Nas figuras (5.6) e (5.7) mostramos as densidades representadas junto com o momento de dipolo total obtido com os cálculos RHF usando a base $6-31 \mathrm{G}++(\mathrm{d}, \mathrm{p})$ na ausência do Ps. Os resultados com as demais bases apresentam o mesmo comportamento.

\begin{tabular}{|l|l|l|l|l|l|l|l|}
\hline Configurações: & \multicolumn{2}{l|}{ A (debye) } & \multicolumn{2}{l|}{ B (debye) } & \multicolumn{2}{l|}{ C (debye) } & \\
\hline & I & II & I & II & I & II & \\
\hline$\langle\mu\rangle=$ & 13.63 & 16.10 & 10.50 & 11.81 & 12.26 & 14.29 & $6-31 \mathrm{G}++(\mathrm{d}, \mathrm{p})$ \\
\hline$\langle\mu\rangle=$ & 13.46 & 12.51 & 10.37 & 11.72 & 12.10 & 14.18 & $6-311 \mathrm{G}++(\mathrm{d}, \mathrm{p})$ \\
\hline$\langle\mu\rangle=$ & 15.96 & 15.42 & 9.79 & 11.36 & 11.42 & 13.87 & aug-cc-pVDZ \\
\hline
\end{tabular}

Tabela 5.3: Momento de dipolo total obtido nos cálculos RHF para as configurações A, B e C com os procedimentos I e II ambos na ausência do Ps, usamos o isovalor 0.03 .

O momento de dipolo total de todas as configurações adotando os procedimentos I e II apresenta um valor expressivo. Observamos uma tendência de orientação das 
(A)

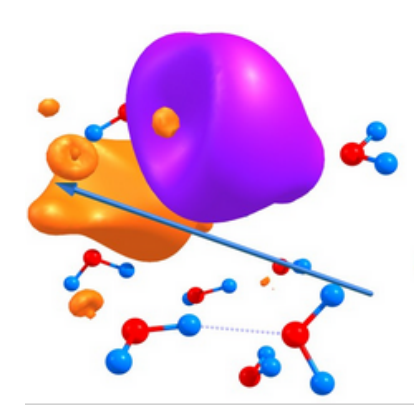

(B)

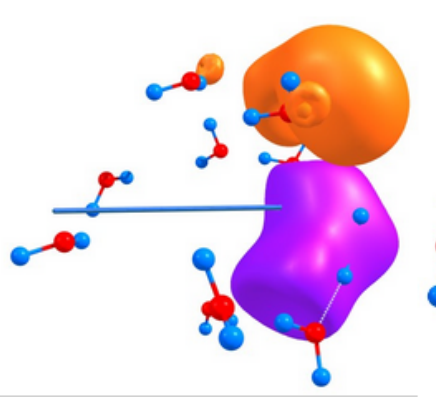

(C)

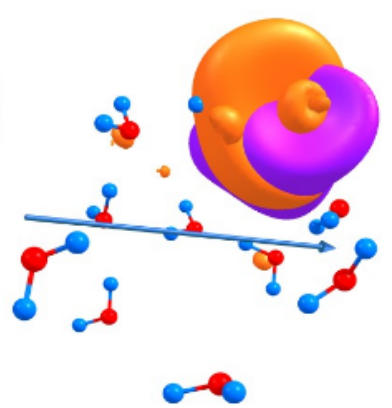

Figura 5.6: Momento de dipolo total representado junto com os orbitais SOMO eletrônico (laranja) e positrônico (roxo), as densidades foram representadas com o isovalor 0.03. Esses resultados foram obtidos com a base $6-31 \mathrm{G}++(\mathrm{d}, \mathrm{p})$ e o procedimento $\mathbf{I}$.

\section{(A)}

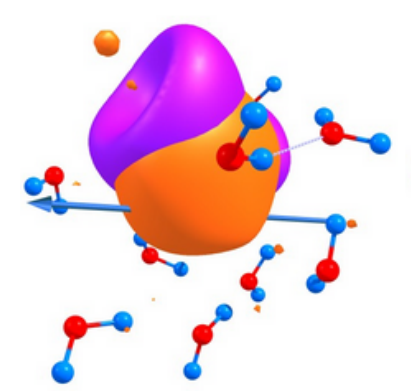

(B)

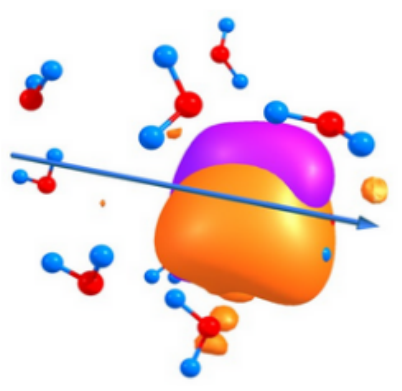

(C)

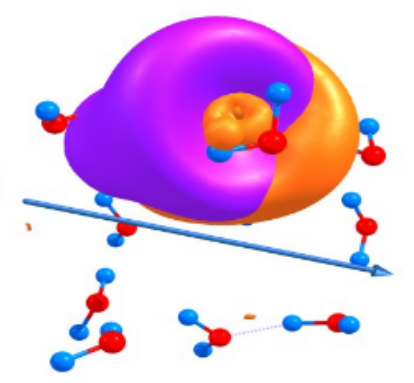

Figura 5.7: Momento de dipolo total representado junto com os orbitais SOMO eletrônico (laranja) e positrônico (roxo), as densidades foram representadas com o isovalor 0.03. Esses resultados foram obtidos com a base 6-31G++(d,p) e o procedimento II.

densidades perpendicularmente ao momento de dipolo. Sobre a presença do banho eletrostático do aglomerado na abordagem QM, podemos notar o aumento do momento de dipolo do mesmo. Por outro lado, sobre as densidades eletrônica e positrônica o banho introduz um potencial sem direção preferencial clara, sendo neste sentido bem diferente do potencial do momento de dipolo do aglomerado sobre o Ps. Com isso, o efeito do potencial eletrostático do banho é localizar o Ps visto que mesmo com a indução de momento de dipolo no cluster o Ps comporta-se como se sujeito a um potencial menos direcional. 
Além do momento de dipolo, o fato das densidades permanecerem na periferia dos aglomerados também pode estar ligado à região considerada explicitamente no cálculo quântico. Portanto, outra análise importante seria em relação ao efeito do aumento da região tratada quanticamente no cálculo sobre as posições das densidades. Então, realizamos novamente cálculos UHF com as mesmas bases considerando toda a primeira camada de solvatação (22 moléculas de água) quanticamente e 128 moléculas de água como cargas pontuais. Na figura (5.8) apresentamos os orbitais SOMO eletrônico e positrônico do Ps da configuração C, e o momento de dipolo total obtido para o aglomerado na ausência do Ps. As demais configurações apresentaram o mesmo comportamento utilizando as demais bases.

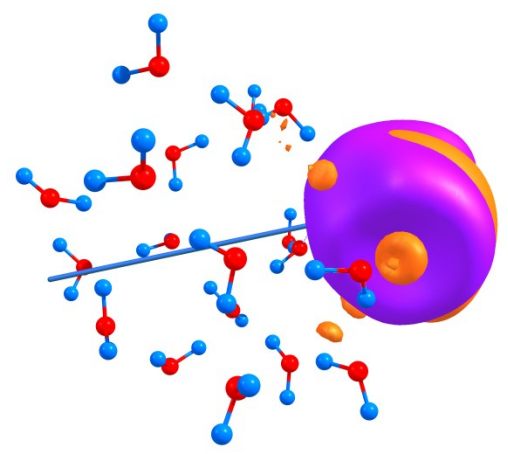

Figura 5.8: Momento de dipolo total representado junto com os orbitais SOMO eletrônico (laranja) e positrônico (roxo) usando o isovalor 0.03. Esses resultados foram obtidos com a base $6-31 \mathrm{G}++(\mathrm{d}, \mathrm{p})$ para a configuração $\mathrm{C}$ considerando toda a primeira camada de solvatação explicitamente com o procedimento II.

O momento de dipolo calculado deste aglomerado com 22 moléculas de água é igual a 19.33 Debye, demonstrando o fato do aumento da região tratada quanticamente resultar em um dipolo grande assim como nos casos dos aglomerados com apenas 10 moléculas de água. Para as densidades, o aumento da região quântica confirma o posicionamento das mesmas na periferia do aglomerado estando sobrepostas devido ao efeito do potencial do banho eletrostático. Portanto, a abordagem QM para o Ps 
hidratado utilizando centros de expansão do pósitron sobre os átomos de oxigênio leva ao posicionamento das densidades do Ps na periferia do cluster com os procedimentos I e II.

\subsubsection{Centro de Expansão do Pósitron na Origem}

Outra maneira de representar o Ps em um cálculo quântico seria aquela em que posicionamos o centro de expansão da base positrônica apenas na origem da cavidade, enquanto para a base eletrônica usamos um centro de expansão adicional na origem além dos demais posicionados nos sítios atômicos. Essa representação do Ps permite analisar se a representação da densidade de carga na região da densidade é melhor utilizando centros nos oxigênios, ou apenas na origem.

Os centros de expansão eletrônico e positrônico posicionados apenas na origem são referentes a funções de base do átomo de hidrogênio, as bases utilizadas foram a 6$31 \mathrm{G}++(\mathrm{d}, \mathrm{p}), 6-311 \mathrm{G}++(\mathrm{d}, \mathrm{p})$, aug-ccpVDZ, aug-ccpVTZ e aug-ccpVQZ. Os demais centros de expansão eletrônicos, posicionados nos sítios atômicos, utilizam funções de base dos respectivos átomos de cada sítio e as bases usadas foram a 6-31G++(d,p), 6-311G++(d,p) e aug-cc-pVDZ.

Para os cálculos usamos as seguintes combinações de bases: descrevemos todo o sistema com as bases 6-31G++(d,p), 6-311G++(d,p) e aug-cc-pVDZ, e como segunda opção utilizamos a base $6-31 \mathrm{G}++(\mathrm{d}, \mathrm{p})$ apenas nos sítios atômicos das águas combinada com as bases aug-cc-pVDZ, aug-cc-pVTZ e aug-cc-pVQZ posicionadas na origem. Usamos o método UHF nestes cálculos, e os resultados obtidos para as energias dos orbitais SOMO eletrônico e positrônico do Ps estão dispostos nas tabelas (5.4) e (5.5).

Em geral, observamos que as energias dos orbitais SOMO do elétron e do pósitron estão mais próximas entre si nessa representação do que na anterior na qual posicionamos os centros de expansão positrônico nos oxigênios. Esse comportamento seria 


\begin{tabular}{|l|l|l|l|l|l|l|l|}
\hline Configurações: & \multicolumn{2}{l|}{$\mathrm{A}(\mathrm{eV})$} & \multicolumn{2}{l|}{$\mathrm{B}(\mathrm{eV})$} & \multicolumn{2}{l|}{$\mathrm{C}(\mathrm{eV})$} & \\
\hline & I & II & I & II & I & II & \\
\hline SOMO $e^{-}$ & -4.27 & -4.81 & -3.56 & -3.65 & -4.73 & -4.76 & $6-31 \mathrm{G}++(\mathrm{d}, \mathrm{p})$ \\
\hline SOMO $e^{-}$ & -4.52 & -4.99 & -3.83 & -3.88 & -4.93 & -4.91 & $6-311 \mathrm{G}++(\mathrm{d}, \mathrm{p})$ \\
\hline SOMO $e^{-}$ & -4.56 & -4.97 & -3.91 & -3.95 & -4.96 & -4.58 & aug-cc-pVDZ \\
\hline SOMO $e^{-}$ & -4.52 & -5.01 & -3.78 & -3.86 & -4.97 & -4.93 & aug-cc-pVDZ/6-31G++(d,p) \\
\hline SOMO $e^{-}$ & -4.43 & -4.97 & -3.84 & -3.87 & -4.98 & -4.81 & aug-cc-pVTZ/6-31G++(d,p) \\
\hline SOMO $e^{-}$ & -4.36 & -4.95 & -3.82 & -3.86 & -4.98 & -4.78 & aug-cc-pVQZ/6-31G++(d,p) \\
\hline VTZ-VDZ & 0.09 & 0.04 & -0.06 & -0.01 & -0.01 & 0.12 & \\
\hline VQZ-VTZ & 0.07 & 0.02 & 0.02 & 0.01 & 0.00 & 0.03 & \\
\hline
\end{tabular}

Tabela 5.4: Energias do orbital SOMO eletrônico do Ps obtidas com o centro de expansão do pósitron na origem com os procedimentos I e II. As diferenças entre os resultados com as bases aug-cc-pVTZ e aug-cc-pVDZ estão indicadas por VTZ-VDZ, e para o caso da aug-cc-pVQZ e aug-cc-pVTZ indicamos por VQZ-VTZ.

\begin{tabular}{|l|l|l|l|l|l|l|l|}
\hline Configurações: & \multicolumn{2}{l|}{$\mathrm{A}(\mathrm{eV})$} & \multicolumn{2}{l|}{$\mathrm{B}(\mathrm{eV})$} & \multicolumn{2}{l|}{$\mathrm{C}(\mathrm{eV})$} & \\
\hline & I & II & I & II & I & II & \\
\hline SOMO $e^{+}$ & -4.13 & -4.40 & -4.93 & -5.44 & -4.17 & -4.51 & $6-31 \mathrm{G}++(\mathrm{d}, \mathrm{p})$ \\
\hline SOMO $e^{+}$ & -4.65 & -4.69 & -5.33 & -5.69 & -4.51 & -4.79 & $6-311 \mathrm{G}++(\mathrm{d}, \mathrm{p})$ \\
\hline SOMO $e^{+}$ & -4.65 & -4.72 & -5.16 & -5.50 & -4.42 & -4.58 & aug-cc-pVDZ \\
\hline SOMO $e^{+}$ & -4.57 & -4.58 & -5.18 & -5.58 & -4.38 & -4.75 & aug-cc-pVDZ/6-31G++(d,p) \\
\hline SOMO $e^{+}$ & -4.68 & -4.71 & -5.35 & -5.71 & -4.46 & -4.88 & aug-cc-pVTZ/6-31G++(d,p) \\
\hline SOMO $e^{+}$ & -4.72 & -4.72 & -5.36 & -5.73 & -4.44 & -4.91 & aug-cc-pVQZ/6-31G++(d,p) \\
\hline 6311G-631G & -0.11 & -0.13 & -0.17 & -0.13 & -0.08 & -0.13 & \\
\hline VDZ-6311G & -0.04 & -0.01 & -0.01 & -0.02 & 0.02 & -0.03 & \\
\hline
\end{tabular}

Tabela 5.5: Energias do orbital SOMO positrônico do Ps obtidas com o centro de expansão do pósitron na origem com os procedimentos I e II. As diferenças entre os resultados com as bases aug-cc-pVTZ e aug-cc-pVDZ estão indicadas por VTZ-VDZ, e para o caso da aug-cc-pVQZ e aug-cc-pVTZ indicamos por VQZ-VTZ.

mais próximo ao do Ps em vácuo, onde as energias orbitais seriam idênticas. Ainda em comparação com os resultados usando a representação com centros nos oxigênios, podemos concluir que ocorre um aumento das VDEs eletrônicas e positrônicas indicando uma coesão maior do Ps. Isso ocorre porque o centro extra na origem favorece a interação entre o elétron e pósitron do Ps. Embora as VDEs sejam variáveis físicas interessantes, devemos atentar para a energia total, uma vez que utilizamos um método 
variacional. As energias totais obtidas nestes cálculos estão dispostas na tabela (5.6).

\begin{tabular}{|l|l|l|l|l|l|l|}
\hline \multicolumn{2}{|c|}{ A (Hartree) } & \multicolumn{2}{l|}{ B (Hartree) } & \multicolumn{2}{l|}{ C (Hartree) } & \\
\hline I & II & I & II & I & II & \\
\hline-760.3346 & -807.8176 & -760.3474 & -807.8611 & -760.3498 & -807.8300 & $6-31 \mathrm{G}++(\mathrm{d}, \mathrm{p})$ \\
\hline-760.5568 & -808.0375 & -760.5667 & -808.0771 & -760.5704 & -808.0470 & $6-311 \mathrm{G}++(\mathrm{d}, \mathrm{p})$ \\
\hline-760.4387 & -807.9081 & -760.4489 & -807.9455 & -760.4523 & -807.9152 & aug-cc-pVDZ \\
\hline-760.3393 & -807.8293 & -760.3474 & -807.8618 & -760.3532 & -807.8335 & aug-cc-pVDZ $/ 6-31 \mathrm{G}++(\mathrm{d}, \mathrm{p})$ \\
\hline-760.3478 & -807.8293 & -760.3537 & -807.8674 & -760.3611 & -807.8407 & aug-cc-pVTZ/6-31G++(d,p) \\
\hline-760.3500 & -807.8307 & -760.3554 & -807.8689 & -760.3635 & -807.8428 & aug-cc-pVQZ/6-31G++ (d,p) \\
\hline
\end{tabular}

Tabela 5.6: Energias totais das configurações A, B e C obtidas nos cálculos UHF com o centro de expansão do pósitron posicionado apenas na origem usando os procedimentos I e II.

Através dos resultados da tabela (5.6) podemos concluir que em todos os casos o sistema possui a energia total mais baixa utilizando a base $6-311 \mathrm{G}++(\mathrm{d}, \mathrm{p})$ descrevendo todo o sistema. Isso está de acordo com o esperado para métodos como o UHF, tendo em vista que esse conjunto de funções base apresenta o maior número de gaussianas em sua composição comparado aos demais conjuntos. Com isso, existe uma maior flexibilidade na minimização da energia utilizando esta base. Por outro lado, quando utilizamos a base 6-31G++(d,p) para a descrição das moléculas de água junto das bases VDZ, VTZ e VQZ com centro de expansão na origem obtemos resultados da energia total muito próximos e com custo computacional acessível. Logo, usando essa maneira de representar o Ps podemos assumir a utilização da 6-31G++(d,p) com centros de expansão sobre os sítos atômicos das águas e a base aug-cc-pVTZ com centros apenas na origem sem prejuízos para a descrição do sistema.

Além das discussões sobre as energias totais e orbitais, observamos um comportamento típico da distribuição das densidades com essa representação dos Ps analisando os orbitais SOMO obtidos nos cálculos com a base $6-31 \mathrm{G}++(\mathrm{d}, \mathrm{p})$ representados nas figuras (5.9) e (5.10). Os demais orbitais obtidos com as demais bases apresentaram o mesmo comportamento. 
(A)

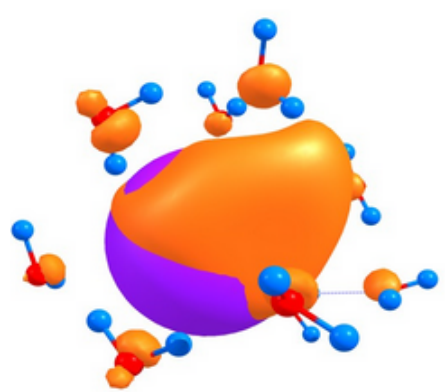

(B)

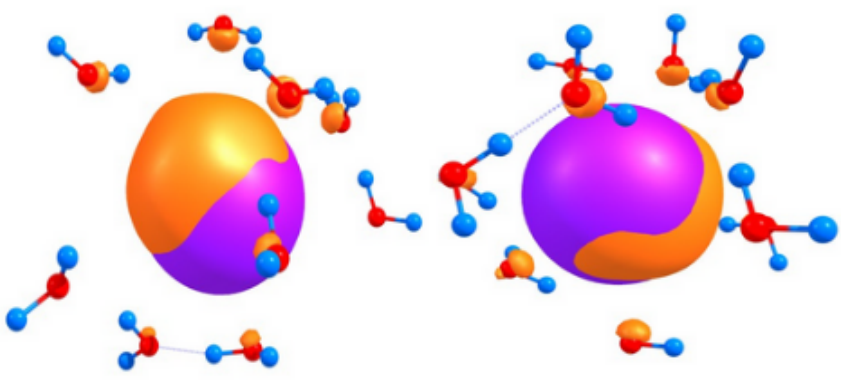

Figura 5.9: Orbitais SOMO eletrônico em laranja e positrônico em roxo obtidos com a base $6-31 \mathrm{G}++(\mathrm{d}, \mathrm{p})$ e o procedimento $\mathbf{I}$, usamos o isovalor 0.03 .

(A)

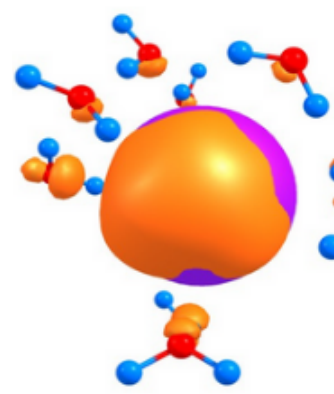

(B)

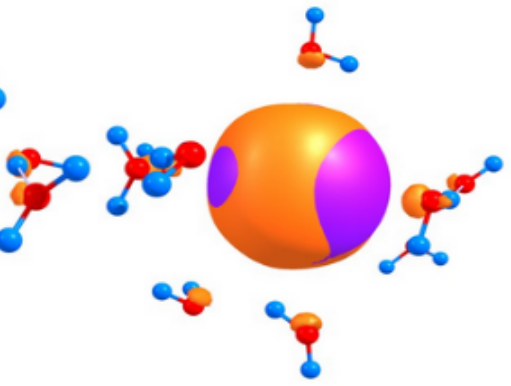

(C)

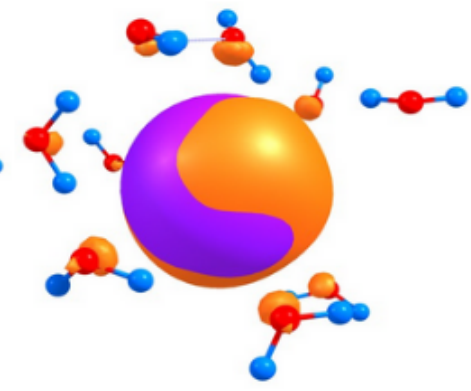

Figura 5.10: Orbitais SOMO eletrônico em laranja e positrônico em roxo obtidos com a base $6-31 \mathrm{G}++(\mathrm{d}, \mathrm{p})$ e o procedimento II, usamos o isovalor 0.03 .

As densidades eletrônicas e positrônicas obtidas com essa representação são muito próximas entre si, assemelhando-se ao caso do Ps em vácuo (densidades idênticas) e estão presentes no centro da cavidade em todos os casos. Os resultados obtidos com o procedimento II, mostram uma maior localização do Ps com a sobreposição das densidades na origem.

\subsubsection{Centro de Expansão do Pósitron na Origem e nos Oxigênios}

Uma alternativa interessante do ponto de vista metodológico seria unir as duas maneiras de representar o Ps discutidas até agora, ou seja, podemos posicionar o centro de expansão do pósitron sobre os oxigênios e na origem. Além disso, para o 
elétron também seria usado um centro extra apenas na origem da cavidade. Realizamos cálculos UHF utilizando esta representação com os procedimentos I e II, os resultados para as energias dos orbitais SOMO eletrônico e positrônico estão dispostos nas tabelas (5.7) e (5.8).

\begin{tabular}{|l|l|l|l|l|l|l|l|}
\hline Configurações: & \multicolumn{2}{l|}{$\mathrm{A}(\mathrm{eV})$} & \multicolumn{2}{l|}{$\mathrm{B}(\mathrm{eV})$} & \multicolumn{2}{l|}{$\mathrm{C}(\mathrm{eV})$} & \\
\hline & I & II & I & II & I & II & \\
\hline SOMO $e^{-}$ & -3.63 & -4.37 & -3.39 & -3.59 & -4.42 & -4.53 & $6-31 \mathrm{G}++(\mathrm{d}, \mathrm{p})$ \\
\hline SOMO $e^{-}$ & -3.56 & -4.42 & -3.47 & -3.66 & -4.46 & -4.58 & $6-311 \mathrm{G}++(\mathrm{d}, \mathrm{p})$ \\
\hline SOMO $e^{-}$ & -3.40 & -4.31 & -3.48 & -3.66 & -4.42 & -4.50 & aug-ccpVDZ \\
\hline 6311G-631G & 0.07 & -0.05 & -0.08 & -0.07 & -0.04 & -0.05 & \\
\hline VDZ-6311G & 0.16 & 0.11 & -0.01 & 0.00 & 0.04 & 0.08 & \\
\hline
\end{tabular}

Tabela 5.7: Energias do SOMO eletrônico do Ps em eV calculadas utilizando o centro de expansão positrônico sobre a origem e nos oxigênios, com os procedimentos I e II. As diferenças entre os resultados com as bases 6$311 \mathrm{G}++(\mathrm{d}, \mathrm{p})$ e $6-31 \mathrm{G}++(\mathrm{d}, \mathrm{p})$ estão indicadas por $6311 \mathrm{G}-631 \mathrm{G}$, e para o caso da aug-cc-pVDZ e 6-311G++(d,p) indicamos por VDZ-6-311G.

\begin{tabular}{|l|l|l|l|l|l|l|l|}
\hline Configurações & \multicolumn{2}{l|}{$\mathrm{A}(\mathrm{eV})$} & \multicolumn{2}{l|}{$\mathrm{B}(\mathrm{eV})$} & \multicolumn{2}{l|}{$\mathrm{C}(\mathrm{eV})$} & \\
\hline & I & II & I & II & I & II & \\
\hline SOMO $e^{+}$ & -3.79 & -4.82 & -5.10 & -5.66 & -4.29 & -4.63 & $6-31 \mathrm{G}++(\mathrm{d}, \mathrm{p})$ \\
\hline SOMO $e^{+}$ & -3.67 & -4.86 & -5.20 & -5.71 & -4.34 & -4.69 & $6-311 \mathrm{G}++(\mathrm{d}, \mathrm{p})$ \\
\hline SOMO $e^{+}$ & -3.52 & -4.84 & -5.08 & -5.58 & -4.24 & -4.62 & aug-cc-pVDZ \\
\hline 6311G-631G & 0.12 & -0.04 & -0.10 & -0.05 & -0.05 & -0.06 & \\
\hline VDZ-6311G & 0.15 & 0.02 & -0.12 & 0.13 & 0.10 & 0.07 & \\
\hline
\end{tabular}

Tabela 5.8: Energias do SOMO positrônico do Ps em eV calculadas utilizando o centro de expansão positrônico na origem e nos oxigênios, com os procedimentos I e II. As diferenças entre os resultados com as bases $6-311 \mathrm{G}++(\mathrm{d}, \mathrm{p})$ e $6-31 \mathrm{G}++(\mathrm{d}, \mathrm{p})$ estão indicadas por $6311 \mathrm{G}-631 \mathrm{G}$, e para o caso da aug-ccpVDZ e 6-311G++(d,p) indicamos por VDZ-6-311G.

As energias dos orbitais SOMO eletrônicos e positrônicos são novamente próximas, demonstrando um comportamento semelhante ao da representação com centro de expansão do pósitron apenas na origem e também do caso do Ps isolado. Em relação as densidades, essa representação também apresenta um comportamento análogo ao da representação com centro apenas na origem conforme podemos notar através das 
figuras (5.11) e (5.12). Os resultados com as demais bases para as densidades foi análogo.

(A)

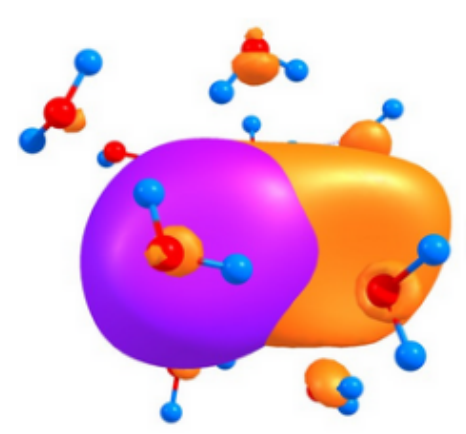

(B)

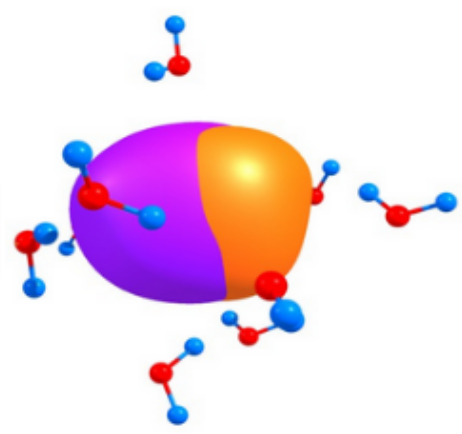

(C)

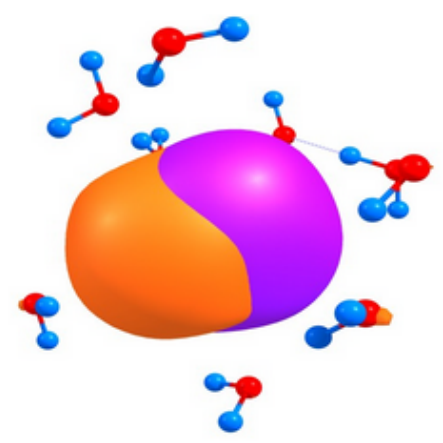

Figura 5.11: Orbitais SOMO eletrônico em laranja e positrônico em roxo obtidos com a base $6-31 \mathrm{G}++(\mathrm{d}, \mathrm{p})$ e o procedimento $\mathbf{I}$, usamos o isovalor 0.03 .

(A)

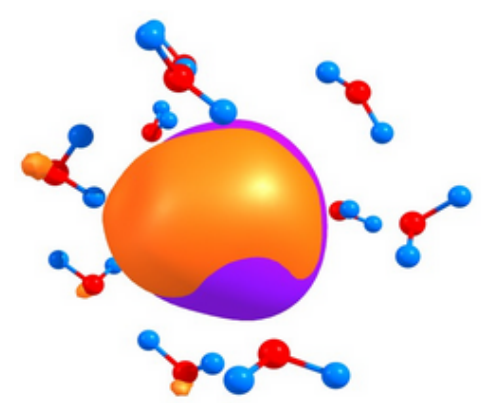

(B)

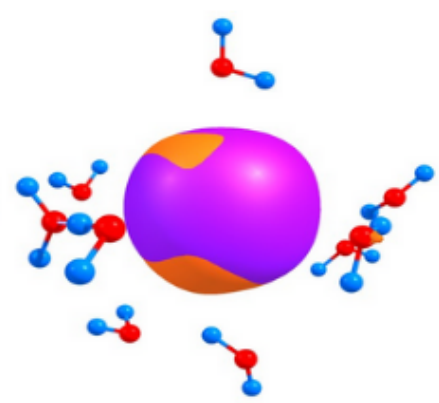

(c)

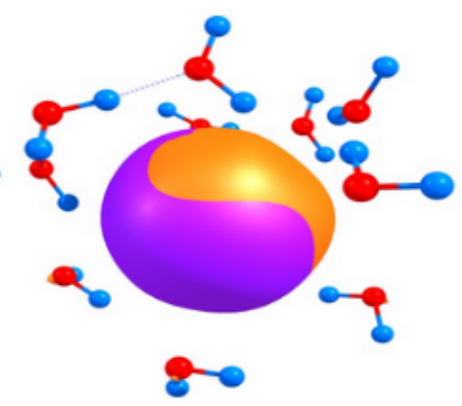

Figura 5.12: Orbitais SOMO eletrônico em laranja e positrônico em roxo obtidos com a base $6-31 \mathrm{G}++(\mathrm{d}, \mathrm{p})$ e o procedimento II, usamos o isovalor 0.03 .

Portanto, podemos concluir que ao posicionarmos um centro de expansão do pósitron na origem as densidades dos orbitais SOMO estão sempre situadas na origem mesmo quando também usamos centros sobre os átomos de oxigênio. $\mathrm{O}$ efeito do banho eletrostático de maneira geral altera pouco as energias orbitais, sendo o principal efeito do banho visto na distribuição das densidades que são sobrepostas entre si devido ao potencial eletrostático do banho ser praticamente esférico. Essas conclusões sobre o 
banho são observadas para as três formas de representar o Ps nos cálculos quânticos.

Outra comparação importante em relação às demais representações utilizadas, seria em relação à energia total do sistema que pode indicar com qual representação minimizamos melhor a energia no cálculo UHF. Os conjuntos de funções de base 6$31 \mathrm{G}++(\mathrm{d}, \mathrm{p}), 6-311 \mathrm{G}++(\mathrm{d}, \mathrm{p})$ e aug-cc-pVDZ foram utilizados para descrever todo o sistema usando as três formas de representar o Ps, conforme discutimos anteriormente. Logo, podemos fazer a comparação da energia total obtida com cada um desses conjuntos de funções de base para as diferentes representações do Ps. Na tabela (5.9) estão dispostos os resultados das energias totais obtidas com a base $6-31 \mathrm{G}++(\mathrm{d}, \mathrm{p})$ nos cálculos UHF usando as diferentes maneiras de representar o Ps na abordagem QM. Os resultados com as bases $6-311 \mathrm{G}++(\mathrm{d}, \mathrm{p})$ e aug-cc-pVDZ apresentaram o mesmo comportamento.

\begin{tabular}{|l|l|l|l|l|l|l|}
\hline Configurações: & \multicolumn{2}{|l|}{ A (Hartree) } & \multicolumn{2}{l|}{ B (Hartree) } & \multicolumn{2}{l|}{ C (Hartree) } \\
\hline & I & II & I & II & I & II \\
\hline$E_{1}$ & -760.3294 & -807.7671 & -760.3324 & -807.7946 & -760.3196 & -807.7798 \\
\hline$E_{2}$ & -760.3346 & -807.8176 & -760.3474 & -807.8611 & -760.3498 & -807.8300 \\
\hline$E_{3}$ & -760.3592 & -807.8362 & -760.3599 & -807.8714 & -760.3676 & -807.8463 \\
\hline$E_{2}-E_{1}=$ & -0.0052 & -0.0505 & -0.015 & -0.0665 & -0.0302 & -0.0502 \\
\hline$E_{3}-E_{2}=$ & -0.0246 & -0.0186 & -0.0125 & -0.0103 & -0.0178 & -0.0163 \\
\hline
\end{tabular}

Tabela 5.9: Energias totais obtidas com a base $6-31 \mathrm{G}++(\mathrm{d}, \mathrm{p})$ representando todo o sistema com os procedimentos I e II, usando o centro de expansão do pósitron nos oxigênios $\left(E_{1}\right)$, apenas na origem $\left(E_{2}\right)$ e usando centros na origem e nos oxigênios $\left(E_{3}\right)$.

A análise destes resultados deve ser feita levando em conta alguns aspectos de cada representação do Ps. Devemos notar que a utilização de centros de expansão positrônicos sobre os átomos de oxigênio usando os conjuntos de funções de base deste átomo para descrever o pósitron, resulta em um grande número de gaussianas para representar o mesmo. Por outro lado, a representação utilizando somente o centro de expansão positrônico na origem da cavidade com um conjunto de função de base 
do hidrogênio resulta em um número de gaussianas menor. Evidentemente, quando combinamos as duas maneiras de representar o Ps temos a representação do pósitron com o maior número de gaussianas dentre as três representações utilizadas. Do ponto de vista dos métodos variacionais, como é o caso do UHF utilizado, um maior número de funções de base deve auxiliar na minimização da energia fornecendo energias totais menores. Tendo em vista esses aspectos, os resultados apresentados indicam para todos os conjuntos de funções de base que as energias totais obtidas com o centro de expansão positrônico posicionado apenas na origem $\left(E_{2}\right)$ é sempre inferior as energias obtidas com centros apenas nos oxigênios $\left(E_{1}\right)$. Sendo assim, ainda que o número de gaussianas utilizado seja menor obtivemos energias inferiores usando o centro apenas na origem. Isso indica o fato dessa maneira de representar o Ps nos cálculos quânticos favorecer a convergência da base variacional. Quando comparamos os resultados obtidos combinando as duas maneiras de representar o Ps $\left(E_{3}\right)$, também observamos valores da energia total inferiores aos demais para todos os conjuntos de funções de base. Essa outra comparação reforça nossa conclusão de que usando centros de expansão na origem da cavidade estabilizamos melhor o sistema. Utilizando centros na origem e nos oxigênios obtemos os menores valores da energia total em todos os casos, mas é importante ressaltar que a comparação entre os resultados com centro apenas na origem e com centros na origem e nos oxigênios exibe diferenças menores que as comparações com os resultados usando centro apenas nos oxigênios.

\subsubsection{Conclusões do Modelo de Coordenação}

A análise das energias totais obtidas permite concluir que o sistema é mais estável quando utilizamos o centro de expansão positrônico na origem. E quando combinamos as duas maneiras de representar o Ps, estabilizamos ainda mais o sistema mas as diferenças nesse caso não são tão expressivas. É importante o fato da utilização de 
centros extras elevar o custo computacional dos cálculos. Os VDEs eletrônico e positrônico obtidos nas duas representações que utilizam centro de expansão do pósitron na origem foram semelhantes, e a consideração do banho eletrostático não resultou em mudanças expressivas dessas energias orbitais. Deste modo, podemos concluir com base nos resultados apresentados nessa seção que o Ps hidratado pode ser representado satisfatoriamente utilizando os centros de expansão para as bases eletrônicas e positrônicas do Ps apenas na origem da cavidade usando funções de base do átomo de hidrogênio. Com isso, as densidades eletrônicas e positrônicas do Ps estão na origem da cavidade sobrepostas representando o elétron e o pósitron ligados formando o átomo de positrônio em solução. A análise das energias orbitais permite concluir que a base aug-cc-pVTZ do hidrogênio descreve bem as energias dos orbitais SOMO do Ps com as moléculas de água sendo descritas com a base 6-31G++(d,p).

\subsection{QM/MM Sequencial}

Com as conclusões sobre as bases adequadas para o cálculo do VDE eletrônico e positrônico do Ps, e da maneira adequada de representar o Ps quanticamente, utilizamos o método S-QM/MM discutido na seção (2.7) para obtermos uma média convergida da propriedade de interesse. Utilizamos a base $6-31 \mathrm{G}++(\mathrm{d}, \mathrm{p})$ com centros de expansão posicionados apenas sobre os sítios atômicos das moléculas de água, na origem posicionamos centros extras eletrônico e positrônico referentes a base aug-cc-pVTZ do hidrogênio. Assim, realizamos 60 cálculos quânticos com o método UHF utilizando 60 configurações descorrelacionadas obtidas através das simulações MC. Cada configuração é composta pelo Ps e 22 moléculas de água tratadas quanticamente, e 128 moléculas de água consideradas como cargas pontuais. Em seguida, realizamos a média dos resultados das energias dos orbitais SOMO eletrônico e positrônico do Ps afim de obtermos os valores do VDE tomando o negativo dessas médias. No gŕafico 
da figura (5.13) apresentamos as médias acumuladas dos valores dos VDEs eletrônico e positrônico do Ps hidratado.
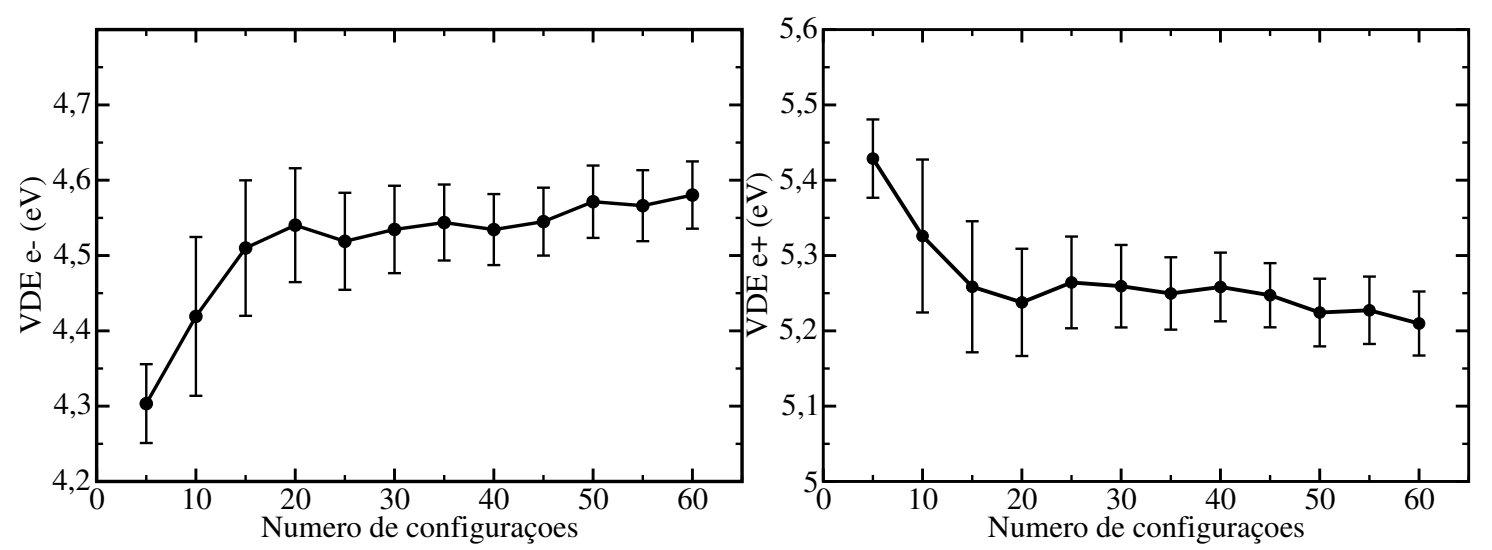

Figura 5.13: Médias acumuladas do VDE eletrônico e positrônico, utilizamos a base 6-31G++ (d,p) com centros de expansão nos sítos atômicos e a aug-ccpVTZ com os centros de expansão posicionados sobre a origem.

A média dos resultados destes 60 cálculos quânticos forneceram um VDE eletrônico igual a $4.58 \pm 0.04 \mathrm{eV}$, e o positrônico de $5.21 \pm 0.04 \mathrm{eV}$. É interessante ressaltar a comparação entre o VDE do elétron hidratado com o VDE eletrônico do Ps hidratado. A interação do elétron com o pósitron formando o Ps em solução leva a um VDE eletrônico superior ao do elétron hidratado, o qual possui valores reportados na literatura entre 3.3 e $3.6 \mathrm{eV}[83,84,85]$. Os orbitais SOMO eletrônico e positrônico do Ps obtidos nestes cálculos são semelhantes a orbitais do tipo s e estão representados na figura (5.14).

O modelo bolha do Ps solvatado considera o átomo de positrônio como uma partícula quântica pontual sujeita a um poço de potencial finito, e a profundidade dessa barreira de potencial subtraída da energia do Ps pode ser comparada aos VDEs determinados em nosso estudo. As diferentes versões do modelo bolha propostas na literatura consideram poços de potencial nos quais essa diferença é de $2.91 \mathrm{eV}$ e $1.88 \mathrm{eV}$ [21], e portanto estão distantes dos nossos resultados dos VDEs eletrônico e positrônico. 


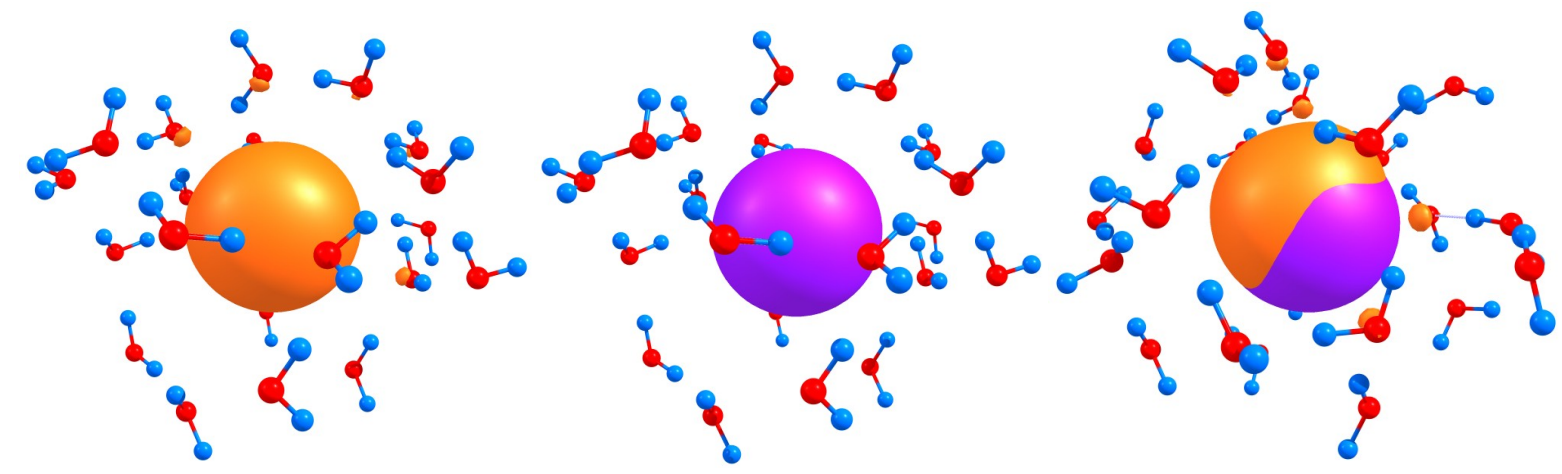

Figura 5.14: Orbitais SOMO eletrônico em laranja e positrônico em roxo obtidos em um dos 60 cálculos quânticos realizados, a figura da direita mostra ambos os orbitais representados simultaneamente. Utilizamos o isovalor 0.03.

\subsection{ASEC}

Uma maneira distinta de estudar um sistema em solução seria através do ASEC, discutido na seção (2.7). Com esta metodologia o solvente é representado apenas por cargas pontuais resultantes da sobreposição de todas as configurações descorrelacionadas. Logo, a única maneira viável de representar o Ps neste caso seria posicionando os centros de expansão do elétron e pósitron do Ps na origem. Realizamos cálculos UHF com as bases aug-cc-pVDZ, aug-cc-pVTZ e aug-cc-pVQZ do hidrogênio com os quais encontramos os valores do VDE eletrônico e positrônico do Ps dispostos na tabela $(5.10)$

\begin{tabular}{|c|c|c|}
\hline & VDE $e^{-}(\mathrm{eV})$ & $\mathrm{VDE} e^{+}(\mathrm{eV})$ \\
\hline aug-cc-pVDZ & 3.77 & 5.00 \\
\hline aug-cc-pVTZ & 3.73 & 5.04 \\
\hline aug-cc-pVQZ & 3.74 & 5.05 \\
\hline
\end{tabular}

Tabela 5.10: Energias dos VDE eletrônico e positrônico do Ps obtidas com um cálculo UHF usando a configuração gerada com o procedimento ASEC.

Os valores apresentados na tabela (5.10) indicam para o fato da escolha da base augcc-pVTZ ser novamente uma boa escolha de base, considerando as variações pequenas entre os resultados com diferentes bases. A grande vantagem da utilização do ASEC 
está no fato de ser necessário realizar apenas um cálculo quântico, o que possibilita a utilização de outros métodos mais precisos para os cálculos de estrutura eletrônica. Com isso, foi possível realizar também cálculos quânticos utilizando propagadores de segunda ordem (P2) e teoria de pertubação de segunda ordem (MP2). Os resultados desses cálculos estão dispostos na tabela (5.11).

\begin{tabular}{|c|c|c|}
\hline & $\mathrm{VDE} e^{-}(\mathrm{eV})$ & $\mathrm{VDE} e^{+}(\mathrm{eV})$ \\
\hline UHF & 3.73 & 5.04 \\
\hline MP2 & 3.73 & 5.04 \\
\hline P2 & 3.65 & 5.32 \\
\hline
\end{tabular}

Tabela 5.11: Energias dos VDEs eletrônico e positrônico do Ps obtidas com cálculos UHF, MP2 e P2 usando a base aug-cc-pVTZ e a configuração gerada com o procedimento ASEC.

Nestes cálculos quânticos consideramos somente um elétron e um pósitron quanticamente, com isso temos apenas a correlação elétron-pósitron descrita no cálculo MP2 resultando em uma correção ínfima para as energias orbitais. A utilização do ASEC resulta em uma interação do soluto com o solvente dada apenas pela interação eletrostática das cargas pontuais com o soluto. Por outro lado, nos cálculos com o procedimento S-QM/MM consideramos 22 moléculas de água quanticamente e com isso estamos considerando também a interação de troca entre os elétrons do sistema. O tratamento quântico desses elétrons leva a uma correção do VDE eletrônico, resultando em um valor diferente daquele obtido com o ASEC. Para o VDE positrônico os resultados obtidos com ASEC e S-QM/MM estão próximos, e isso deve-se ao fato de não haver interação de troca do pósitron com os elétrons tratados quanticamente no cálculo sequencial. Portanto, a determinação da energia do orbital SOMO eletrônico do Ps com a configuração gerada usando ASEC não fornece bons resultados. 



\section{Conclusões e Perspectivas}

O objetivo central deste trabalho consiste em estabelecer um procedimento a partir do qual podemos estudar propriedades do átomo de positrônio em solução. O primeiro passo para o estudo desse sistema foi a determinação do campo de força do Ps em água, que foi possível com o estabelecimento de um modelo a partir do qual podemos determinar os parâmetros do campo de força para diversos solventes. O campo de força do Ps solvatado em água, assim como o modelo proposto, foram validados com a observação do comportamento adequado de grandezas termodinâmicas como a densidade nas simulações clássicas de Monte Carlo. Portanto, o principal resultado desta etapa do trabalho foi atingido permitindo que o campo de força do Ps para a solvatação em água fosse determinado. A estrutura da água na presença do Ps obtida indicou a formação de uma camada de solvatação típica de solutos hidrofóbicos, conforme esperado do ponto de vista físico e em acordo com os modelos presentes na literatura para a solvatação do Ps. A energia livre de solvatação obtida indicou que a solvatação do Ps em água não é espontânea, sendo composta em grande parte pela contribuição da cavitação do solvente. Por outro lado, a variação entrópica na solvatação do Ps indicou uma diminuição da entropia conforme esperado para solutos hidrofóbicos.

Na segunda parte do trabalho realizamos a abordagem quântica do sistema, com os procedimentos S-QM/MM e ASEC. Definimos um modelo de coordenação que resultou em três configurações a partir das quais realizamos testes com diferentes formas de 
representar o Ps quanticamente usando alguns conjuntos de funções base. Os testes indicaram que o uso do centro de expansão do pósitron na origem leva a uma energia total do sistema menor, enquanto as VDEs do elétron e do pósitron são mais próximas com essa representação. As densidades eletrônicas e positrônicas do Ps por sua vez também apresentaram comportamentos distintos com cada representação, de maneira geral o uso do centro de expansão positrônico na origem resulta em densidades dos orbitais SOMO eletrônico e positrônico situadas na origem. Por outro lado, com o centro de expansão do pósitron apenas nos oxigênios temos densidades situadas na periferia dos aglomerados do modelo de coordenação. O banho eletrostático alterou pouco as VDEs, mas introduz um potencial eletrostático responsável por localizar ainda mais os orbitais eletrônicos e positrônicos do Ps.

Os caĺculos com os procedimentos s-QM/MM e ASEC possibilitaram a determinação dos VDEs do Ps, e através desses resultados identificamos que a abordagem quântica usando o ASEC não descreve de maneira adequada a energia do SOMO eletrônico. Observou-se que o elétron ligado ao pósitron em solução possui um VDE superior ao do elétron hidratado, tendo em vista a interação elétron-pósitron no átomo de positrônio.

O procedimento estabelecido para o estudo do Ps solvatado forneceu resultados adequados para este átomo em solução, e com isso pode ser aplicado a solvatação do Ps em diversos solventes nos quais a formação do mesmo é reportada experimentalmente. Além da solvatação, podemos extender nossa metodologia para o estudo do Ps em outros sistemas como polímeros. 


\section{Referências Bibliográficas}

[1] P. A. M. Dirac. On the Annihilation of Electrons and Protons. Mathematical Proceedings of the Cambridge Philosophical Society, 26, 361-375, 1930.

[2] C. D. Anderson. The Positive Electron. Physical Review, 43, 491-494, 1933.

[3] C. C. Robilotta. A tomografia por emissão de pósitrons: uma nova modalidade na medicina nuclear brasileira. Revista Panamericana de Salud Pública, 20, 134-142, 2006.

[4] F. F. Henriques. Estudo de complexos envolvendo ions lantanídeos trivalentes e ligantes orgânicos, utilizando espectroscopias de aniquilação de pósitrons e óptica. Tese de Doutorado - UFMG, 2013.

[5] St. Mohorovičić. Möglichkeit neuer Elemente und ihre Bedeutung für die Astrophysik. Astronomische Nachrichten, 253, 93-108, 1934.

[6] M. Deutsch. Evidence for the Formation of Positronium in Gases. Physical Review, 82, 455-456, 1951.

[7] Y. C. Jean, P. E. Mallon, D. M. Schrader. Principles and Applications of Positron 6 Positronium Chemistry. World Scientific, 2003.

[8] S. J. Gilbert, C. Kurz, R. G. Greaves and C. M. Surko. Creation of a monoenergetic pulsed positron beam. Applied Physics Letters, 70, 1944-1946, 1997. 
[9] C. M. Surko and R. G. Greaves. A multicell trap to confine large numbers of positrons. Radiation Physics and Chemistry, 68, 419-425, 2003.

[10] J. R. Danielson, D. H. E. Dubin, R. G. Greaves and C. M. Surko. Plasma and trap-based techniques for science with positrons. Reviews of Modern Physics, $87,247-306,2015$.

[11] D. B. Cassidy and A. P. Mills. The production of molecular positronium. Nature, 449:(7159)195-197, 2007.

[12] C. M. Surko. A whiff of antimatter soup. Nature, 449(7159):153-155, 2007.

[13] D. B. Cassidy, T. H. Hisakado, H. W. K. Tom and A. P. Mills. Efficient Production of Rydberg Positronium. Physical Review Letters, 108, 043401, 2012.

[14] A. Deller, A. M. Alonso, B. S. Cooper, S. D. Hogan and D. B. Cassidy. Eletrostatically guided Rydberg positronium. Physical Review Letters, 117, 073202, 2016.

[15] R. D. White, W. Tattersall, G. Boyle, R. E. Robinson, S. Dujko, Z. Lj. Petrovic, A. Bankovic, M. J. Brunger, J. P. Sullivan, S. J. Buckman and G. Garcia. Lowenergy electron and positron transport in gases and soft-condensed systems of biological relevance. Applied Radiation and Isotopes, 83, 77-85, 2014.

[16] M. Eldrup, O. Mogensen and G. Trumpy. Positron Lifetimes in Pure and Doped Ice and in Water. The Journal of Chemical Physics, 57, 495-504, 1972.

[17] S. V. Stepanov, V. M. Byakov, D. S. Zvezhinskiy, G. Duplâtre, R. R. Nurmukhametov and P. S. Stepanov. Positronium in a Liquid Phase: Formation, Bubble State and Chemical Reactions. Advances in Physical Chemistry, 431962, 1-17, 2012. 
[18] R. A. Ferrel. Long Lifetime of Positronium in Liquid Helium. The Physical Review, 108, 167-168, 1957.

[19] O. E. Mogensen. Spur reaction model of positronium formation. The Journal of Chemical Physics, 60, 998-1004, 1974.

[20] Z. Zhang and Y. Ito. A new model of positronium formation: Resonant positronium formation. The Journal of Chemical Physics, 93, 1021-1029 1990.

[21] G. N. Chuev, D. M. Schrader, S. V. Stepanov and V. M. Byakov. Quantum Mechanics of Solvated Complexes: A Test for Positronium. International Journal of Quantum Chemistry, 88, 634-641, 2002.

[22] S. V. Stepanov, V. M. Byakov, B. N. Ganguly, D. Gangopadhyay, T. Mukherjee, B. Dutta-Roy. A molecular basis of the bubble model of positronium annihilation in liquids. Physica B, 322, 68-79, 2002.

[23] H. Schmitz and F. Müller-Plathe. Calculation of the lifetime of positronium in polymers via molecular dynamics simulations. The Journal of Chemical Physics, 112, 1040-1045, 2000.

[24] L. Larrimore, R. N. McFarland, P. A. Sterne and A. L. Graves. A TwoChain Path Integral Model of Positronium. The Journal of Chemical Physics, 113(23):10642-10650, 2000.

[25] A. Camacho. Positronium lifetime in polymers. The Journal of Chemical Physics, 121(11):5451-5454, 2004.

[26] Y. Kobayashi, K. Ito, T. Oka and K. Hirata. Positronium chemistry in porous materials. Radiation Physics and Chemistry, 76(2):224-230, 2007. 
[27] M. P. Allen and D. J. Tildesley. Computer Simulations of Liquids. Claredon Press, 1987.

[28] S. Miertus, E. Scrocco and J. Tomasi. Electrostatic interaction of a solute with a continuum. A direct utilization of $\mathrm{AB}$ intio molecular potentials for the prevision of solvent effects. Chemical Physics, 55:(1)117-129, 1981.

[29] K. Coutinho and S. Canuto. Solvent Effects from a Sequential Monte Carlo Quantum Mechanical Approach. Advances in Quantum Chemistry, 28, 89-105, 1997.

[30] S. R. A. Salinas. Introdução à Fúsica Estatística. Edusp, 2013

[31] D. Frenkel and B. Smit. Understanding Molecular Simulation: From Algorithms to Applications. Academic Press, 2002.

[32] K. Coutinho. Modelo Discreto de Solvente. Solvatocromismo no Espectro de Absorção Molecular. Tese de Doutorado - USP, 1997.

[33] N. Metropolis, A. W. Rosenbluth, M. N. Rosenb, A. H. Teller and E. Teller. Equation of State Calculations by Fast Computing Machines. The Journal of Chemical Physics, 21, 1087-1092, 1953.

[34] Fernando da Silva. Estudo teórico de propriedades eletrônicas e da solvatação de carbonatos orgânicos em meio aquoso. Dissertação de Mestrado - USP, 2011.

[35] L. M. Cornetta. Interação entre elétrons e nucleotídeos. Dissertação de Mestrado - USP, 2015.

[36] W. L. Jorgensen, J. K. Buckner, S. Boudon and J. T. Rives. Efficient computation of absolute free energies of binding by computer simulations. Application 
to the methane dimer in water. The Journal of Chemical Physics, 89, 37423746, 1988.

[37] W. L. Jorgensen, J. M. Briggs, M. L. Contreras. Relative partition coefficients for organic solutes from fluid simulations. The Journal of Chemical Physics, 94(4):1683-1686.

[38] H. M. Cezar, S. Canuto and K. Coutinho. DICE (v3.0beta) A Monte Carlo program for molecular liquid simulation. University of São Paulo, Brazil (2018).

[39] ISAACS. http://isaacs.sourceforge.net/phys/pbc.html.

[40] N.H. Morgon and K. Coutinho. Métodos de Química Teórica e Modelagem Molecular. Editora Livraria da Física, 2007.

[41] C. Bistafa. Efeito de Solvente no Espectro de Absorção da 5-Fluorouracil. Análise de Diferentes Procedimentos Teóricos Dissertação de Mestrado - USP, 2011.

[42] K. Coutinho, H. C. Georg, T. L. Fonseca, V. Ludwig and S. Canuto. An efficient statistically converged average configuration for solvent effects. Chemical Physics Letters, 437(1-3):148-152, 2007.

[43] P. Hoggan and L. U. Ancarani. State of The Art of Molecular Electronic Structure Computations: Correlation Methods, Basis Sets and More. Academic Press, 2019.

[44] M. Born and J. R. Oppenheimer. On the Quantum Theory of Molecules. Annalen Der Physik, 84, 457-484, 1927.

[45] J. D. M. Vianna, A. Fazzio and S. Canuto. Teoria Quântica de Moléculas e Sólidos. Editora Livraria da Física, 2004. 
[46] P. Atkins and R. Friedman. Molecular Quantum Mechanics. Oxford University Press, 1997.

[47] A. Reyes, M. V. Pak and S. Hammes Schiffer. Investigation of isotope effects with the nuclear-electronic orbital approach. The Journal of Chemical Physics, 123, 064104, 2005.

[48] M. Nummela, H. Raebiger, D. Yoshida and M. Tachikawa. Positron Binding Properties of Glycine and Its Aqueous Complexes. The Journal of Physical Chemistry A, 120, 23, 4037-4042, 2016.

[49] J. Charry, J. Romero, M. T. do N. Varella and A. Reyes. Calculation of positron binding energies of amino acids with the any-particle molecular-orbital approach. Physical Review A, 89, 052709, 2014.

[50] J. Charry, M. T. do N. Varella and A. Reyes. Binding Matter with Antimatter: The Covalent Positron Bond. Angewandte Chemie - International Edition, 57, 29, 8859-8864, 2018.

[51] I. L. Thomas. The protonic structure of methane, ammonia, water, and hydrogen fluoride. Chemical Physics Letters, 3(9):705-706, 1969.

[52] M. Tachikawa, K. Mori, H. Nakai, K. Iguchi. An extension of ab initio molecular orbital theory to nuclear motion. Chemical Physics Letters, 290, 437-442, 1998.

[53] H. Nakai. Simultaneous Determination of Nuclear and Electronic Wave Functions without Born-Oppenheimer Approximation: Ab Initio NO+MO/HF Theory. International Journal of Quantum Chemistry, 86, 511-517, 2002. 
[54] M. Tachikawa, K. Mori, K. Suzuki, K. Iguchi. Full variational molecular orbital method: Application to the positron-molecule complexes. International Journal of Quantum Chemistry, 70, 491-501, 1998.

[55] S. P. Webb, T. Iordanov, S. Hammes-Schiffer. Multiconfigurational nuclearelectronic orbital approach: Incorporation of nuclear quantum effects in electronic structure calculations. The Journal of Chemical Physics, 117, 4106-4118, 2002.

[56] A. Reyes, F. Moncada and J. Charry. The any particle molecular orbital approach: A short review of the theory and applications. International Journal of Quantum Chemistry, e25705, 2018.

[57] A. Szabo and N. S. Ostlund. Modern Quantum Chemistry, Dover, 1982.

[58] C. C. J. Roothaan. New Developments in Molecular Orbital Theory. Reviews of Modern Physics, 23, 69-89, 1951.

[59] Chr. Møller and M. S. Plesset. Note on an Approximation Treatment for ManyElectron Systems. Physical Review, 46, 618-622, 1934.

[60] E. Schrödinger. Quantisierung als Eigenwertproblem. Annalen Der Physik, 80, 361-376, 1926.

[61] J. Romero, J. A. Charry, R. Flores-Moreno, M. T. do N. Varella and A. Reyes. Calculation of positron binding energies using the generalized any particle propagator theory. The Journal of Chemical Physics, 141, 114103, 2014.

[62] J. Romero. Development of propagator methods for studying ionization processes in molecules using the Any Particle Molecular Orbital (APMO) approach 
and its computational implementation in LOWDIN program. Dissertação de Mestrado - Universidad Nacional de Colombia, 2013.

[63] H. J. C. Berendsen, J. R. Grigera and T. P. Straatsma. The Missing Term in Effective Pair Potentials. The Journal of Physical Chemistry, 91, 6269-6271, 1987.

[64] W. L. Jorgensen, D. S. Maxwell and J. Tirado-Rives. Development and Testing of the OPLS All-Atom Force Field on Conformational Energetics and Properties of Organic Liquids. Journal of the American Chemical Society, 118(45):11225-11236, 1996.

[65] W. D. Cornell, P. Cieplak, C. I. Bayly, I. R. Gould, K. M. Merz, D. M. Ferguson, D. C. Spellmeyer, T. Fox, J. W. Caldwell, and P. A. Kollman. A second generation force field for the simulation of proteins, nucleic acids, and organic molecules. Journal of the American Chemical Society, 117(19):5179-5197, 1995.

[66] V. Ludwig, K. Coutinho and S. Canuto. Sequential classical-quantum description of the absorption spectrum of the hydrated electron. Physical Review B, 70, 214110, 2004 .

[67] V. Ludwig. Estrutura Eletrônica e Interações Intermoleculares em Líquidos. Tese de Doutorado - USP, 2005.

[68] K. T. Tang. Dynamic Polarizabilities and van der Waals Coefficients. Physical Review, 177(1):108, 1969.

[69] F. London. The General Theory of Molecular Forces. Transactions of the Faraday Society, 33, 8b-26, 1937. 
[70] A. R. Swann, J. A. Ludlow and G. F. Gribakin. van der Waals coefficients for positronium interactions with atoms. Physical Review A, 92(1):012505, 2015

[71] J. Mitroy and M. W. J. Bromley. van der Waals coefficients for positroniumatom interactions. Physical Review A, 68(3):035201, 2003

[72] A. Tkatchenko and M. Scheffler. Accurate Molecular Van Der Waals Interactions from Ground-State Electron Density and Free-Atom Reference Data. Physical Review Letters, 102, 073005, 2009.

[73] X. Chu and A. Dalgarno. Linear response time-dependent density functional theory for van der Waals coefficients. The Journal of Chemical Physics, 121, 4083-4088, 2004.

[74] M. Eldrup. Journal de Physique IV, 5, 93, 1995.

[75] L. Kevan. Solvated electron structure in glassy matrixes. Accounts of Chemical Research, 14(5):138-145, 1981.

[76] A. H. Narten and H. A. Levy. Liquid Water: Molecular Correlation Functions from XRay Diffraction. The Journal of Chemical Physics, 55, 2263-2269, 1971.

[77] C. C. Chambers, G. D. Hawkins, C. J. Cramer and D. G. Truhlar. Model for Aqueous Solvation Based on Class IV Atomic Charges and First Solvation Shell Effects. Journal of Physical Chemistry, 100, 16385-16398, 1996.

[78] C. Zhan and D. A. Dixon. The Nature and Absolute Hydration Free Energy of the Solvated Electron in Water. Journal of Physical Chemistry B, 107, 44034417, 2003. 
[79] A. Kumar, J. A. Walker, D. M. Bartels and M. D. Sevilla. A Simple ab initio Model for the Hydrated Electron that Matches Experiment. Journal of Physical Chemistry A, 119(34):9148-9159, 2015.

[80] W. L. Jorgensen, J. F. Blake and J. K. Buckner. Free energy of TIP4P water and the free energies of hydration of $\mathrm{CH}$, and $\mathrm{Cl}^{-}$from statistical pertubation theory. Chemical Physics, 129, 193-200, 1989.

[81] T. P. Straatsma, H. J. C. Berendsen and J. P. M. Postma. Free energy hydrophobic hydration: A molecular dynamics study of noble gases in water. Journal of Chemical Physics, 85, 6720-6727, 1986.

[82] R. Haselmeier, M. Holz, W. Marbach, H. Weingaertner. Water Dynamics near a Dissolved Noble Gas. First Direct Experimental Evidence for a Retardation Effect. The Journal of Chemical Physics, 99, 2243-2246, 1995.

[83] K. R. Siefermann, Y. Liu, E. Lugovoy, O. Link, M. Faubel, U. Buck, B. Winter and B. Abel. Binding energies, lifetimes and implications of bulk and interface solvated electrons in water. Nature Chemistry, 2, 274-279, 2010.

[84] L. Turi. Hydrated Electrons in Water Clusters: Inside or Outside, Cavity or Noncavity?. Journal of Chemical Theory and Computation, 11, 1745-1755, 2015.

[85] M. P. Coons, Z. You and J. M. Herbert. The Hydrated Electron at the Surface of Neat Liquid Water Appears To Be Indistinguishable from the Bulk Species. Journal of the American Chemical Society, 138, 10879-10886, 2016. 